Portland State University

PDXScholar

\title{
Understanding Financial and Human Resource Capacity Challenges among Small Nonprofits in Oregon: How to Overcome Challenges Unique to Size and Urban-Rural Divide
}

Anindita Mukerjee

Portland State University

Follow this and additional works at: https://pdxscholar.library.pdx.edu/open_access_etds

Part of the Public Affairs Commons, and the Public Policy Commons Let us know how access to this document benefits you.

\section{Recommended Citation}

Mukerjee, Anindita, "Understanding Financial and Human Resource Capacity Challenges among Small Nonprofits in Oregon: How to Overcome Challenges Unique to Size and Urban-Rural Divide" (2021). Dissertations and Theses. Paper 5691.

https://doi.org/10.15760/etd.7564

This Dissertation is brought to you for free and open access. It has been accepted for inclusion in Dissertations and Theses by an authorized administrator of PDXScholar. Please contact us if we can make this document more accessible: pdxscholar@pdx.edu. 
Understanding Financial and Human Resource Capacity Challenges among Small

Nonprofits in Oregon: How to Overcome Challenges Unique to Size and Urban-Rural

Divide

by

Anindita Mukerjee

A dissertation submitted in partial fulfillment of the requirements for the degree of

\author{
Doctor of Philosophy \\ in \\ Public Affairs and Policy
}

Dissertation Committee:

Craig W. Shinn, Chair

Billie Sandberg

Masami Nishishiba

Christine Cress

Portland State University

2021 
(C) 2021 Anindita Mukerjee 


\begin{abstract}
Nonprofit and voluntary organizations are part of the political economy that add to the services of public and private sectors by addressing civic interests, participation in democracy and providing social programs that improve quality of life. This sector is mostly comprised of small organizations whose impact is more than their budget size. At the advent of this study, information existed about the needs and capacity challenges of Oregon nonprofits in general but lacked specifics on smaller organizations, especially differentiating the urban rural distinction. The aim of this research was to explore the financial and human resource capacity of small nonprofit and voluntary organizations in Oregon to fulfill their objectives and thus provide policymakers, nonprofit capacity building organizations and key leaders in the third sector in Oregon an assessment of what these organizations need to achieve their missions. The study through telephone interviews specifically sought to find a) what core capacities do small urban and rural nonprofits in Oregon currently possess in the financial and human capacity domains, and b) how should capacity builders and policy makers customize capacity building initiatives for small urban and rural nonprofits separately to help them achieve sufficient competencies.
\end{abstract}

In general, the study found that there is a deficit between demand and supply of finances as well as human resources in small nonprofits in both urban and rural areas. The demand for services is always more than what can be supplied. Urban nonprofits struggle to provide the level and diversity of services required in areas where populations are not homogenous and have distinct issues at stake. While rural areas demand less, they 
have limited pools of volunteers and donors and hence the supply side gets constrained. Additionally, rural nonprofits struggle with finding representative voices in their boards and workforce even as they communities they serve become more diverse. Absence of diversity often translates to needs of the minority not being understood or catered to.

An emergent research that cropped up in this study was that current definitions of urban and rural are based more on geography or demographics. While those are important and not to be dismissed, they are insufficient in understanding how 'location' and 'impact' of the nonprofit organization classifies them as either urban or rural. The methodology proposed in this study helps to overcome the limitation of overestimation of ruralness that arises using the traditional definitions.

The small size of nonprofits posits unique challenges to all organizations, whether urban or rural. It is difficult to maintain a 'checks and balances' relationship between the board and workforce in a setting where often these two are comprised of the same people. Some organizations further reported conflicts between workers who only served in programs versus those who served on the boards as well the workforce. The economies of scale also translate into challenges in keeping administrative or overhead costs low, trying to generate income from sources other than individual donations, hiring professional grant-writers or designing strategies to increase history and visibility. Finally, resource deficits lead small nonprofits to focus more on addressing technical and management capacity issues that are easier to identify rather than devising strategies to issues like succession planning and adapting to changes in the external environment. 


\section{Acknowledgements}

To Doctor Craig Shinn, my advisor and guide, a big thank you. It would not have been possible to finish this work without your encouragement. You were a beacon of hope when I wondered what the next step was and needed a guide to point me in the right direction.

To Doctor Billie Sandberg thank you for your encouragement and profound wisdom. I will always remember what you said that a dissertation is actually not the best piece of work by a doctoral student. One must aim to do better as their academic career progresses. Probably the most enlightening piece of advice that nobody else gave me.

To Doctor Masami Nishishiba, thank you for your detailed and organized feedback and inputs for my methodology. Your notes kept me organized and on track and I was able to put my thoughts into action when things became too abstract.

I want to thank Doctor Christine Cress who was a wonderful mentor and taught me aspects of service learning that I hope to incorporate in my future career. Without your classes, my teaching and mentoring interdisciplinary subjects at University Studies would have been incomplete.

All the people, colleagues and networks at University Studies, Dr Dana Lundell who has been the best supervisor and all others I cannot mention here, thank you for your support. I have made cherished memories at Portland State University which I will treasure for the rest of my life. 


\section{Table of Contents}

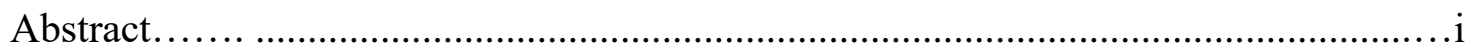

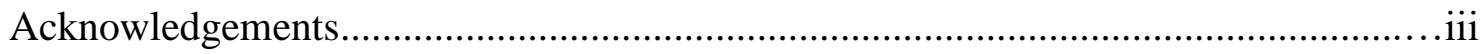

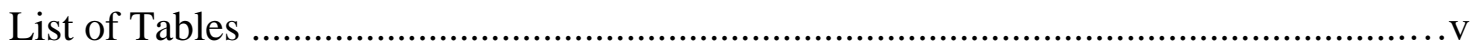

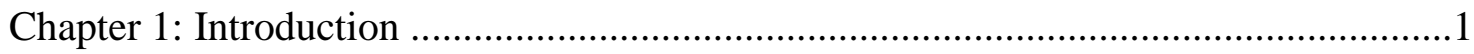

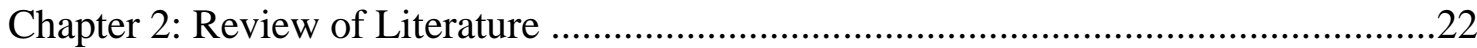

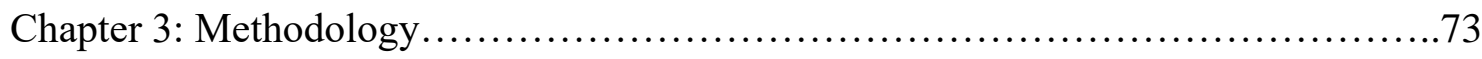

Chapter 4: Revisiting the Urban Rural Distinction...............................91

Chapter 5: Results and Findings........................................ 109

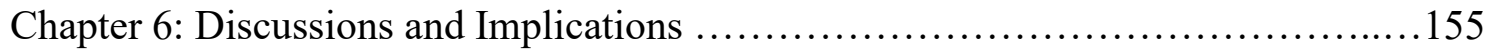

References............................................................... 175

Appendix A: Questionnaires............................................191

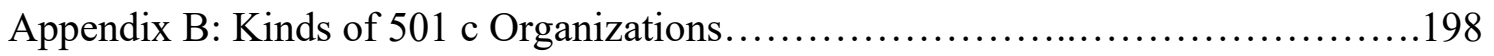




\section{List of Tables}

Table 1.1: Oregon's Nonprofit Sector by Annual Budget, 2009-15..................9

Table 1.2: Oregon's Nonprofit Sector by Annual Budget and Urban / Rural Distinction

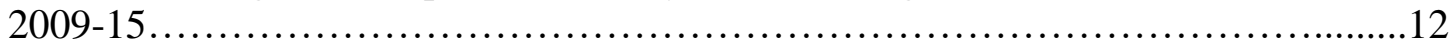

Table 1.3: Oregon's Nonprofit Sector by Annual Budget and Regions, 2009-15.....13

Table 2.1: Distribution of Nonprofits by NTEE Classification in USA, 2013 .........24

Table 2.2: Oregon's Nonprofit Sector by Annual Budget and Subsector, 2009-15....36

Table 2.3 A Comparison of Light's and Golmar's Studies on Capacity Building Activities, Ranked................................................................53

Table 2.4: Participation in Collaboration, Oregon Rural / Urban Nonprofits in 2011 . .70

Table 2.5: Challenges to Collaboration among Oregon Nonprofits, $2011 \ldots \ldots \ldots \ldots \ldots . .71$

Table 3.1: Study Respondents by Annual Budget................................82

Table 3.2: Study Respondents by Interview Chosen and Method .......................84

Table 3.3: Research Questions and Link to Interview Question 1.....................85

Table 3.4: Research Questions and Link to Interview Question 2.....................86

Table 3.5: Research Questions and Link to Interview Question 3...................87

Table 3.6: Research Questions and Link to Interview Question 4....................88

Table 4.1: RUCC Codes Classification System for Defining 'Urban and Rural'......96

Table 4.2: UIC Codes Classification System for Defining 'Urban and Rural' ........97

Table 4.3: RUCA Codes Classification System for Defining 'Urban and Rural'......98

Table 4.4: Mukerjee's Methodology for Classifying Nonprofits as 'Urban and Rural' .106

Table 4.5: Respondents by Annual Budget and Urban / Rural Distinction, 2009-15...107 
Table 5.1: List of Themes for Financial Capacity by Category and Labels.............110

Table 5.2: List of Themes for Collaborative Capacity by Category and Labels........110

Table 5.3: List of Themes for HR Capacity by Category and Labels..................111

Table 6.1: Comparing Study Respondents to ONSR 3 Respondents.................163 


\section{Chapter 1: Introduction}

\section{Background for the Study}

Nonprofit and voluntary organizations play an important role in uplifting the quality of life in their communities by addressing the interests of citizens and services demanded by them that cannot be met by the state or through private players. All communities have members that have needs and problems that need solutions. If needs are unmet and the problems remain unsolved, then it negatively impacts the overall wellbeing of the community (Keegan, 1990, p. 3). Small community-based nonprofit organizations deliver programs and services that are geared to meeting the needs of the people and solving their problems. Nonprofits working at the grassroots level therefore are a measure of the how healthy a community is socially, politically, economically, spiritually and culturally (De Vita \& Fleming, 2001). As Bielefield, Murdoch and Waddell (1997) state,

The nonprofit sector is closely linked to the vital signs of local communities... it may be unreasonable to expect communities to be adequately serviced by nonprofits not located near them. For those wishing to assist communities, therefore the most appropriate strategy may be to promote local community-based organizations. For larger centrally located organizations, this may mean establishing outreach or satellite operations in target communities. (p. 222)

Nonprofit organizations can vary in sizes; and could either be a solo, unique organization or a smaller establishment that has a parent organization (e.g. Boys and Girls Club, the National Alliance for the Mentally Ill, Habitat for Humanity, etc.). According to Guidestar (2018), nonprofits whose budgets fall below \$1 million are classified as 'very small' nonprofits, those between $\$ 1-5$ million are 'small' nonprofits 
and those between \$5-10 million are 'mid-size' nonprofits. Such small nonprofits are small only in budget size, their impact is important to building neighborhoods, towns and even big cities. The Urban Institute classified $88 \%$ of all US nonprofits as having revenue below \$3 million in 2015. According to Natenshon and Walker (2018), small nonprofits serve our societies in two important ways. Firstly, they serve certain niches in communities, i.e. sometimes services to a very small unique group may be carried out by a small rather than a large nonprofit. To give an example, nonprofits that serve veterans who fought in a specific war or those who have suffered from a particular impairment rather than all veterans. This highlights the second merit of small nonprofits, namely they could and often, provide one on one services to their beneficiaries (as opposed to a 'one size fits all' service to every client) and maintain closer relationships with them than bigger nonprofits do. A local example could be the nonprofit Micro Enterprise Services of Oregon (MESO) in Portland that provides financial and technical assistance to people about to start a small business. All of MESO's training, and training assistance programs are provided one-on-one compared to Mercy Corps Northwest, a bigger million-dollar nonprofit which provides similar services but allows twenty or more people per training seminar. Finally, it is often small nonprofits have nimbler decision - making structures which gets them to make everybody learn faster (The Leap of Reason Ambassadors Community, 2017).

Despite more nonprofits falling in the small size category and the benefits they give to society, constraints in their financial and human resource capacities hinders them from realizing their full potential. The Nonprofit Finance Fund (2012) found that small 
nonprofits lack the financial capacity to be successful because they may be limited in their knowledge of financial skills, they lack money to support their operations, and because of limited staff, they are usually interested in making sure that the figures meet the bare financial compliances and not use them as an effective tool for decision making. Small nonprofits are also constrained in their human resource capacity, that is, getting staff, volunteers and board members with the right skills and available time to operate their programs (Nuehoff \& Dunckeman, 2011). Financial and human resource deficits add to poor organizational management, ineffective management, high turnover, inconsistent planning and decision making and the absence of well documented procedures and processes. Because of this, small nonprofit organizations face challenges in accountability to their community members to whom they provide services, funders and donors who give them money, volunteers and board members who help them staff their programs and donate time, money, knowledge, resources and invaluable skills and of course the government agencies that regulate and monitor them (Light, 2004).

Small nonprofits, whether they service their small rural communities or smaller groups or niches in large urban areas are passionate about providing high quality services or results to people or causes they serve. However, this requires having access to resources that would increase their performance. To do this, they need not necessarily have to emulate bigger nonprofits but can also learn from similar sized organizations or sister organizations in other regions who are facing comparable challenges. Hence, while their resources may remain local, through networks and training programs, they can learn strategies for better capacity building from similar organizations in other communities. 
By understanding the current strengths and weaknesses of small nonprofits, it is also possible for nonprofit consultants, capacity building strategists and civil society leaders to explore if these skills, strategies and resources are transferable and can be shared through coalitions and collaborations.

These strengths and weaknesses are influenced by whether the organization is urban or rural as local participation and giving in communities are impacted by demographics and diversity (Pohjoispuro, 2006). Both rural and urban nonprofits face challenges when it comes to enhancing their capacities, though their challenges may be greater in one domain and lesser in another. For example, smaller communities in rural areas make it easier for the nonprofits located there to have more contact with their individual donors at special events; at the same time a smaller population base to draw on for staff and volunteers makes it more challenging to deliver their services (Pohjoispuro, 2006). So, while rural nonprofits may have greater financial capacity while receiving individual donations, their human capacity in acquiring sufficient staff and volunteers to be engaged in their programs will be challenged. Small rural nonprofits will be limited in their capacity to spend heavily on recruitment, training and retention programs (Stowe \& Barr, 2005) while their urban counterparts may find it equally challenging to invest in more fundraising and special events to draw in more individual donations.

\section{Overview of the US Nonprofit Sector}

According to the National Center for Charitable Statistics (NCCS) in 2013, 1.41 million nonprofits were registered with the Internal Revenue Service (IRS) who contributed an estimated $\$ 905.9$ billion to the US economy, composing $5.4 \%$ of the 
country's gross domestic product (McKeever, 2015). They provided services in healthcare and counseling, education, youth development, arts and culture, animal welfare and environment, human services (including affordable housing, food distribution, job placement and training), relief efforts and civil rights and advocacy. Apart from providing such services, a huge number of them are involved in providing grants, and philanthropy and research in social and physical sciences.

Since 2010, churches, religious organizations and nonprofits with less than $\$ 50,000$ in annual revenue were not required to register with the IRS, though many do. Instead of filling in the regular 990 tax form, they could e-file Form 990N. Even after excluding organizations with gross receipts below the $\$ 50,000$ filing threshold, NCCS estimates showed that small organizations compose the majority of public charities in America. The figures for 2013 showed that $66.4 \%$ of US nonprofits had less than $\$ 500,000$ in expenses. Two-thirds of the nonprofit sector thus comprised of small and micro nonprofit organizations who had little to no paid staff and worked entirely on a volunteer force. A quarter of Americans over the age of 16 volunteered through a nonprofit between 2010-14 (National Center for Charitable Statistics, 2015).

According to the Independent Sector (2016), and Nonprofit Finance Fund (2015), $76 \%$ of nonprofits saw an increase in demand for their services in 2014 (as compared to 2013) but more than $52 \%$ of them were unable to meet community demand in 2014 , and $71 \%$ said they would be unable to continue doing so in 2015 . These figures pointed out that while the third sector / nonprofit sector was huge and critical for addressing 
community needs, it was dominated mostly by small organizations that lacked capacity to deliver programs and social services effectively.

Capacity deficits are also influenced by the urban rural distinction. A 2010 study by the Bridgespan group (Nuehoff \& Dunckelman, 2011), showed that rural areas accounted for $22 \%$ of the nation's poor regions but the share of rural nonprofits in public service expenses was only $8 \%$. The study pointed out that rural nonprofits lacked critical human capacity because of limited access to talent and skilled people and the infrastructure for recruiting, retaining, and training nonprofit managers and board leaders needed an overhaul in rural areas. The study did find that despite lack of access to funding resources outside of their local community, rural nonprofits had better financial health than urban nonprofits because their expenses were likely to be below revenues earned and hence they were more likely to have cash reserves.

\section{Overview of the Oregon Nonprofit Sector}

The first Oregon Nonprofit Sector Report (ONSR) estimated that in 2010, nonprofits employed about $13 \%$ of the region's paid workforce (corresponding figures at the national level are $9.2 \%$ according to NCCS, 2015) and provided opportunities for about 38.3 volunteer work hours annually to every Oregonian (Schroeer, Medora, Mukerjee \& Wallinger, 2012, p. 10-12). Nonprofits in Oregon have increasingly contributed to the local economy. In 2008 and 2010, they contributed to about 160,000 jobs in the private sector, which increased to 172,857 jobs in 2013 and 183,075 jobs in 2015. (Eagan, 2009, 2011; Fridley, 2014; Fridley 2017). According to the Nonprofit Association of Oregon (2017), 
“In 2016, Oregon's 19,786 nonprofits employed over 183,000 Oregonians, with over $\$ 8.7$ billion in annual payroll. The workforce of the nonprofit sector in Oregon comprises over $12 \%$ of the total private workforce in the state. By comparison, manufacturing in Oregon comprises only $10 \%$ of the total private workforce." (2017 Oregon Non-profit Economic Snapshot report, p. 1)

It is interesting to note that the economic contribution of both urban and rural nonprofits to Oregon was equally remarkable. From 2008 to 2015, about 9\% of all jobs in rural Oregon were accounted for by nonprofits while urban county nonprofits employed 10-11\% of their population in 2013 (Fridley, 2015, p. 7; Fridley 2017). In 2015, nonprofits in Oregon accounted for $10.3 \%$ of the state's employment (both public and private), about the same amount as the manufacturing sector in Oregon. Despite their lower numbers, rural Oregon nonprofits paid $12 \%$ more in wages than their national average while urban ones paid $4 \%$ less than their national counterparts.

In spite of their impactful contributions, nonprofits, especially small ones, faced immense challenges especially with limited access to resources that hindered upgrading or expanding systems and programs, much less avoid cutting or eliminating existing services. Between 2010 and 2011, 65\% of the organizations surveyed in ONSR 2012 reported an increase in their demand for services; however only $44 \%$ reported an increase in revenue within the same time-period. Of those $44 \%$ respondents, $64 \%$ were big nonprofits with annual budgets greater than 10 million (ONSR, 2012, p. 13).

Further, in the same time period, $26 \%$ of these nonprofits reported that they had to scale or cut back programs while $51 \%$ turned away clients due to lack of resources like funding, volunteers, staff, space, etc. (p. 14). It would at first appear that Oregon's nonprofits did better than the national average, because as pointed earlier, $52 \%$ nonprofits 
at the national level scaled back programs or cut off services around the same time. But a closer look at the Oregon data revealed that four-fifths of those organizations who had to scale back or turn clients away were small nonprofits operating below a $\$ 500,000$ annual budget or small nonprofits. While the overall nonprofit sector in Oregon performed better than the national average, it is hard to say the same for small Oregon nonprofits.

From 2011 to 2017, I compiled a database from the Oregon Department of Justice's active nonprofit lists (all seven years). The active lists get updated after a time lag of approximately two years. There were about 11000 organizations under active 501c3 status as of Dec 31, 2015. When running analysis on the tables generated from that data, I found that $70 \%$ of nonprofits in Oregon had an average annual budget below $\$ 100,000$ from $2009-15$, and $87.3 \%$ had a budget below $\$ 500,000$ (See the breakdown in Table 1.1).

The national average, showed about $67 \%$ organizations below $\$ 500,000$ within the same time period. Guidestar defines nonprofits below a million-dollar budget as 'very small' nonprofits and those between \$1-5 million as 'small' nonprofits (Guidestar, 2018, Appendix Table 7, p. 24). Oregon was thus, in the time period studied, and still remains primarily a micro / very small nonprofit state. 


\section{Table 1.1}

Oregon's Nonprofit Sector by Annual Budget, 2009-15

\begin{tabular}{lcc}
\hline \multicolumn{1}{c}{ Annual budget size } & Frequency & Percent \\
\hline Below $\$ 50,000$ & 6470 & 59.8 \\
$\$ 50,000-\$ 100,000$ & 1146 & 10.6 \\
$\$ 100,000-\$ 250,000$ & 1164 & 10.8 \\
$\$ 250,000-\$ 500,000$ & 668 & 6.2 \\
More than $\$ 500,000$ & 1378 & 12.7 \\
Total & 10826 & 100.0 \\
\hline
\end{tabular}

Note. Figures computed from Oregon Department of Justice. Databases were downloaded from 2011 to 2017 every year around mid-June and figures amended on a yearly basis. Those who did not file taxes or organizations below $\$ 50,000$ who did not e-file $990 \mathrm{~N}$ for more than two of these years were not counted.

Despite being a small nonprofit state, previous surveys on the sector in Oregon had an over representation of large and big budget nonprofits. The first Oregon Nonprofit Sector Report 2012 where I served as Chief Data analyst was conducted in 2011-12. In this report $37 \%$ of its respondents operated below $\$ 100,000$ annually; however, figures computed from the National Council for Charitable Statistics found that about $71 \%$ of all Oregon nonprofits fell into this group at the time of the survey (Schroeer, Medora, Mukerjee \& Wallinger, p. 7). The 2014 Northwest Nonprofit Sector Report had $48 \%$ respondents under a $\$ 500,000$ budget while numbers computed from the Department of Justice around the same time showed $69 \%$ of Oregon nonprofits had revenues below $\$ 500,000$. The 2015 State of the Northwest Nonprofit Sector Report had 65 respondents from Oregon and only 29\% of these operated below \$500,000 in 2014 (Nonprofit Finance Fund, 2015). The 2016 Northwest State of the Sector report had slightly better figures 
with 118 respondents from Oregon with $49 \%$ below a \$500k annual budget (Nonprofit Association of Oregon, 2017).

Many respondents in fact, stated in the ONSR 2012 report that "small organizations frequently do not have the organizational or staff capacity to respond to survey requests" (Schroeer, Medora, Mukerjee \& Wallinger, 2012, p 7). Others stated that rather than collecting numbers alone, studies should include small organizations whose needs are different from big budget organizations and towards whom online surveys are usually geared to. Comments received at the end of the survey and personal emails from respondents who declined / did not finish the survey expressed doubts on whether aggregating the results from the survey would help because small nonprofits felt certain questions were not applicable to them.

'If we had to have paid 'employees'...the expense would close us down. When you're in an extremely rural area, with low population numbers, grant funding is always in the very low amounts. As with government dollars! We are not eligible for any federal funding simply because we don't have 'employees'....even though we are the only one of our kind out here providing a multitude of services" (small, rural family services organization in Lake County).

"Our organization is tiny, all volunteer, annual budget under $\$ 10000$ most years. Our only volunteers are pretty much our six board members. I don't know that including our responses without acknowledging that scale will be of value in using this survey's results. We are a support group for people with hearing loss. Most participants want just to attend meetings to hear presentations and share stories. Seems like we could do more but lack good leadership and I say that as the person who reluctantly agreed to be its president this year" (small, urban human service organization in Portland).

Many respondents in the ONSR 2012 report pointed out that the urban rural distinction should have been asked as it influences the impact of the services. One participant responded, 
"As a very small community-based organization, I didn't have all the data needed to answer your questions. We have limited capacity in managing volunteers, and specific data that does with that. I would have liked if you had asked how old your NGO was, and if it was an urban or rural NGO. Rural rarely gets its due. (small, rural food distribution service in Tillamook County)

To get an idea of how many of Oregon's nonprofits were rural and how many were urban, I looked for definitions that classified them as such. There were no definitions of urban and rural explicitly stated for nonprofits. The most commonly used methodology was checking the primary location where the nonprofit was located and finding where that city (either incorporated or not) was urban or rural. The Oregon Office of Rural Health defines that a place is considered urban if it is within a 10-mile radius of a city of population 40,000 or more.

The database of all Oregon nonprofits noted earlier, was compiled from 7 years of Oregon Department of Justice listings, I found nonprofits in 376 incorporated and unincorporated areas in the state. One must note that some nonprofits do not share their actual location but only a PO Box in public records, which makes accurate estimates difficult. Therefore, this number is a best estimate of where the nonprofits are located. By using the above definition, 288 of those Oregon incorporated and unincorporated places would be classified as rural, the rest 88 as urban. A list of all zip-codes in Oregon (these include both 241 incorporated cities in the state and unincorporated areas) as defined rural or urban by this classification is available from the Oregon Office of Rural Health at https://www.oregon.gov/oha/HSD/AMHPAC/Documents/OR-Zip-Codes-Urban-Rural-

\section{Designations.pdf}


Using the list provided at the above link I coded the nonprofit organizations in the database I had created as urban or rural based on their 2015 location. In total, $37 \%$ of nonprofits in Oregon were found to be in rural Oregon places while the rest $63 \%$ were in urban areas. So overall urban Oregon has twice as many nonprofits than in the rural areas. However, only about $15 \%$ of urban and $9 \%$ of rural nonprofits had an average annual budget greater than $\$ 500,000$ during 2009-2015 (see the breakdown in table 1.2). Oregon is thus mostly a small nonprofit state; in fact, after running simple regression and correlation tests between budget size and urban-rural-ness, I found that larger organizations were more likely to be in urban areas $(\mathrm{F}=138.17, \mathrm{R}=0.112, \mathrm{p}<0.001)$.

\section{Table 1.2}

Oregon's Nonprofit Sector by Annual Budget and Urban / Rural Distinction, 2009-15

\begin{tabular}{lcc}
\hline \multicolumn{1}{c}{ Budget size } & Urban & Rural \\
\hline Below 50,000 & $3874(56.2 \%)$ & $2596(66.0 \%)$ \\
$50,000-100,000$ & $733(10.6 \%)$ & $413(10.5 \%)$ \\
$100000-250,000$ & $782(11.3 \%)$ & $382(9.7 \%)$ \\
$250,000-500,000$ & $466(6.8 \%)$ & $202(5.1 \%)$ \\
More than 500,000 & $1037(15.0 \%)$ & $341(8.7 \%)$ \\
\hline
\end{tabular}

Note. Figures computed from Oregon Department of Justice. Databases were downloaded from 2011 to 2017 every year around mid-June and amended on a yearly basis. The urban rural distinction was computed based on OSU Rural Explorer's definition of urban and rural.

As seen in table 1.3 further (computed from the same sources), across Oregon, smaller nonprofits with budgets less than $\$ 50000$ account for about two-thirds of all 
nonprofits in their region except in the predominantly urban Metropolitan Portland area where their percentages were lower compared to other rural parts of the state.

\section{Table 1.3}

Oregon's Nonprofit Sector by Annual Budget and Regions, 2009-15

\begin{tabular}{lccccc}
\hline \multicolumn{1}{c}{ Budget size } & $<\$ 50 \mathrm{~K}$ & $\$ 50-100 \mathrm{~K}$ & $\$ 100-250 \mathrm{~K}$ & $\$ 250-$ & $>\$ 500 \mathrm{~K}$ \\
& & & & $500 \mathrm{~K}$ & \\
\hline Central Oregon $^{\mathrm{a}}$ & $432(62 \%)$ & $76(11 \%)$ & $70(10 \%)$ & $42(6 \%)$ & $78(11 \%)$ \\
Eastern Oregon $^{\mathrm{b}}$ & $361(66 \%)$ & $55(10 \%)$ & $62(11 \%)$ & $21(4 \%)$ & $49(9 \%)$ \\
Southern Oregon $^{\mathrm{c}}$ & $664(63 \%)$ & $104(10 \%)$ & $115(11 \%)$ & $59(6 \%)$ & $123(12 \%)$ \\
Coastal Oregon $^{\mathrm{d}}$ & $553(66 \%)$ & $97(12 \%)$ & $73(9 \%)$ & $46(6 \%)$ & $65(8 \%)$ \\
Willamette Valley $^{\mathrm{e}}$ & $1869(63 \%)$ & $286(10 \%)$ & $284(10 \%)$ & $164(5 \%)$ & $383(13 \%)$ \\
Metropolitan & $2671(56 \%)$ & $528(7 \%)$ & $560(12 \%)$ & $336(7 \%)$ & $680(14 \%)$ \\
Portland $^{\mathrm{f}}$ & & & & & \\
\hline
\end{tabular}

Note. Figures computed from Oregon Department of Justice. Databases were downloaded from 2011 to 2017 every year around mid-June and figures amended on a yearly basis. The regional distinction was computed based on Oregon Community Foundation's classification of which counties are within which region of Oregon.

${ }^{a}$ Crook, Deschutes, Gilliam, Hood River, Jefferson, Sherman, Wasco, Wheeler

${ }^{\mathrm{b}}$ Baker, Grant, Harney, Malheur, Morrow, Umatilla, Union, Wallowa

${ }^{\mathrm{c}}$ Jackson, Josephine, Klamath, Lake

${ }^{\mathrm{d}}$ Clatsop, Columbia, Coos, Curry, Lincoln, Tillamook

e Benton, Douglas, Lane, Linn, Marion, Polk, Yamhill

${ }^{\mathrm{f}}$ Clackamas, Multnomah, Washington

There are some limitations of using this definition of urban and rural. Defining a nonprofit as urban because it is located in a small town within a 10-mile radius of a big 
city assumes that the impact of the small nonprofit extends not only within the town located but also to the big city in its vicinity. It is possible, for example, a rural nonprofit's work is limited only to high school students within the town and not the city in its vicinity and hence this nonprofit would be rural and not urban. Secondary data from the Oregon Department of Justice, Guidestar and the National Center on Charitable Statistics cannot tell us whether a particular nonprofit's impact is limited only to the immediate vicinity of its location or further. Because of this, figures in tables 1.2 and 1.3 should be considered approximate but not accurate estimates.

In my literature review, I will further explain the existing definitions of urban and rural and lay the rationale for why in my study, I took respondents' opinions on whether they were an urban or rural nonprofit and their reasons for the same instead of classifying them as urban and rural based on their location. In fact, this became an emergent finding as this study progressed and I have laid more details in Chapter 4 to make some contribution on how to define a nonprofit as urban or rural.

ONSR 2012, the Nonprofit Finance Fund Survey 2014, the NAO Northwest Nonprofit Survey 2014 - all of these surveys provided numbers that showed that nonprofits, especially smaller ones had to turn clients away, and most of their funding was not enough to help them provide services to those who needed it. However, these studies did not give information on describing these challenges, or an insight into what kind of capacity building initiatives be tailored towards small organizations. The latest 2016 Northwest capacity report (Nonprofit Association of Oregon, 2017) which incidentally was published around the same time I was conducting my interviews for this 
study, found out that capacity building needs among nonprofits in Northwestern US are most required in

1. Human capacity - need to acquire staff members, board members, and volunteers with specific skills

2. Facilities \& Equipment - need for capital to acquire land, asset acquisition and repair, buying equipment for programs and administrative purposes

3. Money - need for diverse funding streams that are sustainable, ability to find the right grants, requiring people with knowledge of managing and monitoring budgets

4. Communications - the need for greater community outreach, awareness, and education. Also getting new members, and new clients.

5. Leadership and Strategy - need for better organizational management, strategic management, and leadership development. (2017 Northwest capacity report, p. 6)

This report gave an insight into specific capacity namely building needs among nonprofits in Northwest USA but did not distinguish if these needs were different across rural and urban regions and across big and small organizations. Overall, data on the nonprofit sector in Oregon and the needs of the organizations existed when I began my research. Research was however, lacking about small Oregon nonprofits, especially studies that differentiated by the urban versus rural distinction. Past studies as quoted above, agreed there was a capacity challenge among Oregon nonprofits and that a high percentage of these organizations did not have enough cash reserves or had to cut down 
programs because of lack of resources (either financial or human). However, reasons for the capacity challenges were missing and research needed to be done to understand the specific financial and human capacity constraints that small nonprofits faced in Oregon and how these differed across urban and rural settings.

Nonprofit and voluntary organizations have always played a vital role in Oregon's economy, but it is important to know if they possessed the capacity to fully utilize their existing resources and gather new ones. The aim of this research, therefore, was to explore the financial and human resource capacity of small nonprofit and voluntary organizations in Oregon to fulfill their objectives and thus provide policymakers, nonprofit capacity building organizations and key leaders in the third sector in Oregon an assessment of what these organizations needed to improve in their capacity to achieve their missions.

By understanding the unique difficulties and challenges that small urban and rural Oregon nonprofits have faced in fulfilling their missions, leaders and capacity builders should be able to build the right capacity-building initiatives that are specifically tailored to address the capacity deficit in small nonprofits, depending on whether they are rural or urban. By showcasing deficits in capacity, the study did not aim to paint a negative picture of the third sector in this state. Rather, the aim was to highlight the unique strengths and resilience of small nonprofits and strategies they have adopted to acquire and effectively utilize resources, thus providing creative insights for capacity building programs and initiatives in future. 


\section{Research Problem}

This study was guided by the following research questions:

What capacity deficits, in financial and human capacity, exist across small nonprofit organizations in Oregon? How are these different between urban and rural nonprofits? How should capacity builders and policy makers customize capacity building initiatives for small urban and rural nonprofits separately so as to help them achieve sufficient financial and human competencies to achieve their missions?

The following sub-questions helped to answer the research questions:

1) What core capacities do small urban and rural nonprofits in Oregon currently possess, in the financial and human capacity domains?

2) What knowledge and skills do they possess that can serve as valuable examples for other similar organizations? Which areas do they have a deficit and need to learn strategies to overcome this deficit?

3) How should capacity builders and policy makers customize capacity building initiatives for small urban and rural nonprofits separately so as to help them achieve financial and human competencies sufficient to achieve their missions?

\section{Significance of the Study}

The information gathered through this research should help capacity builders design programs that focus on imparting better training programs online to remotely located rural nonprofits, workshops on building social networks among urban nonprofits and / or exploring potential partnerships that could draw on the strengths of the other group. The study may also have implications for other states with a substantial 
urban/rural divide and whose nonprofit sector is majorly composed of organizations that operate on small budgets.

Past studies among the third sector in Oregon nonprofits mostly involved surveys with multiple choice questions, some of which may not be applicable to smaller nonprofits. Many respondents to the first Oregon Nonprofit Sector report for instance, commented that the questionnaire catered to the professional corporate big nonprofits and failed to capture the uniqueness and stories that highlight the resilience of small nonprofits and their capacity building challenges. For this study too, I felt that small organizations would be unwilling to provide confidential data online because they would be compared to larger nonprofits whose capacity building problems are on a different scale from theirs. They would feel more comfortable answering open-ended questions that did not require them to provide exact financial figures or data for their organization. To truly capture the capacity deficit across small nonprofits, a qualitative data collection (interviews or focus groups) supplemented by short pen and paper surveys would be more effective at drawing respondents who were understaffed and / or unwilling to provide confidential information on their capacities through off-site web surveys.

This study was thus not only important because it contributed to gathering information where it was missing in Oregon but also because in its most basic form, this research argued for the need to analyze small nonprofits separately. This study has value in application to practice, policy formation or evaluation. Aggregating responses of both small and big nonprofits through quantitative surveys that have higher representations of large nonprofits leads to proposing theories of capacity-building that, if implemented in 
practice, may not be geared towards the needs of smaller organizations. This study excluded nonprofit organizations with more than an annual budget of $\$ 500,000$ and as such aimed to build theory geared towards smaller organizations. In fact, the largest proportion of respondents in this study had budgets below $\$ 50,000$ annually; a category that is often missing in national estimates and web surveys because these small organizations are not required to register with the IRS. In Oregon though, small organizations need to register with the state Department of Justice, the database from where I framed my list. Also, this study argued for the need for more qualitative research rather than web surveys for small organizations.

Finally, this study may have implications for regions that have an urban / rural divide similar to what exists in Oregon. Oregon State University and its Rural Explorer Program provides many insights into the kinds of communities in rural Oregon and provide indicators of community well-being in rural areas. These include but are not limited to demographic, social, education, economic, health and infrastructure. The kinds of services nonprofits provide are impacted heavily by these indicators, hence a study that stressed on the urban/rural distinction in nonprofits also gave insights on how to build civic capacity. As Conolly and Lukas (2002, 2003) point out, capacity building produces a ripple effect. Improving the capacity of each individual within the nonprofit organization improves organizational capacity collectively. The nonprofit further uses this to increase the capacity of the community it serves and thus builds up a resilient and stable nonprofit sector that contributes positively to civil society (Strawser, 2017, p. 11). 
In summary, while this study was based in Oregon, it may have future implications for states or regions elsewhere that have a similar nonprofit sector comprised mostly of small nonprofits and have a significant urban rural divide.

\section{Overview of Chapters}

Chapter 2 provides a review of literature relevant in understanding capacity in small nonprofits, both rural and urban. This chapter presents context for many concepts; like why nonprofits exist and how the urban rural distinction affects their demand and supply in an economy. I also argue how social capital and social origin theories make the case for nonprofits that provide indirect services like arts and culture, environmental protection and animal rights. Next, I delve into why capacity building matters, especially for small nonprofits. Combining essential elements of four prominent models and taking into consideration assumptions of Resource Dependence and Strategic Management theories, I make the case for studying capacity in small nonprofits under three categories - namely financial capacity, human resources (board members and volunteers) and collaborations.

Chapter 3 introduces the methodology of the study and describes the research instruments and data sources. I lay the rationale behind adopting an inductive emergent study design and outline the process involved in the sequential-priorities, mixed-methods approach where a preliminary quantitative study was followed by a core qualitative study. I talk about which research participants were selected and the sampling process. I detail the coding process, along with how themes, categories, domains and labels were applied. 
In Chapter 4, I revisit the urban/rural distinction and study its historical trends in Oregon and how that has influenced the nonprofit sector in Oregon. Next, I study definitions of urban and rural, showcasing their current limitations of being applicable to the nonprofit sector and suggest exploring for alternate ones, based on emergent themes in this study. Here I try and operationalize the urban rural/variable based on what 'emerged' in the study and how that definition is similar or different to ones existing in current literature.

Chapter 5 presents the results of the study. Since this is primarily a qualitative study, this chapter includes many quotes from the interview participants. I discuss all findings related to financial capacity, boards, volunteers and collaborations under three headings - general findings, findings in conjunction with small size, and findings in conjunction with the urban rural distinction. I discuss how the findings agree or disagree with current literature or add to the possibility of generating new theory.

Finally, in Chapter 6 I talk about the implications of the findings for capacity builders, trainers and other entities whose aim is to help with capacity building initiatives in the third sector. I conclude with what contributions to theory and practice this research made, limitations of the study, and recommendations for future research. 


\section{Chapter 2: Review of Literature}

This chapter examines the literature related to nonprofit capacity building, especially in their financial and human resource domains. It begins with definitions of nonprofits. Next, I will explore the urban/rural distinction among nonprofits; this is best explained while understanding why nonprofits exist in the first place. Then I examine the major theories that define capacity and capacity building and make a case for analyzing the concept under the broad spectrums of financial and human capacity. I then review the literature on how size and urban / rural distinction affects these various dimensions of capacity. The study explores if small nonprofits can benefit through collaborations (including urban rural alliances), hence I will examine the literature on collaboration in nonprofits. By presenting literature that currently existed before this study, I will lay down the rationale for how this study aimed to create value by exploring questions previously unanswered.

\section{What is a Nonprofit?}

According to the National Council of Nonprofits, nonprofit organizations in the USA are groups that are tax-exempt under Internal Revenue Code Section 501(c)(3) as "public charities" because they are formed to provide "public benefit." Community foundations and private foundations are also part of this group. There are actually 29 types of organizations that are tax-exempt under Section 501(c) (see Appendix $\mathrm{C}$ for the full list). These organizations are exempt from certain taxes because of the contributions they make in the community. However, only 501(c)(3) groups will provide donors with a tax-deduction for their contribution. 
Within section 501(c)(3) there are two kinds of organizations: those organized as private foundations (includes family, corporate and private operating foundations) and those organized as public charities. Public charities (what we refer to as charitable nonprofits, to distinguish them from private foundations) have many different missions. The easiest way to distinguish between the two when looking at their documentation is to see which tax form they have filled. Essentially all tax forms filled by 501 (c) organizations are either form 990 or $990 \mathrm{EZ}$ or $990 \mathrm{~N}$ (for those below $\$ 50,000$ budget) and essentially ask the revenues and expenses for the last tax year. The tax form filled by foundations is the $990 \mathrm{PF}$ and also asks for grants given in the last tax year apart from revenues and expenses (copies of the latest forms are available on the IRS website). Further, public charities are classified by the National Taxonomy of Exempt Entities (NTEE) into 645 categories in eight primary groups as shown in Table 2.1 below. Note that the table includes public charities only and excludes nonprofits in NTEE Categories T, U and V (foundations and research organizations). Human services groups - such as food banks, affordable housing and homeless shelters, youth services, senior care centers, sports organizations, employment services, public safety and disaster management services, and family or legal services - composed over one-third of all public charities $(35.5 \%)$. Education organizations which accounted for $17.1 \%$ of all public charities include booster clubs, parent-teacher associations, educational institutions (schools, colleges and universities), fraternities / sororities, libraries and financial aid / scholarship groups. The 'healthcare' subsector not only includes hospitals, clinics and other healthcare organizations but also mental health and crisis intervention 
organizations, those that perform medical research and study medical diseases and disorders. It was the third largest subsector in 2013 comprising about $13 \%$ of all nonprofits.

\section{Table 2.1}

Distribution of Nonprofits by NTEE Classification in USA, 2013

\begin{tabular}{lcc}
\hline \multicolumn{1}{c}{ Subsector } & NTEE code ${ }^{\mathrm{a}}$ & Percent $^{\mathrm{b}}$ \\
\hline Arts and Culture & $\mathrm{A}$ & 9.9 \\
Education & $\mathrm{B}$ & 17.1 \\
Environment/Animal Welfare & $\mathrm{C}, \mathrm{D}$ & 6.2 \\
Health & $\mathrm{E}, \mathrm{F} \mathrm{G}, \mathrm{H}$ & 12.9 \\
Human Service & $\mathrm{I}, \mathrm{J}, \mathrm{K}, \mathrm{L}, \mathrm{M}, \mathrm{N}, \mathrm{O}, \mathrm{P}, \mathrm{Y}$ & 35.5 \\
Foreign Affairs & $\mathrm{Q}$ & 2.1 \\
Community and Civil Rights & $\mathrm{R}, \mathrm{S}, \mathrm{W}$ & 11.6 \\
Religion & $\mathrm{X}$ & 6.1 \\
\hline
\end{tabular}

Source. What is a nonprofit? https://www.councilofnonprofits.org/what-is-a-nonprofit

${ }^{\text {a }}$ All NTEE codes available at https://nccs.urban.org/sites/all/nccsarchive/kbfiles/324/NTEE_Two_Page_2005.pdf).

${ }^{\mathrm{b}}$ Percentages do not necessarily add up to 100 as most nonprofits operate across multiple subsectors

\section{Why Do Nonprofits Exist?}

Salamon and Anheier (1998) point out that the reasons behind the existence of non-governmental organization / nonprofits / public charities vary among nations and regions. Nineteenth century America saw the rise of Tocquevillian voluntarism that gave rise to the modern US welfare state and public charities. Germans saw the principle of subsidiarity and local self-governance shape their nonprofit conglomerates, and associationalism which was a counteracting force to both the church and state shaped the 
sector in Italy (p.90-91). In recent times, neoliberalism, social capital and globalization have shaped the existence and nature of the third sector.

Neoliberalism and new public management which gained prominence under Margaret Thatcher in the UK and Ronald Reagan in the USA started with the aims of having more government cuts and public services being outsourced to other agencies. The nonprofit sector was seen as the answer to 'government cuts' and therefore a healthy supplement to the public sector. As Peter Dobkin Hall (2016) explained, Reagan's Conservative policies had a twofold effect. On one hand, with less government funding, nonprofits were restricted in how they could respond to their clients' needs. On the other hand, increased stress on privatization of social services fueled the rise of more nonprofits.

Economic theories, on the other hand, posit that nonprofits are not a supplement but a substitute for the public and private sector, i.e. they step in when markets and governments fail. In 1975, the economist Burton Weisbrod was among the first to publish a theory that attempted to explain the existence of nonprofit organizations in market economies. Wolch and Geiger (1983) studied unincorporated communities in Los Angeles County, California and found there were more nonprofits in cities with higher average incomes. The more heterogeneous the population, the higher is the probability of more nonprofit organizations in existence. This is primarily because according to Weisbrod's 'public good theory of nonprofits' (1975), nonprofits exist because of two reasons: the median voter and demand heterogeneity for the provision of public good. 
Public goods are non-excludable and non-rival - hence 'for-profit' organizations do not have the incentive to supply them. Public agencies are more interested in providing those services that serve as the choice of the median voter and even if they supply other public goods, the quality of their services may be inferior or the quantity may be insufficient (Anheier, 2005, pp 120-122). Galbraith (1998) for instance, argued that government investment, especially in public education has been scarce in the US because the average American median voter spends more and is interested more on material goods than on education, causing government to focus less on public goods like public education. By the same analogy, poorer neighborhoods are more likely to be endowed with lower quality public schools because the poor often view education as a luxury and are less likely to demand the government for better schools. So, the duty of advocating and / or providing for cheap school education for poor children becomes the responsibility of nonprofit organizations.

In short, nonprofits step in where both the state and private firms fail. For the same reason they are often referred to as the 'third sector'. To assess what kinds of services will be in demand within a particular region, public agencies look at what the median voter wants. Weisbrod (1975) reasons that societies that are more heterogeneous have a wider median voter demand curve and hence are more likely to have higher instances of government failures and hence more nonprofit organizations. Salamon and Anheier (1998) tested this proposition and found that with the exception of Ireland, Belgium, Israel and the Czech Republic, most countries were in accordance with the theory (Anheier, 2005, pp 122-123). Similar studies by James (1993) and Chang and 
Tuckman (1996) found that population heterogeneity / diversity was directly proportional to the number of nonprofits serving that population.

There are of course limitations to Weisbrod's public goods theory of nonprofits. Firstly, it assumes that nonprofits provide only public goods, but they can also provide quasi-public goods (goods that can be provided either by government or the market). Examples would be roads and bridges that collect a fee or tax, private schools that provide education, etc. Second, it assumes that nonprofits through support from donations will be a substitute for government spending i.e. they will be diverted into areas where there is less government spending. That would mean if the government started spending more on the same sphere, private donations to nonprofits working in that arena would decrease. But that may not necessarily happen.

As Anheier (2003) explains, Weisbrod's theory explains why there is a demand for nonprofits, but the supply side of the equation is equally important. Avner Ben-Nur in his 'stakeholder theory of nonprofits' posited that some consumers of nonprofits services feel very strongly about the quality of service being provided (Ben-Nur \& van Hoomissen, 1991). This makes them want to exercise control over the output so that they can minimize the costs of information asymmetry and moral hazard. By volunteering or working for nonprofits themselves, consumers of nonprofit services ultimately get to exercise control on the service themselves (Anheier, pp 129).

'Trust theories of nonprofits' like those given by Arrow (1963) and Nelson and Krashinsky (1973) also focused on information asymmetry. Consumers of public service may be unsure if the public good provided by the government is good enough because 
they do not have as much information as they would like to, or they may not trust the government. However, a nonprofit to which they regularly donate or volunteer or participate in board meetings may gather enough trust for its services (Anheier, 2014, p 206).

Finally, there are 'entrepreneurship theories of nonprofits'. James (1987) and Rose-Ackerman (1996) are the main theorists of this approach and they define social entrepreneurs as those who create social value rather than profit or monetary value. They do this by

"adopting a mission to create and sustain social value; recognizing and relentlessly pursuing new opportunities to serve that mission; engaging in a process of continuous innovation, adaptation, and learning; acting boldly without being limited to resources currently in hand; and exhibiting a heightened sense of accountability to the constituencies served and for the outcomes created" (Anheier, 2014, p 209).

In fact, James posits that, non-profit leaders are social entrepreneurs who try to maximize non-monetary returns such as faith, believers, adherents, etc. She even goes on to say that nonprofits especially are hugely located in healthcare and disability, services for the aged and dying etc. because people who need such help are more open to religion than others (Anheier, 2014, James, 1987).

The stakeholder theories, entrepreneurship theories and trust theories thus do not posit that nonprofits are a substitute and should step in when both governments fail. In fact, their reasoning is that the sector is a complement to the government and market sectors and not a substitute. It is the third sector with government being the first and private players being the second. In a healthy economy, all three sectors work in 
complement to each other and sometimes may even collaborate. This is in fact the positioning of the 'interdependency theory of nonprofits' posited by Salamon and Anheier (1987). Just like government failure and market failure, there can be failure within the nonprofit sector as well. Termed as voluntary failure, this can happen if resources and finances in the third sector are insufficient, nonprofits focus only on select clienteles and ignore some other groups, nonprofits lack accountability or there is shortage of skilled staff and volunteers in the third sector. To prevent this, the other two sectors must step in as complements; they can provide donations, grants and contracts, and the government can frame regulations that set up accountability and selectivity controls and the private sector can provide consulting skills to replace essential HR personnel.

\section{How Economic Theories Explain the Urban Rural Distinction: Do We See Evidence in}

\section{Oregon?}

As explained, the economic theories explain the existence of nonprofits both from the demand and supply side. As the public goods theory posits, to understand where nonprofits are in demand more, we should look at how heterogeneous the region is; more diversity translates to more demand for nonprofits, especially those that provide direct social services to people. Urban areas are more diverse than rural areas and will have more demand for nonprofit organizations as the state and private players often cannot cater to all the diverse needs and demands of a population that is not homogenous. However, this does not mean that rural areas have lesser challenges for nonprofits because there is a lower demand for their services there. For this, we must understand the 
supply side of the equation as posited by the stakeholder, trust and entrepreneurship theories.

Diversity not only explains what services will be in demand but also gives insights into the kind of services that are more likely to attract social entrepreneurs, board members and volunteers and generate more revenue from community donations. Hence, in rural areas where there is less diversity, nonprofits will be constrained on the supply side - they will face capacity challenges in recruiting and retaining sufficient human capital, especially those who focus on issues that are seen as less relevant by the rural population.

Before understanding the state of nonprofits in Oregon, it is important to study that characteristics that define the state and have an impact on how nonprofits are shaped. Oregon had been historically a rural, agrarian, and resource-based economy, currently it has characteristics of a post-industrial society with most people employed in the service sector and continues to change in terms of demographics, urbanization and technical advances (Clucas, Henkels \& Steel, 2011, p. 113). Post-industrial societies are more open to policies dealing with environmental issues and civil rights related to women, different races / ethnicities, etc. (Inglehart \& Weizel, 2010).

Clucas, Henkels and Steel (2011) claim that as Oregon changed from to a resource-based economy in the nineteenth century to a post-industrial society, there were changes in attitudes and voting patterns accordingly. In the past, people were mostly concerned with issues related to shelter, food and nutrition, clean drinking water but with industrialization people became more concerned with employment, education systems, 
access to affordable health care, public transportation, etc. However, when current patterns are broken down beyond the state level by different regions, a clear urban-rural divide emerges. Urban areas display higher post-materialist values with favorable attitudes towards gender equity, gay rights and affirmative action, while rural areas retain materialist values with lesser interests on similar issues (p. 117-119). Rural counties are more opposed to government spending on health services and education and less likely to favor laws that ban hunting.

Higher cultural and religious heterogeneity positively influence the number of nonprofit agencies in a region i.e. areas with more heterogeneous / diverse populations have more nonprofits (James, 1987). This could explain why urban counties in Oregon have more nonprofits with special focus on immigrant and foreign-born communities while rural Oregon counties have a high number of preschools, daycare, high schools and senior service facilities run by faith-based organizations. Diversity and heterogeneity therefore, in Oregon have to some extent, determined what kinds of nonprofit services are in higher demand than others.

Similar studies outside of Oregon and the US show interesting results. Hooghe and Botterman (2012) for instance found that in Belgium, population density and urbanization did not affect community social networks and forms of voluntary participation. However, traditional forms of association like working for small community-based organizations are higher in rural settings in America because of higher participation from the elderly as well as children who have lesser opportunities for alternate leisure activities as in urban areas and because the youth feel socially excluded 
and challenging to maintain their individualities in communities dominated by the elderly (Schucksmith, 2004; Torgerson \& Edwards, 2013).

Hence, the urban / rural distinction is important; diversity and heterogeneity are not the same across urban and rural areas. In urban areas where there is higher diversity, more people will need nonprofit services and nonprofits here will be constrained in their capacity to meet those demands. However, in rural areas where there is less diversity, nonprofits will be constrained on the supply side - they will face capacity challenges in recruiting and retaining sufficient human capital, especially those who focus on issues that are seen as less relevant by the rural population.

The economic theories of why nonprofits exist and how demand and supply of nonprofits is affected by the urban-ness or rurality of the region, though, applies more to nonprofits who provide direct services to people. Nonprofits like performing arts organizations (orchestras, theater, dance clubs, etc.), museums, genealogy and historical societies and organizations dedicated to ethnic folklore and arts usually do not provide direct tangible services like housing, healthcare, education, advocating for issues or other human services. Then there are nonprofits who run programs for animal welfare and environment preservation. Some of these organizations provide direct services to people who are pet owners by providing services to their animals. But there are other organizations in these categories that are into wildlife and exotic animal care, preservation of natural habitats or protecting trees, oceans, forests, wetlands or other geographical places that are threatened by environmental degradation (or at least require cleanups and maintenance from time to time). These are indirect services too because 
essentially the costs of not providing these services is not apparent to the general population in the present. The costs will be incurred in the future.

Arts organizations and environment and animal protection organizations provide intrinsic values to the society, unfortunately these may be less demanded by the median voter or even in regions with diverse populations. So why would such nonprofits exist? Here we must look to other theories that explain the existence of nonprofits, apart from those that posit them as complements or substitutes to other sectors or study only the demand and supply side of the equation.

\section{Other Theories that Explain Indirect Services of Nonprofits}

The economic theories posit nonprofits exist as the third sector and their demand and supply is created by government or market failure so they can provide services which private and public firms cannot. However, according to the 'social capital persuasion theory', nonprofits are a tool for community building because of their contributions to social capital, ties and trust and participatory activities. Participating in voluntary work helps to build bonds of trust and social capital among people and leads to higher civic capacity (Putnam, 2000; Salamon \& Anheier, 1998). It is the reason environmental and animal welfare organizations will draw volunteers and donations to their cause. Participating in their activities may not create direct services to people but it builds social interaction and promotes solidarity among community members when they come together to do something that future members in their community will enjoy the benefits of.

Nonprofits that belong to NTEE category A (Arts, culture and humanities) usually provide activities and programs in visual media (paintings, print or celluloid media 
including film and broadcasting), music, performing arts (dance, theater, etc.) humanities (legacies and museums) and ethnic folk arts (could relate to certain groups or nationalities). While arts organization generally do not provide direct services to people (except arts-based education nonprofits), they create an intrinsic value that builds up social capital, bridges people across different communities (e.g. by highlighting ethnic folklore and arts to other groups) and contributes to a healthy civic community. As Eco Northwest (2012) puts it, "The public benefits of culture stem from the value people place on the pure existence of art and culture, from the value people place on having the option to experience arts and culture at some point (if they so choose), from the value people place on passing their culture, experience, and wisdom to future generations, from the value that people place on social cohesion and collective expression, and from the value people place on the prestige associated with sharing a community with renowned artists or cultural institutions" (p. ES-4).

The 'social origins theory' (Salamon \& Anheier, 1998) on why nonprofits exist, on the other hand, does not make the case for arts and culture nonprofits, at least in America. This theory posits that it is not individual consumer choices that determine provision of key services as the economic demand and supply theory suggests. In fact, historical developments and powers of certain groups will over time lead a society to lay down norms, habits and customs that will fundamentally determine over time which kinds of nonprofit services are perceived to be of a higher value. This explains why in American culture, often individuals are less inclined to give money to arts and culture 
organizations that are considered elitist and perceived to be of value for the rich and privileged and not the poor and underserved (Markusen \& Kitchener, 2012).

Another challenge that performing organizations, museums, and environmental and animal welfare organizations face is that they often have huge capital assets (theater building, museum grounds, large equestrian ranches, huge areas of wetlands, wildlife refuges, or habitats, etc.) that contribute to large utility and overhead costs to maintain them. Money from foundations and corporations often comes with conditions that specify keeping overhead and administrative costs low, which proves challenging to these nonprofits. Whether in urban or rural areas, nonprofits providing indirect services face an unfair disadvantage when competing for money or human capital since they have to compete with human service organizations. This is a noticeable issue for a state like Oregon where the third largest sector within nonprofits in Oregon is the arts and culture sector. In 2011 for instance, ONSR 2012 reported that next to religious organizations and human service organizations, arts and culture organizations made up the third largest sector within nonprofits in the state. Estimates of the number of arts and culture nonprofits at the turn of this decade account for about $13 \%$ of all nonprofits in Oregon. This is actually the $13^{\text {th }}$ highest $\%$ age among all the states. $56 \%$ of these organizations are in urban and the rest in rural areas (Eco NW, 2012).

When compiling figures for nonprofits from 2009-15 (see table 2.2) the author noticed that every small town in Oregon, no matter how remotely located has at least one arts and culture organization in the community and / or a museum devoted to the local history. A majority of these organizations fall in the small nonprofit budget range. 
Similarly, while environmental and animal welfare do not constitute the top five kinds of nonprofits in Oregon, their numbers as seen in the table below are higher in the small budget range. In Oregon, many small towns and unincorporated communities have small nonprofits that are named "Friends of.." and most of these low budget organizations are dedicated to protecting local habitats and environmental regions.

Table 2.2

Oregon's Nonprofit Sector by Annual Budget and Subsector, 2009-15

\begin{tabular}{llllll}
\hline Budget size & $\begin{array}{l}\text { Below } \\
\$ 50 \mathrm{~K}\end{array}$ & $\$ 50-100 \mathrm{~K}$ & $\begin{array}{l}\$ 100- \\
250 \mathrm{~K}\end{array}$ & $\begin{array}{l}\$ 250- \\
500 \mathrm{~K}\end{array}$ & $\begin{array}{l}\text { More than } \\
\$ 500 \mathrm{~K}\end{array}$ \\
\hline $\begin{array}{l}\text { Philanthropy/grant } \\
\text { making/foundations }\end{array}$ & $1429(22 \%)$ & $265(23 \%)$ & $259(22 \%)$ & $132(20 \%)$ & $224(16 \%)$ \\
Arts/culture & $937(14 \%)$ & $130(11 \%)$ & $130(11 \%)$ & $63(9 \%)$ & $79(6 \%)$ \\
Education & $818(13 \%)$ & $120(10 \%)$ & $93(8 \%)$ & $57(9 \%)$ & $179(13 \%)$ \\
Human Services & $434(7 \%)$ & $95(8 \%)$ & $111(10 \%)$ & $71(11 \%)$ & $205(15 \%)$ \\
Youth development & $450(7 \%)$ & $103(9 \%)$ & $87(7 \%)$ & $36(5 \%)$ & $65(5 \%)$ \\
Recreation & $422(7 \%)$ & $62(5 \%)$ & $62(5 \%)$ & $25(4 \%)$ & $25(2 \%)$ \\
/leisure/sports & & & & & \\
Healthcare & $273(7 \%)$ & $42(5 \%)$ & $62(5 \%)$ & $25(4 \%)$ & $25(2 \%)$ \\
Environment & $304(5 \%)$ & $44(4 \%)$ & $59(5 \%)$ & $51(8 \%)$ & $80(6 \%)$ \\
Religion a & $184(3 \%)$ & $60(5 \%)$ & $66(6 \%)$ & $46(7 \%)$ & $92(7 \%)$ \\
Housing & $66(1 \%)$ & $36(3 \%)$ & $68(6 \%)$ & $41(6 \%)$ & $99(7 \%)$ \\
Animal Welfare & $190(3 \%)$ & $41(4 \%)$ & $30(3 \%)$ & $18(3 \%)$ & $18(1 \%)$ \\
Food \& Agriculture & $116(7 \%)$ & $24(5 \%)$ & $25(5 \%)$ & $12(4 \%)$ & $24(2 \%)$ \\
All Others & $832(13 \%)$ & $123(11 \%)$ & $112(10 \%)$ & $64(10 \%)$ & $130(9 \%)$ \\
\hline
\end{tabular}

a These figures are derived from the Oregon Department of Justice database that excludes churches which is why religion does not rank first in this table. Actually, religious organizations including churches comprise the highest percentage of nonprofits in Oregon (ONSR 2012, p. 6), followed by foundations and philanthropic organizations and then arts and culture organizations. 
When exploring capacity building challenges across small nonprofits in Oregon it is thus justifiable to focus separately on the capacity challenges of organizations that provide indirect services and researching if their challenges are different and how can they better serve Oregon by reducing their capacity deficits. For the same reason, when drawing a list of contacts for this study, care was taken to see that all nonprofit categories were represented equivalently close to their proportion in the state figures; i.e. stratified random sampling was used. Arts and culture organizations did end up being represented in this study more than others; that was because of the timing of the study. Most interviews were in February and March, a time when performing organizations take a break after the Christmas holidays and there are few occasions to showcase performances.

So far, I have discussed the importance of why to study small nonprofits (including those that provide direct or indirect services) in Oregon separately from big nonprofits and why the urban-rural distinction is important. It is also necessary to operationalize 'urban and rural' for this study; hence I will explore current definitions and discuss on their potential for applications to this study. For this study specifically since I am analyzing capacity, I will research the literature on the concept of capacity first as it relates to nonprofits, before turning to definitions of 'urban and rural'.

\section{Defining Capacity}

The most basic definition of capacity is the ability to achieve the mission for which the organization was formed (Backer, 2000). The concept is not restricted to whether the organization is public or private or nonprofit. In this section I will focus on 
the definition of 'capacity' and 'capacity-building' as they pertain to the nonprofit sector. I start with how each sector has a perspective on nonprofit capacity; namely the governmental perspective, the foundation (private and public) perspective and the nonprofit perspective. I deal next with four models of capacity building; those postulated by Lucas and Conolly (2002, 2003), Barbara Blumenthal (2003), DeVita and Fleming (2001) and Paul Light (2004). Based on the elements of these models and assumptions of Resource Dependence and Strategic Management theories, I make the case for analyzing small nonprofit capacity under three categories - financial capacity, human resources and collaborations. Literature on those aspects follows.

\section{Three Perspectives of Nonprofit Capacity Models}

'Capacity building' refers to activities that strengthen nonprofits so they can better define their mission and vision and gather resources that achieve their mission, goals and outcomes (Backer, 2000; De Vita \& Fleming, 2001; Light, 2004; Light, Hubbard and Kibbe, 2004). The National Council of Nonprofits defines

"Capacity building is whatever is needed to bring a non-profit to the next level of operational, programmatic, financial, or organizational maturity, so it may more effectively and efficiently advance its mission into the future. Capacity building is not a one-time effort to improve short-term effectiveness, but a continuous improvement strategy toward the creation of a sustainable and effective organization." (https://www.councilofnonprofits.org/tools-resources/what-capacity-building)

Capacity, as defined by Light (2004) is an output of all organizational activities like recruiting the people to run the nonprofit, training them, generating ideas, fundraising, managing and monitoring budgets, building alliances and networks, and evaluating programs (p. 15). Capacity building, therefore, refers to grants / money, 
technical assistance and training that makes the nonprofit better and more effective in delivering its programs. In fact, capacity building in the US is defined by three different perspectives - the governmental (or public administration) perspective, the foundation perspective, and the nonprofit organization perspective (Brown, 2014).

According to the governmental perspective, a large fraction of the capacity required to create public value exists outside government today. Public functions are no longer the exclusive domain of governments. (Agranoff \& McGuire, 2003). Nonprofits are, according to this perspective, partners of the government in providing public services. It is why they are characterized by dedicated individuals who can press elected officials for enhanced program funds and provide volunteers in support of public cause (Cooper, 2003 pp 64-65). This perspective, unlike the economic theories of nonprofits does not advocate that that nonprofits step in when there is government or market failure. Nonprofits are not substitutes that step in when there is government failure but complementary entities to the public sector in providing public services and programs. They offer programs that contribute to a participatory democracy by offering opportunities for both individual and community engagement (Brown, 2014; Warren, 2001). Despite their impactful contributions, nonprofits are often single interest advocates, may have little or no professional legal assistance, heavily dependent on their Executive Director in shaping the organizations' values and mission and under continuous pressure for more resources (Cooper, 2003, p. 66-67). Hence their need for capacity-building programs and / or partnerships, networks, and collaborative governance with public sector entities (Bevir, 2010). 
For the same reason, many 501 (c) organizations may be partnered with a public agency to deliver programs jointly. Examples are 501 (c) 13 organizations that provide burial services and maintenance of cemeteries along with city governments or 501 (c) 6 organizations that assist city Chambers of Commerce. Public charities that are 501 (c) 3 may also partner with governments to deliver their services e.g. an organization like Friends of the 'XYZ City' Parks or through government contracts and in turn, get assisted by the City's capacity building grants to improve their program effectiveness which may include vouchers, or loans.

The foundation perspective views 'capacity building' as grants that enhance program impact and effectiveness, make the nonprofit sustainable in the long run and overall, be a counteractive force to declining individual donations (Connolly \& Lukas, 2002). According to the Foundation Center Grantspace, "A foundation is a nongovernmental entity that is established as a nonprofit corporation or a charitable trust, with a principal purpose of making grants to unrelated organizations, institutions, or individuals for scientific, educational, cultural, religious, or other charitable purposes" (https:/grantspace.org/resources/knowledge-base/what-is-a-foundation/). A private foundation like the Ford Family Foundation derives its money from a family, an individual, or a corporation. A public foundation is a grantmaking public charity and derives its support from diverse sources, which may include foundations, individuals, and government agencies.

This perspective believes that investing in capacity-building programs increases impact on the larger community while investing only in general nonprofit programs 
increases the impact of the program on the individual and not necessarily the whole community. Such programs, according to Backer, Bleeg and Groves (2004), focus on training workshops, either online or face-to-face and impart skills in leadership, creating collaborations and networking opportunities and tools to evaluate nonprofit programs so they can be enhanced over time (Brown, 2014; Conolly \& Lukas, 2002)

The third perspective known as the nonprofit perspective, suggests that capacity building programs are important because they help nonprofits grow and adapt to the environment. Nonprofits after all, do not distribute their profits to their staff or stakeholders but re-invest it in the organization's mission. Since they cannot offer incentives to their staff and volunteers, they must resort to other ways to motivate their workforce and make them perform better without the temptation for a monetary reward in return. In other words, they must constantly find ways to 'do more with less' or achieve the maximum with least resources (Brown, 2014).

This perspective also draws heavily on Resource Dependency Theory and Strategic Management Theory, both of which believe there are interdependencies between nonprofit organizations and the organizations they are embedded in (Brown, 2014; Pfeffer \& Salancik, 1978; Strawser, 2017; Wright, 2011). By participating in capacity-building programs, nonprofits showcase their successes to those who will provide them their most needed resources i.e. donors, foundations, government and the local community (the resource dependency perspective). Likewise, as per the strategic management theory, capacity-building helps nonprofits to align their internal 
environment (cultures, customs and norms within the organization) to the external environment so they can survive and sustain themselves over time (Selznick, 1957).

Models defining capacity take into account several dimensions; however, there is no easy formula that combines elements of all models. The common elements have always included the following: mission, vision and strategy, human capacity, financial capacity, other resources, networks and social capital, infrastructure and operations and leadership and strategic planning (Doherty, Misener \& Kuskelly, 2014). I will explore four models and try to draw a list of the most important factors or resources that contribute to effective capacity building in nonprofit organizations.

Conolly and Lukas Model. This model defines capacity building as strengthening capacities to improve performance and impact (Conolly \& Lukas, 2002, p.7). In this model, "capacities include capabilities, knowledge, and resources a non-profit needs in order to fulfill its mission through a blend of sound management, strong governance, and a persistent rededication to achieving results" (Hyman, 2006). All activities like strategic planning, technical and operational process improvements, and board leadership development are capacity building activities as they aim to make the organization achieve its mission successfully. This framework for understanding organizational capacities consists of four key areas: leadership capacity, management capacity, technical capacity, and adaptive capacity (Connolly \& York, 2003).

Leadership Capacity is the "ability of all organizational leaders to inspire, prioritize, make decisions, provide direction and innovate, all in an effort to achieve the organizational mission” (p. 21). This can be done by educating the community served 
about the organization and forming strategic partnerships and networks with funders, grantors, individual donors as well as important members of the community. People working in nonprofits have different functions related to day to day activities, providing programs and services, writing grants, managing volunteers and fundraising but the leaders i.e. board members and management have additional duties of decision making and being the image of their organization. Portraying what the nonprofit is all about helps them to gather resources that are necessary to providing programs and services while their decision-making skills helps to set priorities and direction so that the mission and vision of the organization can be realized. Leadership capacity in essence includes good governance (board policies / processes to direct and manage the nonprofit), sound leadership in the management outside of the board, and leadership sustainability in both board and management which includes career planning for existing leaders, transition planning and mentoring incoming leaders and an equitable distribution of power across board and management and across individual leaders (Claussen, 2011, p. 6).

Adaptive Capacity is the "ability of a nonprofit organization to monitor, assess and respond to internal and external changes" (Conolly \& York, 2003, p. 21). Organizations with high adaptive capacity regularly monitor their performance, evaluate their programs and services and leverage collaborations and networks to enhance and innovate their current existing capability (p. 22). An organization with high adaptive capacity learns from three sources - the environment (the community it serves, networks with leaders and funders), its programs (can access client needs, evaluate whether its 
programs are meeting them and if not, how can they be enhanced) and finally from the organization itself through self-assessments and strategic plans (Claussen, 2011, p. 7) Management Capacity is the "ability of a nonprofit organization to ensure the effective and efficient use of organizational resources" (Conolly \&York, 2003, p. 21). And as Claussen (2011) points out, this means effective management of money and people (staff, volunteers, board) - the two most basic resources which every nonprofit needs. Finally, Technical Capacity is the ability of a nonprofit organization to implement all of the key organizational and programmatic functions" (Conolly \& York, 2003, p. 21). This requires having the relevant technology and people with the relevant technical skills and also people who are skilled in fundraising and finances.

Barbara Blumenthal Model. According to Barbara Blumenthal (2003), capacity building is a broad term that encompasses "actions that improve nonprofit effectiveness, in terms of organizational and financial stability, program quality, and growth”. Capacity building initiatives under this model include but are not limited to:

- training and development opportunities for human resources like board members, management, staff and volunteers

- networking and building social capital within and beyond the community served

- collaborating with other nonprofits for finances, people, office space or achieving common goals / outcomes

- developing new sources for earned income and achieving financial stability through sustainable revenues and grants. 
Blumenthal's model takes into account organizational effectiveness as it is seen by external funders. As such her model highlights the above aspects as they are a key element of capacity building initiatives by grant makers and foundations. Funders can use these to improve and innovate on nonprofits' management practices. In fact, Blumenthal identifies three different approaches, all of whom involve consultants (Fernsler, 2005).

The first is to use 'capacity grants' to help the grantee organization identify its current strengths and weaknesses and hence its areas for improvement. External consultants access the organizational needs and design improvement projects. (Blumenthal, 2003, p. 45). Under the second approach, the grant maker selects a development partner, to work with the nonprofit organization (Getha-Taylor, 2006). The partner is thus like an intermediary consultant who focuses on long term change within the nonprofit unlike the grant maker whose partnership might only last for the short term or only as long the grant is renewed (Blumenthal, 2003, p. 71).

The third approach requires nonprofits to go through specific steps as part of a performance management program through 'structured programs' (Fernsler, 2005). Most nonprofits use inputs, outputs, and outcomes to check their performance over time and / or with benchmarks in the industry. The first two approaches focus prominently on inputs and outputs e.g. programs designed by intermediary consultants or funds from capacity grants will check and see if the target has been met when it comes to training how many workers, if the required number of training hours were met and how many outputs were generated. 
Structured programs lay out the path from inputs, to outputs, to outcomes. For example, a nonprofit focused on drug rehabilitation may have input targets on number of patients enrolled, hours of classes, hours of training for counsellors and so on. The output targets could be the number of patients who successfully complete the program. The outcomes however will measure if there were actually any behavioral changes in the patients as a result of the program and not just the number of hours they participated in it. Outcomes are more difficult to quantify than inputs or outputs and the structured programs help the nonprofit to not only define outcomes and link them to inputs and outputs but also provide tools to measure them. Inputs and outputs contribute to good data but outcomes contribute to rich information. Without measuring outcomes, performance management falls prey to the data rich information poor (DRIP) syndrome (term first coined by Waterman Jr, 1982). Blumenthal's third approach concentrates on whether organizational performance improves over time by evaluating outcomes rather than concentrating on improving inputs and outputs (Blumenthal, 2003, p. 106).

De Vita and Fleming Model. As De Vita and Fleming (2001) explain, capacitybuilding is important because firstly it allows nonprofits to effectively fulfill their missions despite their limited resources and secondly, because it betters the quality of life in the communities the nonprofits serve. An effective capacity building model thus allows a nonprofit to access the needs of the community it serves and also provides pathways to acquire resources to fulfill those needs. Five inter-related, mutually dependent, components that are always present in most nonprofit organizations, (though not equally) serve as the foundations to build an effective capacity building tool. (2001, 
p.15-16). This model offers five components of capacity building: vision and mission, leadership, resources, outreach, and products and services.

Vision and Mission. The vision and mission not only inform how unique the nonprofit is but set guidelines for what programs and services it will offer. The effectiveness of the programs or outcomes will be determined by how well they contribute to the mission and vision. For example, a mission that aims to end hunger within a community will measure outcomes like number of people fed within a specified timeframe while one that aims to provide hot meals to low income people will have success criteria that count the number of low income people served and the number of meals served. While both programs are similar, their impact and success will be measured differently because of their mission and vision and hence their capacitybuilding initiatives will be slightly different.

Donors and foundations (monetary resources) will donate to the nonprofit whose vision and values aligns with their principles. Hence while building financial capacity, it would pay for the nonprofit to apply to those foundations only whose principles align with their mission and not waste time on others. The leadership in this organization comprising of boards, staff and volunteers will maintain or amend the existing mission and vision in accordance not only with what foundations and grantmakers want but also with their career needs; in fact the mission and vision will attract and retain people whose needs closely align with them. Finally, the vision and mission will determine the outreach and impact of the nonprofit. A parent teacher association for instance may want its vision for a better school limited to only the school it is affiliated with while another one may 
want to advocate and influence policy makers that are associated with K-12 education. The second group's outreach will be influenced by the diversity in the larger community where it is hoping to push for a change.

Leadership. Leadership comes from many sources that include staff, board members and volunteers. Apart from channeling the right resources into achieving the vision and mission, leaders provide a public face and reputation of the nonprofit among the community it serves. To build capacity among leaders, existing leadership must be continuously enhanced or bettered and new leaders must be nurtured to takeover when their time arrives (p. 18-19). Board members must be trained to understand their functions while all staff and volunteers must keep upgrading skills. New leaders must be brought in from time to time so that the organizations does not become obsolete and the old leaders must mentor them.

Products and Services. It is important for nonprofits to demonstrate how their programs and services achieve their mission and vision and how they better lives in the communities they serve. Like the other models, De Vita and Fleming also distinguish between outputs and outcomes in performance management. Outputs and inputs provide quantitative data that are easily available but may not necessarily be able to demonstrate whether they have achieved desired benefits or changes. Outcomes are qualitative measures who aim to tell through narratives, observed documentation and ethnographic studies of how the program changed the participants. So while outputs tell us that a cohort of youth completing a leadership program took 72 hours of training / classes in a 
year, outcomes will document their stories / narratives or observe cohorts in the field to see what they have learnt.

The outputs and outcomes provide feedback to the leadership in the organization, to its funders and donors, and to the community it serves, to what extent the mission and vision is being achieved. So if the organization is performing poorly, funders and donors will give less to the organization impacting its resource availability. The organization's outreach in the community may also be negatively affected and this might signal the need for a change in leadership and / or better networks (p.23).

Outreach. "An organization can have a vital mission, good leadership, and sufficient resources, but unless it is known in the community, its impact will be limited." (p. 21) While it is important to focus on programs and services, building a positive image in the community is equally important. Sometimes the good work the organization does through its programs and services remains unknown to the public unless it invests in PR, community education, collaborations, and networks. In fact organizations with a parent or those that join a coalition share information, learn from one another, and coalesce on issues of common concern. In short, they help build social capital that is important for organizational stability (p. 21).

Resources. "Resources come in many forms. Financial resources are arguably the most central aspect of the organization's resource pool because they can affect the recruitment of human resources (paid staff, volunteers, and board members) and the acquisition of physical resources (such as building space and equipment)". (p. 19) 
While financial capacity is often a big issue for most nonprofit firms, strengthening human capacity is equally important. People who work and volunteer for nonprofits or those that preside on the board are often the organization's greatest assets and contribute to its human capacity. Also, the relationships and networks people develop with key stakeholders both within and outside the organization construct structure and processes that link financial and human capacities more efficiently.

Paul Light Model. Light's model, or rather recommendations, are based on a 2003 survey on Capacity Building among 318 US nonprofit organizations. The survey asked the respondents on their definition of 'capacity building' and what it meant to them. Based on the responses, Light divided capacity building definitions into six groups: a) Capacity building is a way and means to increase organizational resources (money, skills, getting support, or tools b) It is a way to improve organizational performance and increase outputs and outcomes i.e. serving more clients, getting services tailored to specific client needs and so on c) a way to get the most out an organization's activities i.e. better quality and productivity and d) a way to maximize resources and efficiency i.e. most effective way to increase number of people served with the least possible resource e) the ability to do what it takes to achieve organizational mission and f) it is the answer to preventing organizational disaster i.e. building emergency liquid funds, getting rid of old rules and procedures that are no longer needed and preventing delays in program delivery, strengthening board member skills and learning how to measure the right outcomes (p. 54-57). 
Along the same lines, capacity building efforts belong to four different categories, based on what they target to improve - external relations, internal relations, leadership or management systems. Collaboration, mergers, strategic planning, fundraising and PR contributed to capacity building efforts that improved external relations. Organizations in this group collaborate to get better program outcomes for all members in the alliance, others work on developing an image for the organization (p. 59, 66). Reorganization efforts, team building, adding staff, staff diversity, emergency liquid funds, and fund for new ideas contributed to improving internal systems. Activities here include eliminating redundant positions or creating relevant ones, mentoring staff to encourage diverse views and team building and creating funds for rainy days (p. 59, 67)

Board development, leadership development, succession planning, change in leadership, and greater delegation were capacity-building activities to improve leadership. Organizations in this sample took steps in changing board size, imposing board member term limits and attendance policies, making a minimum amount of time mandatory in each board meeting to focus on budgeting and fundraising and involving staff and volunteers and not just the managers in decision making. (p. 59, 67). Finally, information technology, accounting systems, personnel system, staff training, evaluation, organizational assessment, and outcomes measurement helped to better management systems. Organizations in this category undertook activities like adopting new technical systems, new accounting tools, allocating budgets to every program and eliminating the less efficient ones, conducting audits on different systems, having job descriptions, and adopting deliverables with timelines for each program (p. 59, 68). 
Golmar (2008) replicated Light's research study among non-profits in the state of Wisconsin. Table 2.3 below shows a comparison of their findings. In Light's study, the top three capacity-building activities were collaboration ( $86 \%$ of organizations in the study participated in this), strengthening fundraising and board development. Golmar's study ranked collaboration, board development and getting new information technology as the top three capacity-building activities.

Both Light's and Golmar's studies are significant because they break up the survey sample by budget size and age and give insights into how capacity building activities differs among small and big nonprofits. Light's study found that among older organizations, smaller ones were less likely to focus on staff diversity and outcomes measurement while the larger ones focused more on staff training, program evaluation, and more delegation or measures to block or counter bureaucratic processes (p. 60). As budget size increases, an organization gets the resources to invest in new technology, staff, and emergency funds but it also creates the need for succession planning, outcomes measurement and evaluation. On the other hand, small organizations that reach a plateau in growth or hover between decline and stagnancy put emphasis on reorganization and change in leadership. In fact, some organizations chose to hover around a middle size budget by choice rather than worrying too much about more growth, mergers or seeking to act smaller and more efficient (p. 61-62). 
Table 2.3

A Comparison of Light's and Golmar's Studies on Capacity Building Activities, Ranked

\begin{tabular}{lcc}
\hline Capacity building activity & $\begin{array}{c}\text { Percentage (Light's study, } \\
\text { 2004) }\end{array}$ & $\begin{array}{c}\text { Percentage (Golmar's } \\
\text { study, 2008) }\end{array}$ \\
\hline Collaboration & 86 & 85 \\
Strengthen fundraising & 79 & 65 \\
Board development & 78 & 80 \\
Strategic planning & 72 & 72 \\
New information & 66 & 80 \\
technology & & \\
Staff training & 66 & 75 \\
Media relations & 64 & 61 \\
Outcomes measurement & 62 & 48 \\
Team building & 57 & 73 \\
Improved accounting & 54 & 62 \\
system & & \\
Leadership development & 54 & 63 \\
Greater delegation & 51 & 67 \\
Staff diversity & 42 & 31 \\
Organizational assessment & 42 & 52 \\
Succession planning & 42 & 27 \\
Reorganization & 40 & 67 \\
Change in Leadership & 40 & 45 \\
Improved personnel & 37 & 39 \\
system & 33 & 37 \\
Establish rainy day fund & 23 & 17 \\
Establish Fund for New & & \\
Ideas & & \\
Merger & & \\
\hline & & \\
\hline
\end{tabular}

Source. Golmar (2008) Table 71, p. 182

Golmar's study, on the other hand, found that NTEE classification, budget size, age, and whether the organization was a satellite operation of a national / state affiliate did not have any significant impact on the frequency of activities. However, these had an influence on how the organization rated its success in that activity. Across the whole 
sample, the top-rated success for activities belonged to Improved Accounting System, Collaboration, Team Building, and Organizational Assessment, while the bottom performers were Merger, New Ideas Fund, Succession Planning, and Greater Diversity. Budget Size affected success of Outcomes Measurement and New Ideas Fund. Age affected the most: Leadership Development, Succession Planning, Rainy Day Fund, Strengthen Fundraising, Reorganization, Greater Delegation, and Board Development (Golmar, 2008).

\section{Integrating the Four Models}

While the above four models cite different ways to build capacity, there are common elements. Blumenthal's use of capacity grants and development partners aims to improve current capabilities and can be seen as a way to enhance existing management and technical capacities, as defined by Conolly and York and management relations as described by Light. Her use of structured programs, on the other hand is more aimed towards improving Conolly and York's 'adaptive and leadership capacities' and Light's improvement on external and internal relations and leadership. In fact, all four models vouch for using outcomes rather than only outputs for performance measurement. A good performance system can tell the organization whether it is effectively utilizing its current resources to achieve the mission and vision, which positively impacts outreach, gets more funding and volunteers and attracts the right people to lead the organization. The right leaders make decisions to use the right performance management system and the DeVita and Fleming model cycle continues. Blumenthal's and Connoly and York's models are based on the foundation perspective to capacity building. DeVita and Fleming and Light 
lean more towards the governmental and non-profit perspective; both models have elements of resource dependency theory and strategic management theory that posit that nonprofits enhance their programs through capacity building and / or collaboration to get their much needed resources and align themselves to the external environment.

Different authors have ranked the various dimensions of capacity e.g. Eisinger (2002) ranked human capacity, networks and institutionalization as the most important dimensions of capacity while Germann and Wilson (2004) stressed on resources, processes, values and internal relationships. Rather than trying to develop a model that combines all elements of capacity building theories, I have chosen to go forward with the following assumptions.

1. Essentially all dimensions of capacity are linked to each other; however, the core elements are financial and human capacity. This belief also stems from my belief in the Resource Dependency theory. Money and people are the two most basic resources which all nonprofits need to start with.

2. Apart from that, four other components of capacity building are important; these include mission, vision and strategy; program delivery and impact; technology upgrades and operational improvements; and collaborations. These elements are important because of the need for nonprofit to adapt to the external environment (Strategic Management theory). To start a nonprofit, one needs funds and staff that will provide the directions and rules for the other four elements. 
3. The four components above will essentially contribute to 'structural capacity' According to Hall, et al, (2003), capacity is closely linked to "capital" because "capacity to work toward a particular objective depends upon the capital deployed" (p. 4). Capital includes not only tangible financial assets but also non-tangible intellectual capital. Hence organizational capacity includes financial capacity (assets, revenues, liquid cash etc.), human capital (competencies, skills and knowledge of employees, volunteers and board members) and structural capacity (networks and relationships, infrastructure, technology and processes and strategic planning capacity).

Based on these simplifying assumptions, this research will study small nonprofits by asking questions on financial and human capacity; however the questions will also inquire into their links into structural capacity that will include collaborations, infrastructure, technology and strategic planning with respect to mission, vision and program delivery and impact. In the next section, I will highlight elements of human capacity and financial capacity and at the same time explain how they are linked to the elements of structural capacity.

\section{Human Capacity}

Acquiring an increase in human capacity implies being able to recruit and retain skilled and knowledgeable employees, volunteers and board members. Human capital is important because the key issue facing the nonprofit sector today is not what the sector 
delivers, but how it operates (Gilmer, 2012). The health and vitality of the nonprofit sector depends on board members and leaders to enhance organizational capacity.

Volunteers are often the driving force behind nonprofits, especially in Oregon where about $71 \%$ of all nonprofits have an operating budget of less than $\$ 100,000$ and operate primarily through unpaid staff (ONSR 2012). Smaller and young organizations are more likely to be understaffed in comparison to their demand for services and be out of business had it not been for volunteers (Hall et al, 2003, p. 28). Volunteers are however, more interested in short term projects and less likely to engage in leadership roles, hence having the capacity to provide training programs that equip them with skills for such roles or even having some kind of recognition programs that motivate them towards leadership roles is very important. However, the number of volunteers available does not necessarily always have a positive linear relationship with the enthusiasm they have for the job. Small nonprofits in rural areas can have access to fewer but typically more motivated volunteers, but they may not be available for all events and retaining them and maintaining a sense of continuity in order to avoid confusion in running programs from one year to another is often a big challenge (Doherty, Misener \& Kuskelly, 2014).

Like with volunteers, nonprofits face capacity issues in recruiting and retaining paid staff. Small nonprofits often work with a full volunteer staff and their inability to provide for compensation and few opportunities for career advancement can hamper retention of skilled staff when competition from larger firms with less 'flat' organizational structures provide more options for promotion. In rural areas, the problem 
has an added complexity; the recruitment pool is small to begin with, limiting the staff pool who often burnout and can give no more (Hall et al, 2003, p. 33).

In both urban and rural areas, there is a growing demand for volunteers in small organizations who have shown to manage volunteers better than larger organizations but there is a lack of knowledge capacity - only $25 \%$ of volunteers in US and Canada get some training in volunteer management (Brudney, 1992).

"The most effective nonprofits always use volunteers as a core strategic function to achieve their social missions. Smaller organizations often do it better, because as they grow the focus shifts to paid staff and acquiring financial assets. But volunteers are an asset we cannot grow out of. They need to be nurtured as much as financial assets. Organizations with at least 10 volunteers are as affective as organizations without, but at $60 \%$ of the median budget." (Brudney \& York, 2015 Alliance National Conference on Nonprofits, Portland, Oct 2015)

Finally, board members play an important role in shaping human capacity. Active board members who communicate their organization's mission to the right stakeholders, understand the organization's financial statements and regularly monitor whether the organization is achieving its mission or not can contribute more to the nonprofits human capacity than board members who are there for seeking status and not really contributing to the organization (Hall, et al, p. 35).

Booz, Allen and Hamilton (2002) found that nonprofits across America find it difficult to get qualified people to serve on their boards, especially small and medium sized nonprofits. Skills in demand for board members and scarcely available include the ability to fundraise successfully and be competent in financial management and networks with influential contacts (Miller, Kruger \& Gauss, 1994). 
There are other ways human capacity influences a nonprofit. Firstly, turnover must be taken into account. Too much turnover affects organizational culture and continuity while too little turnover makes the organization run out on fresh talent and ideas. Second, human capital is linked to financial capacity. Nonprofits who keep their \%age of expenditures on administration and fundraising low are likely to secure more government grants but less funding from United Way or private contributors (Stone, Haiger \& Griffin, 2001). Small nonprofits tend to have a higher volunteer base and larger, more engaged boards and are likely to acquire more private donations (Hodge and Picollo, 2005; Stone, et al, 2001). Larger nonprofits with more professional staff are likely to get more government funding (Rosenthal, 1996; Stone, et al, 2001); so are organizations with smaller but more racially diverse boards (Daily, 1995; Stone, et al, 2001). But for small organizations in rural Oregon where the base population is less diverse than in urban counties, it is tough to have diversity in boards and volunteers.

\section{Financial Capacity}

Financial capital drives a nonprofit to achieve better financial stability, and more cash flow and revenue from diverse sources. Financial capital is important both from a resource dependency perspective and an institutional perspective - nonprofits need money to run and staff their programs and achieving financial stability and a large resource of funders is a measure of legitimacy (Froelich, 1999). Nonprofits acquire revenue from many sources - individual donors, corporate donors, foundation grants, government grants / contracts, sales of tickets or membership and sometimes they might operate a business enterprise to generate revenue (e.g. a nonprofit museum running a 
restaurant in its premises). Each source has its own pros and cons and defines the resource dependency equation differently.

Hodge and Picollo (2005) found that privately funded organizations are more likely to withstand macro-economic changes like recession, inflation etc. than those funded mostly by government. Corporate donors are more likely to fund programs intended for a broader audience rather than a small group (Froelich p. 250-252). Foundations have tendencies to dictate the agenda and goals while supporting grants; all of these three kinds of donors can potentially cause 'goal displacement' and pressurize nonprofits to achieve program outcomes other than those outlined in their mission (p. 254). Hall et al (2003) found that individual donations are often preferred by nonprofits as they 'support the organizations as a whole i.e. provide core funding rather than project funding which is aimed more at specific programs and activities and cannot be used towards administrative or operating costs (p. 21-22)

There are several advantages of government funding; it increases credibility of the nonprofit, gives them an opportunity to influence public policy and may be sometimes accompanied with free technical assistance (Sherman, 2004). But these funds hugely influence the institutional environment by enforcing bureaucratic rules and too many regulations that could result in a decline in the nonprofit's autonomy (Froelich, p. 258). In a nonprofit - government alliance, the government side has control over vital resources required within the collaboration (Saidel, 1991), and as Hardy and Phillips (1998) argue, can therefore bring about coercive isomorphism and influence other partners to adopt their rules and customs. Another problem with excessive reliance on government funding 
would also stem from the fact that such funding has become less diversified, particularly in terms of the sector it is applied to. For example, government funding has especially dwindled in the arts and culture arena forcing nonprofits in this sector to compete with hospitals and social service programs (Harvey, 1999). Also, government funding is often in the form of contracts and most small nonprofits are not eligible for them.

Hence financial capacity should not be a measure of amount of funds available or acquiring large donors from one source, but acquiring a portfolio of diverse funding streams to compensate for goal displacement, volatility in giving and maintaining legitimacy and autonomy at the same time. Revenue diversification i.e. having less than $50 \%$ of revenue coming from one source to be classified as 'not dependable on one source' is a big strength for capacity building; so is revenue stability (Carroll \& Slater, 2008). Revenue diversification which potentially stems from Markowtitz's Modern Portfolio Theory (Carroll \& Slater, 2008) has in many studies shown to have a positive correlation with financial health (Chang \& Tuckman, 1996; Froelich, 1999; Greenlee and Trussell, 2000; Tuckman \& Chang, 1991). Hager (2001) found that a diversified revenue stream decreased the likelihood of closure in arts organizations and Carroll and Slater (2008) found that urban nonprofits have stable revenue structures because of access to diverse revenue streams more than rural nonprofits.

According to the IRS tax Form 990, Schedules A and B, there is a Public Charity Support Test which posits that a public charity should get at least one third of its total income from individual donations and not more than one third of its total income from gross investment income and unrelated business taxable income (see 
https://www.irs.gov/charities-non-profits/exempt-organizations-annual-reportingrequirements-form-990-schedules-a-and-b-public-charity-support-test)

So, if a nonprofit got twice as much money from individual donations than from grants (and assuming these are the only two sources for its revenue), then it would be compliant with the IRS rules but not pass the revenue diversification test. But other sources like government contracts may not be available to small nonprofits. Earned income, provided it does not exceed one thirds of total revenue could be another source. Commercial operations do not jeopardize trust between nonprofits and their individual donors, but they can sometimes divert nonprofits away from their social missions (Bowman, 2011).

Apart from revenues and donations, it is also important to look at expenditures, cash reserves and operating margins. Tuckman and Chang (1991) developed four measures to test the financial vulnerability of a nonprofit. To be less 'at risk' organizations, nonprofits not only had to secure multiple diverse funding streams, but also possess large liquid balances and emergency cash reserves, have low administrative costs and low operating margins. Greenlee and Trussel (2000) who tested the model empirically found that nonprofits who were classified as being financially vulnerable as per the standards above were less likely to emerge from the effects of an economic shock. However, the question of keeping administrative and overhead costs low has mixed opinions / results in the literature. If such costs are high, it reduces donor trust and support as it perceived to be wasteful (Greenlee \& Brown, 1999). Other studies show that higher administrative costs provide financial flexibility that can be useful when donations 
are low (Tuckman \& Chang, 1991) and lead to an increase in total revenue and unrestricted fund balances when these costs are not associated with an increase in executive salaries (Chikoto \& Nealy, 2014).

Financial capacity is also linked to human capacity. Grant writing is time consuming and requires skilled staff / volunteers and board members that have special connections to the community (for individual donations) as well as corporations and foundations that provide grants. Better financial capacity can translate to provision of training programs for volunteers or board members in book-keeping and financial management skills. (Hall, et al, 2003, p. 26).

\section{Collaborations}

I have explained how human capacity and financial capacity are linked to structural capacity, especially technology and operational improvements, leadership development and enhancing mission and vision and strategy. The last element of structural capacity is collaborations and coalitions which I explore in more detail next. There are two reasons for which I am exploring this aspect of structural capacity more than the others: first, it is small nonprofits who are more often than bigger ones pressurized to merge, collaborate or build alliances to survive and second, I was examining if urban -rural alliances in the third sector could be a strategy for small nonprofits to survive.

Traditionally, policy is formulated by political institutions that managed top down through bureaucratic rules and regulations. However, with the transition from 'public administration to governance' as Frederickson (2005) puts it, it has been recognized that 
a large fraction of the capacity required to create public value exists outside government today. Public functions are no longer the exclusive domain of governments (Agranoff \& McGuire, 2003; Cooper, 2003). The question of governance and public service existing outside of government is not totally new as pluralists, corporatists and new corporatists have talked of interest groups but most of these paradigms represented policy process as a top down one while lately the term 'polity' is associated with private, public and nonprofit actors who interact in a horizontal loose network. It is therefore not surprising when there is such a lot of talk in public administration and nonprofit management to talk about how collaborations with other non-government actors can lead to creation of better public value. For a collaboration to work however, it is extremely important to know the constraints and motivations of all the partnering agencies.

Barbara Gray (1989) in Collaborating: Finding Common Ground for Multiparty Problems describes collaboration as "a process through which parties who see different aspects of a problem can constructively explore their differences and search for solutions that go beyond their own limited vision of what is possible" (p. 5). The domain is the set of actors (individuals / leaders and organizations and groups) that come together because they have a common interest or a similar goal (Gray, 1985) or they want to reduce resource dependencies, decrease transactional costs or have through previous collaborations gained trust in the partnering agency and its legitimacy (Bryson, Crosby \& Stone, 2006).

According to Gray (1985), organizations collaborate when they are faced by problems that exceed the capability of any single firm to control them. These 'messes' 
cannot be governed internally and the solutions to them depend hugely on external pressures and decisions taken by other organizations. For example, it is often difficult for public bureaucratic organizations to adapt to complex external uncertainties as bureaucratic rules demand accurate figures and standard operating procedures (Allison, 1969; Rainey, 2003). Partnering with nonprofit organizations that rely less on standard rules can help in reducing this mess, yet the partnering nonprofit might find it difficult setting up performance measures that judge the efficiency, desired outcomes and outputs and thus rely on other partners to help in this regard (Salamon, 2003, p. 25). In such a situation, the public agency can provide the nonprofit with capacity-building activities that might help them set up an efficient program evaluation system (in line with the government perspective to capacity-building).

Collaborations may not necessarily be between public agencies and nonprofits but also between different nonprofits. Sometimes nonprofits within similar program spheres can have similar mutual interests but different goals (Milward, 1982). For example, a nonprofit agency may have a goal of ending hunger in Oregon while the other one with whom it is collaborating in this aspect is maybe interested in creating a healthier and abler population within the state. The former's goal is related to human development while the latter is interested in economic growth and higher employment rates.

All this highlight the fact that the solution to the problem does not just focus on the needs and interests of a single institution but also on the interdependencies that exist among the various stakeholders all of whom claim a right to influencing the outcome (Trist, 1983). Entering into collaborations helps to create value in relationships and 
resources for the partners by encouraging communication and joint problem solving, figuring out key strategies for the survival and growth of the participating agencies and opening avenues for future opportunities and partnerships (Kanter, 1994).

Such changes in culture, strategies and practices within the collaborating organizations can hugely affect the institutional environments in which they work. The term 'institution' is defined as taken for granted patterns of organizing or cultural rules and habits that shape societal behavior and help to interpret social activities (Geertz, 1973). Phillips, Hardy and Lawrence (2000) explain that an institution creates value in an alliance economically by creating innovative solutions, cognitively by forcing the partners to think beyond the boundaries of the traditional rules and socially by giving access to legitimate resources. Within the collaboration, all participating institutions create the 'institutional field'.

Phillips et al, (2000) assert that institutional rules and resources are used in any collaborative process to 1) define the issue or problem 2) the membership of the collaboration and 3) the practices utilized in response to the problem. A solution to a problem framed by a collaborative alliance will be hugely defined by the existing institutionalized collaborative practices; certain groups will be included and certain groups will excluded in the collaboration process. Additionally, the pattern of practices (the process to arrive at solutions) will be derived from the institutionally legitimate set of practices available to the participants.

In this whole process, the participants will simultaneously reconstruct the institutional rules and structures. Current decisions and actions will become the backdrop 
for future collaborations. There is thus a process of isomorphism (DiMaggio \& Powell, 1983) involved in partnerships that can come due to either a coercive process (vulnerable organizations adopt practices to maintain resources or legitimacy) or a mimetic one (when organizations facing uncertainty adopt practices set up by leading firms in the field) or a normative process (when organizations join groups or unions and must utilize the collective arrangements that are in place).

Powerful parties may be able to advocate their interests more forcefully and shape the institutional environment more coercively. Hardy and Phillips (1998) argued that three forms of power are important in understanding the dynamics of collaboration: formal authority, control of critical resources and discursive legitimacy. If one policy actor has the formal authority to have the final word or has control to vital resources required within the collaboration, then it can bring about coercive isomorphism and influence other partners to adopt its rules and customs. Some actors may possess discursive legitimacy or the ability to speak for issues or be a representation of a populist opinion that is so powerful that government agencies cannot ignore them even if they desire. A good example is given by Provine (2010) in Phoenix where policy makers keen to promote the image of the global city that is open to immigrants are held back by grassroots interest groups that strongly favor the anti-immigration movement (p. 231). In contrast, bureaucrats in eastern North Carolina were able to implement programs for Hispanic immigrants in the 2000 s helped by schools and non-regular medical agencies that were staffed by natives (Marrow, 2011, p. 207). 
The conclusion is that both alliances and institutional environments are hugely shaped by each other. This is also the basis for Strategic Management Theory which posits that nonprofit leaders will make their nonprofits in capacity-building activities so they can align and adapt to the external institutional environment and be a part of the 'innovative solutions' that come up and hence enhance their organizational image in the community. This also grants them access to much needed resources, another quest which nonprofits pursue as per the resource dependency theory. However, as the two contrasting examples given above show, even if all participants have understood the issues or problems, rules, resources, legitimacy of stakeholders and practices to be adopted, it will not necessarily translate into leading to the desired outcome. Hence it is important to explore whether the outcomes of collaboration are always positive or not.

Longoria (2005) cites a 1998 study by Glisson and Hemmelgarn who conducted a quasi-experimental longitudinal study on inter-organizational services coordinated among 32 children's service programs (all public agencies and nonprofits) and found that the collaboration had a negative impact on the quality of child and family services and had no effect on key service outcomes. Van deVen and Walker (1984) used quantitative methodology and a longitudinal study of early childhood development organizations and found that the factors that led to positive outcomes were frequent communication, consensus about the terms of the collaboration among the partners and the perception of resource dependency because this had a positive effect on money transactions and helped to maintain the collaborative process. Both of the above studies have however concluded 
one thing in common; that collaboration should not be a zero-sum game where one party wins and the other loses.

Linda Milbourne (2009) on the other hand, studied collaborations in the UK between nonprofits working in the field of children's mental health that provide home-school support for vulnerable young people and parents. Small nonprofits found the availability of better infrastructure from their collaborating partners to be a great help and eased restrictive processes and regulations. At the same time, though, their clients were confused by the joint initiatives and were more likely to trust and thank particular individuals who provided high quality service to them and not acknowledge the agencies in the coalition as much. As Milbourne (2005) found out that it is the individuals with good social networks and that are willing to set aside hierarchical roles in their own agency and provide quality services to the clients benefitting from a collaborative venture who are the actual heroes in making such joint projects successful.

For collaborations to be successful, the partnering agencies should understand at the beginning what the common goal is that they desire even though the outcome variable used to gauge performance might be different. Only then will they be able to perceive that the solution arrived at through collaboration will be better than what they would have arrived at singularly (Longoria, 2005). Also, the partners must freely exchange information even if it hints at the possibility of a negative outcome. Then participators will be aware of problems and issues at each step of the process, brainstorm together and take measures to negate the undesired outcome and arrive at a final outcome that is better 
than what would have resulted if participants were not made aware of the problems initially.

Nonprofits in Oregon collaborate for many reasons: sharing workspace, joint provision of programs and services, obtaining joint funding, reduce program expenses or advocate on behalf of clients (Schroeer, Medora, Mukerjee \& Wallinger, 2012, p. 32).

When the numbers are broken down by urban and rural nonprofits as shown in table 2.4 below, both regions show a comparable percentage of having engaged in different collaborative activities.

\section{Table 2.4}

Participation in Collaboration, Oregon Rural / Urban Nonprofits in 2011

\begin{tabular}{lcc}
\hline \multicolumn{1}{c}{ Type of collaborative activity engaged in 2011 } & Urban & Rural \\
\hline Collaboration to carry out programs and services & $63.27 \%$ & $60.64 \%$ \\
Collaboration to obtain funding for programs & $61.85 \%$ & $61.17 \%$ \\
Collaboration to advocate on behalf of your clients & $42.65 \%$ & $32.45 \%$ \\
Sharing space with another organization & $41.00 \%$ & $30.85 \%$ \\
Collaboration to reduce program expenses & $33.89 \%$ & $35.64 \%$ \\
Sharing staff with another organization & $27.49 \%$ & $25.53 \%$ \\
Collaboration to reduce administrative expenses & $24.41 \%$ & $24.47 \%$ \\
Group purchasing or cost savings programs & $16.59 \%$ & $14.89 \%$ \\
None of the above & $13.27 \%$ & $19.15 \%$ \\
\hline
\end{tabular}

Source. Numbers were computed from the ONSR 2012 database

Further, as seen in table $2.5,86 \%$ of organizations had engaged in some or the other above forms of collaboration; but only $6 \%$ of urban nonprofits and $2 \%$ of rural ones said they had no challenges to collaborations. The top three impediments to collaboration were lacking the capacity to do so, not having organizations in the region doing similar work and a feeling that value added by collaborations was less than the time and effort 
spent on them. ANOVA tests revealed that there were three areas where rural organizations were less likely to collaborate than urban ones - these were not having capacity to collaborate, not having similar organizations close by to organized activities jointly and difficulties with complying with rules and procedures.

\section{Table 2.5}

Challenges to Collaboration among Oregon Nonprofits, 2011

\begin{tabular}{lcc}
\hline \multicolumn{1}{c}{ Challenges to collaborate } & Urban & Rural \\
\hline $\begin{array}{l}\text { Not possessing the capacity or technical know-how to collaborate } \\
\text { Value added through collaboration is not worth the costs and time }\end{array}$ & $42.76 \%$ & $50.00 \%$ \\
involved & & $13.43 \%$ \\
None or few organizations with similar programs are located in & $8.83 \%$ & $14.18 \%$ \\
our region & $6.71 \%$ & $5.22 \%$ \\
Previous negative experiences with collaborations & $6.01 \%$ & $2.24 \%$ \\
None / no challenges & $4.95 \%$ & $7.46 \%$ \\
$\begin{array}{l}\text { Difficulty in complying with the rules and procedures for } \\
\text { collaboration }\end{array}$ & $3.18 \%$ & $1.49 \%$ \\
Goals, mission, etc. are not aligned / strategic planning and & $2.83 \%$ & $1.49 \%$ \\
leadership missing & $1.77 \%$ & $1.49 \%$ \\
Organizations are too competitive to enter in collaborations & $0.35 \%$ & $2.99 \%$ \\
\hline $\begin{array}{l}\text { Other organizations not willing to collaborate } \\
\text { We have not collaborated / Unsure / Don't know }\end{array}$ & & \\
\hline
\end{tabular}

Source. Numbers were computed from the ONSR 2012 database

Different elements of capacity -building help to increase organizational

effectiveness and help to improve the health of the third sector. Size and urban / rural distinction also influence these factors. How well the nonprofit organization deploys its various capacities directly impact outputs and outcomes (Hall, et al, 2003, p. 6). For example, more finances and staff can be utilized to expand a mentoring class focused on juvenile delinquents and increase output i.e. more students coached. However, the quality of human capital deployed in program development and evaluation will impact outcomes 
like improvements in behavior of the youth coached. Larger organizations are better able to adapt to changes in the funding environment, however small and mid-size nonprofits struggle when funding goes down, especially because they often lack human capacity to pursue alternate sources of revenue or have staff skilled in financial management (p. 62). These differences are also influenced by the urban rural divide.

With small nonprofits, especially human capacity is mostly limited to boards and volunteers because often they do not have budgets to support paid staff and formal institutional structures. Gumulka, Barr, Lasby and Brownlee (2005) found that among voluntary sports clubs with no paid staff and institutional structures (like those in small nonprofits), the most critical elements of capacity were generating revenue and recruiting dedicated volunteers. Wicker and Breuer (2011) noted that the biggest problems in capacity building among voluntary sports clubs were recruitment of volunteers and high expense to revenue ratio. One of the important goals of policy is to ensure equality and equity in communities and regional jurisdictions. Since nonprofits are usually justified as being the 'third sector' that aims to correct market failures (by private organizations) and public failures (by public agencies), they are essentially regarded to be providers of programs and services that bring about general well-being and equity in the service region. It is only justifiable that research involving them as the unit of analysis apply an equitable approach and analyze small and large organizations through different lenses. Making the case for small nonprofits argues for the fact that public agencies should incorporate them in regional policy initiatives and support grants and contracts to small nonprofit firms as well. 


\section{Chapter 3: Methods}

This chapter introduces the methodology of the study and study design and describes the research instruments and data sources. First, I explain the nature of deductive and inductive inquiries and lay the rationale behind adopting an inductive emergent study design. Next, I describe the process involved in the sequential-priorities, mixed-methods approach where a preliminary quantitative study was followed by a core qualitative study (Morgan, 2014). This approach allowed the preliminary quantitative study to locate data sources for a predominantly qualitative project with focus groups and interviews. Finally, I talk about the sampling process and research participants. I detail the coding process for the qualitative data, along with how themes, categories, domains and labels were applied.

As noted in the previous chapters, the research question of this study is:

What capacity deficits, in financial and human capacity, exist across small nonprofit organizations in Oregon? How are these different between urban and rural nonprofits?

The following sub-questions help to answer the research question:

1. What core capacities do small urban and rural nonprofits in Oregon currently possess, in the financial and human capacity domains?

2. What knowledge and skills do they possess that can serve as valuable examples for other similar organizations? Which areas do they have a deficit and need to learn strategies to overcome this deficit? 
3. How should capacity builders and policy makers customize capacity building initiatives for small urban and rural nonprofits separately so as to help them achieve financial and human competencies sufficient to achieve their missions?

\section{Research Design Strategies}

As has been stressed before, research into Oregon's nonprofit sector and its current capacity mostly has been through quantitative methods which is more of a top down process and deductive in nature. Deduction "tests theory through observations, is oriented to cause and effect, has basis in procedures that are of predetermined design, emphasizes things that can be measured where the results do not depend on beliefs and relies on standardized protocols" (Morgan, 2014, p 3-4). My research project employs the deductive approach to understand the capacity measures and deficits among nonprofits by testing the theory and hypotheses through the analyses of the quantitative data collected by instrument such as a survey.

For example, a theory in the literature may lead to the hypothesis that having diversified revenue sources leads to revenue stability which can be tested through a deductive approach through the analysis of quantitative data collected by a survey that measures how many revenue sources there are, how diversified are they and how they contribute to a measure of revenue stability. The process helps to link cause to effects but will not contribute to discovery or exploration or observations which can be used to create theory. The quantitative study that employs deductive approach will either confirm or not confirm if revenue diversity leads to revenue stability but will only be able to 
examine the phenomenon limited to the variables included in the analysis. Frequently, it misses other factors that are not identified as variables a priori to the study. In contrast, a qualitative research that employs inductive approach will ask what situations have led to revenue stability in general without predetermining what are the causal factors. Revenue diversity could emerge as one of the answers, but so could other factors like presence of long-term stable donors. A qualitative study with an inductive approach does not assume that presence of certain variables lead to a certain outcome, and it will allow the researchers to study all circumstances that led to the outcome.

While this study was primarily qualitative in nature, it employed a sequentialpriorities, mixed-methods approach where a preliminary quantitative survey was followed by a core qualitative study (Morgan, 2014). This kind of setting allowed the preliminary quantitative survey to locate data sources for a predominantly qualitative project with focus groups and interviews (Morgan, 2014, p 7-2). Mixed methods studies employ an hourglass shaped process where broader questions are narrowed, units of analysis are observed to arrive at conclusions that raise larger questions in general. The first part of the process thus is top down and deductive in nature while the second part is bottom up and inductive in nature (Trochim, 2006).

I was the chief Data Analyst for the first Oregon Nonprofit Sector Study in 2012. Data from that study has been used extensively in previous chapters to show the collaborative and financial capacities of small nonprofits. Some responses were deleted in the study as they were from small nonprofits who corresponded with the author telling how the questions in the survey did not apply to them, that some of them selected 
answers randomly without understanding the question or left them blank because they felt the questions would not contribute to analysis that was relevant to their small organizations.

It is possible that small nonprofits adhere to the theories of capacity building in the same way that big nonprofits do. But it is also likely that they have a different relationship to capacity building. This study used a deductive approach and checked if small nonprofits' capacities was similar to or different as predicted in the literature. But the primary motivation behind this research stemmed from the need to study them separately and with the aim of generating theory from open ended discussions. I wanted to do a study that was geared to discovery and exploration rather than testing and verifying theories and hypothesis which are more representative of big budget nonprofits.

The study would thus emphasize the emergent themes to explore perspectives and beliefs that have not been associated with a theory before but could contribute to theorybuilding in the future. This is a more subjective approach related to beliefs, meaning and interpretation of research subjects rather than an objective approach where the emphasis would have been on attributes of capacity that could be measured numerically. This does not mean that attributes of capacity that can be measured numerically are irrelevant for small nonprofits; however current theories that measure capacities are more relevant to big nonprofits. By studying the capacity of small nonprofits through an emergent design, in this study it was my hope that the findings might draw researchers and theorists to design instruments of capacity measurement for small nonprofits separately from big ones. 
Overall, this study was more inductive in nature where emerging themes and patterns from qualitative interviews were analyzed to see if any of them opened up the possibility of exploring and testing hypotheses in future. Obviously, such methods overlap with a grounded theory approach because the methods take the researcher into the real world so that the results and findings get grounded to the empirical world (Patton, 2002). A combination of inductive grounded theory approach along with a deductive inquiry that checked how the findings related to existing literature helped me to both test and build theory, be systematic and creative, look at alternative explanations for phenomena and lay down the building blocks for this dissertation (Glaser, 1992; Morgan, 2014: Patton, 2002; Strauss and Corbin, 1990; Trochim, 2006).

\section{Research Participants and Sampling}

An updated list of all nonprofits in Oregon was derived by combining lists from the databases of the Department of Justice and the National Center for Charitable Statistics. I drew a stratified random sample so that small nonprofits across all subsectors (i.e. NTEE classifications like arts, environment, education, etc.) and all regions of Oregon were selected. A stratified sampling approach was used to assure representation of nonprofit across all subsectors, and to increase confidence in generalizing to certain subgroups. As explained before, not all nonprofits provide direct services. Those providing indirect services might face unique capacity constraints, hence it would make sense to check for the same and thus care was taken to make sure every subsector was present in proportion to the population. In other words, if environmental organizations made up $15 \%$ of all small nonprofits in Southern Oregon (the population), then care was 
taken to see that environmental nonprofits in Southern Oregon made up between 12-18\% of the sample.

After a sample was generated, web searches were made to find the contacts. About 800 emails were found from organizational websites and social media profiles. These 800 emails were sent unique links to the short qualifying survey through Portland State University's Qualtrics system. In addition, the Myers Memorial Trust informed about the study in fall 2016 to their internal contacts to create an awareness and visibility of the purpose of the project as well as the kinds of participants being recruited. They also sent one anonymous link to the survey to their contact list (not shared with me).

The short survey asked for the basic characteristics of the organization (age, location, annual operating budget, number of staff, volunteers, board members, etc.). Participants were told in the introductory page of the survey about the purpose of the study and that the survey was aiming to recruit participants for short telephone surveys. The survey with about 12 questions took between 10-15 minutes to complete (questions listed in appendix).

The survey allowed me to select only participants that met the criteria for the study. These were nonprofits who 1) had budgets below $\$ 500,000$ a year and 2) they were based in Oregon - Databases usually place the organization based on the address put forward in the IRS tax form 990. While I had only selected organizations with budgets below $\$ 500,000$, from the original database, it must be pointed that databases for all nonprofits are available after a 2-year time lag. It would have been possible that some of the contacts in the list would have grown in size. Hence the nonprofits were asked 
about budget size to eliminate ones that had grown to a larger size than those interviewed in this study. Also, databases usually place the organization based on the address put forward in the IRS tax form 990. This address may however not be based in Oregon, especially if the nonprofit is in a region close to the border of Washington, California, Idaho or Nevada. Small nonprofits sometimes do not have a formal office space and use a board member's address or a public place like the city library conference hall for their operations. In such cases, some small nonprofits list a PO Box, a board member's house address or sometimes even the address of their tax preparer in the 990 forms. Under such circumstances it is possible that nonprofits listed with an Oregon address are actually operating in a different state. Hence this information was asked in the survey.

I wanted to know whether the organizations were urban or rural. In Chapter 4, I show that there are many definitions that exist, and they all have their pros and cons. I thus decided to pursue this as an emergent research within this study. Respondents were given a multiple-choice question on whether they were urban, rural or both. This was followed by an open-ended question asking them the reasons for their choice. I not only analyzed the written answers in the survey but for those who participated in the final qualitative interview, I pursued the question further and probed them for more details. In doing so, I was able to contribute to what I think should be the standard base for defining whether a nonprofit is rural or urban.

Respondents were asked whether they wished to talk about finances or human resource capacity for their interviews or both. Collaborations was not listed as an option; if during an interview for financial capacity, the respondent spoke about engaging in 
collaborations, I probed them on how that helped better specific aspects of financial or human resource capacity. Only participants wishing to give interviews were asked for phone numbers and name of the person to be contacted for the interview. Respondents were informed they could do the interview one on one or choose to participate in a group setting through a conference call. All interviews were audio only. Those who agreed were emailed or sent through postal mail, detailed information regarding participation requirements and Informed Consent Forms outlining their rights requesting them to sign the letter that documents the purpose for conducting the study, how their information supports the study, and their agreement to participate.

Organizations were assured that their names and contacts would not be listed in the report and all content from the survey and interview would remain confidential. They were told they could withdraw from the interview if they did not agree to the audio recording and transcribing of the interview or to signing the informative consent form. In compliance with Portland State University’s Institutional Review Board, this research project did not involve any known physical or mental risks to the subjects. Each participant and each organization were assigned code names, and actual names of individuals, and organizations are not revealed in this dissertation, or any published reports thereafter. In addition, all the data collected will be kept in a secure file in a private location accessible only to me. These will be destroyed after 5 years of submitting the dissertation. 


\section{Data Management}

I had downloaded the database of all nonprofits in Oregon from the Oregon Department of Justice website for seven years (2011 to 2017). I have provided numbers and data analysis results from these tables in earlier chapters; here I am explaining the details of how I gathered and managed the data. The files are available in a Notebook format which I would convert to Excel. The data was available approximately after a lag of 2 years which meant that the tables I derived pertained to the years $2009-2015$. It is a tedious process to compare yearly databases but by using advanced queries in Access, I was able to get a good snapshot of all organizations in Oregon for the seven years, by deleting duplicate entries. The database included the following information on an annual basis: organization name, the EIN code which is provided by the IRS on registration as a 501c organization, address (including city and zipcode, I added county, region i.e. Southern Oregon, Eastern, etc.), revenue and expenses per year, mission of the organization and the NTEE categories. Guidestar and Charity Navigator provided information on whether the organization had closed or had its status revoked by the IRS within that time period (sometimes the status was restored). This helped to build continuity in the file. Overall, there were about 20000 organizations, but I excluded those that had ceased functioning, had their 501c status revoked (and never reinstated) or those whose 501c status was missing. The toughest challenge was eliminating duplicates that arose when organizations merged or had a name change but queries in Access helped with the same. Additionally, based on the location I coded the organizations as urban or rural and gave codes for budget sizes. This database does not include churches since they 
do not file form 990s and thus this group of nonprofits was excluded from my study. Apart from getting an overview of the Oregon nonprofit sector these tables also helped me to compare my study sample with the state population.

For this dissertation study, 113 organizations filled out the survey and were interested in participating in an interview. Table 3.1 breaks up the distribution of these respondents by size and subsector (along with a comparison to the state figures). About $61 \%$ of respondents had an operating budget below $\$ 100,000$ for the year 2016 and 32\% had a budget of $\$ 100,000$ - $\$ 500,000$ for the same year. About $7 \%$ of the participants who responded to the survey had become big nonprofits or exceeded the $\$ 500,000$ mark after 2015. The survey had only been sent to those whose budgets had been below $\$ 500,000$ till 2015 as updated numbers are always available after a lag of 1-2 years. The time lag probably accounts for why numbers in each budget category in the study is not very close to the corresponding state figures i.e. $61 \%$ in the study had a budget below $\$ 100,000$ compared to $71 \%$ for the state and $32 \%$ were between $\$ 100,000-\$ 500,000$ compared to $19 \%$ for the state.

\section{Table 3.1}

Study Respondents by Annual Budget

\begin{tabular}{lcc}
\hline Annual budget size & $\begin{array}{c}\text { Oregon (average annual } \\
\text { budget between 2009- } \\
15)\end{array}$ & $\begin{array}{c}\text { Study (annual } \\
\text { budget for 2016) }\end{array}$ \\
\hline Below $\$ 50,000$ & $6470(60 \%)$ & $44(39 \%)$ \\
$\$ 50,000-\$ 100,000$ & $1146(11 \%)$ & $25(22 \%)$ \\
$\$ 100,000-\$ 250,000$ & $1164(11 \%)$ & $21(19 \%)$ \\
$\$ 250,000-\$ 500,000$ & $668(6 \%)$ & $15(13 \%)$ \\
More than $\$ 500,000$ & $1378(13 \%)$ & $8(7 \%)$ \\
Total & $10826(100 \%)$ & $113(100 \%)$ \\
\hline
\end{tabular}


Of these 113 , I was able to contact 60 organizations and choose respondents that had been involved with their organizations for at least two years and those who had not left any questions unanswered on the survey. As with small nonprofits, often the contact person was the same for questions related to financial capacity and human resource capacity. Out of the 60 organizations, 34 interviews were conducted in total including one telephonic focus group with three participants. This group was a coalition of nonprofits in Southern Oregon and one interviewee from each of the three different members participated in the discussion. 25 organizations participated in either one of the discussions for financial and human resource capacity, while four participated in both (completed in two separate sessions). Most interviews lasted between 45 to 75 minutes. There were 28 organizations contacted among the initial 60 who did not finally participate in the interview process because of scheduling conflicts or because sufficient responses had been gathered to arrive at emergent themes and aggregate responses. The following table summarizes the breakdown of the organizations participated in the interview. 


\section{Table 3.2}

Study Respondents by Interview Chosen and Method

\begin{tabular}{lcc}
\hline Number of organizations & $\begin{array}{c}\text { Number of interviews per } \\
\text { organization }\end{array}$ & $\begin{array}{c}\text { Total number of } \\
\text { interviews }\end{array}$ \\
\hline $\begin{array}{l}60 \text { (28 did not participate, } \\
32 \text { did - breakup below) }\end{array}$ & 33 (breakup below) \\
25 & $\begin{array}{c}\text { 1 each (13 financial, 12 } \\
\text { HR) }\end{array}$ & 13 financial, 12 HR \\
4 & $\begin{array}{c}\text { (one for financial, one } \\
\text { for HR, conducted } \\
\text { separately) } \\
\text { One focus group }\end{array}$ & 4 financial, 4 HR \\
& $\begin{array}{c}1 \text { focus group (both } \\
\text { financial and HR) }\end{array}$ \\
\hline
\end{tabular}

The questions that asked about the work of the organization, the duties and functions of the person interviewed, and characteristics of the community served were asked in the beginning to serve as icebreakers. Once these were answered, I proceeded to ask questions that were more relevant to dimensions of financial and HR capacity. Organizations were asked questions on collaboration if they mentioned engaging in it. and questions and all interview questions. Tables 3.3 - 3.6 show the connections between the research questions and all interview questions. 
Table 3.3

Research Questions and Link to Interview Question 1

\begin{tabular}{|c|c|c|}
\hline Research question & $\begin{array}{c}\text { Measure of } \\
\text { capacity } \\
\text { building }\end{array}$ & Interview questions \\
\hline \multirow[t]{2}{*}{$\begin{array}{l}\text { What core capacities do } \\
\text { small urban and rural } \\
\text { nonprofits in Oregon } \\
\text { currently possess, in the } \\
\text { financial and human } \\
\text { capacity domains? }\end{array}$} & Financial & $\begin{array}{l}\text { 1. What are your primary } \\
\text { sources of revenue? (Probes - } \\
\text { Individual donations, } \\
\text { corporation grants, foundation } \\
\text { grants, government funding, } \\
\text { earned income, any other } \\
\text { source) Of these sources, } \\
\text { which is the most difficult to } \\
\text { obtain? Why? Which is the } \\
\text { easiest? Why? } \\
\text { 2. What do you do to make } \\
\text { yourselves get more grants } \\
\text { and donations and other } \\
\text { revenues? } \\
\text { 3. What do you do to have stable } \\
\text { revenues and accumulate } \\
\text { liquid cash reserves for } \\
\text { emergency purposes? }\end{array}$ \\
\hline & HR & $\begin{array}{l}\text { 1. What are the activities that } \\
\text { your board members / } \\
\text { volunteers are good at } \\
\text { performing? } \\
\text { 2. What are some areas that your } \\
\text { board members / volunteers } \\
\text { face challenges and need to } \\
\text { improve? } \\
\text { 3. Do you have an inspiring story } \\
\text { about your board / volunteers? }\end{array}$ \\
\hline
\end{tabular}


Table 3.4

Research Questions and Link to Interview Question 2

\begin{tabular}{|c|c|c|}
\hline Research question & $\begin{array}{c}\text { Measure of } \\
\text { capacity } \\
\text { building }\end{array}$ & Interview questions \\
\hline $\begin{array}{l}\text { What core capacities do } \\
\text { small urban and rural } \\
\text { nonprofits in Oregon } \\
\text { currently possess, in the } \\
\text { financial and human } \\
\text { capacity domains? }\end{array}$ & Collaboration & $\begin{array}{l}\text { 1. What are the most pressing } \\
\text { concerns facing the } \\
\text { community you serve? What } \\
\text { are the challenges that small } \\
\text { nonprofits face in your } \\
\text { community in addressing } \\
\text { these concerns? } \\
\text { 2. Have you looked outside of } \\
\text { your community in addressing } \\
\text { these concerns? } \\
\text { Following questions asked if org } \\
\text { mentioned participating in } \\
\text { collaborations } \\
\text { 1. How do you decide whether } \\
\text { to enter into a collaboration? } \\
\text { 2. What do you achieve (or will) } \\
\text { from it? }\end{array}$ \\
\hline
\end{tabular}


Table 3.5

Research Questions and Link to Interview Question 3

\begin{tabular}{|c|c|c|}
\hline Research questions & $\begin{array}{c}\text { Measure of } \\
\text { capacity building }\end{array}$ & Interview questions \\
\hline $\begin{array}{l}\text { What knowledge and } \\
\text { skills do they possess } \\
\text { that can serve as } \\
\text { valuable examples for } \\
\text { other similar } \\
\text { organizations? Which } \\
\text { areas do they have a } \\
\text { deficit and need to } \\
\text { learn strategies to } \\
\text { overcome this deficit? }\end{array}$ & Financial & $\begin{array}{l}\text { 4. What kinds of information do } \\
\text { your donors and grantors ask } \\
\text { from you? What kinds of } \\
\text { information do you think they } \\
\text { should be asking for? } \\
\text { 5. In what way do you feel is } \\
\text { your organization's ability to } \\
\text { fundraise unique? Can you } \\
\text { give examples where you } \\
\text { have tried something new? } \\
\text { What are the biggest } \\
\text { impediments to achieving } \\
\text { sufficient financial capacity } \\
\text { for small nonprofit } \\
\text { organizations? Do you feel } \\
\text { these impediments and } \\
\text { barriers are the same in urban } \\
\text { and rural settings? How? } \\
\text { 4. What are the most common } \\
\text { methods you use to recruit } \\
\text { board members / volunteers? } \\
\text { 5. What specific skills / } \\
\text { attributes do you look for } \\
\text { while recruiting board } \\
\text { members / volunteers? } \\
\text { How long on an average do } \\
\text { they serve your } \\
\text { organization? Do you have } \\
\text { challenges retaining them for } \\
\text { a long time? } \\
\text { 7. What strategies have you } \\
\text { undertaken to achieve the } \\
\text { best potential out of your } \\
\text { workers? Possible probes - } \\
\text { training, orientation, } \\
\text { feedback on performance, } \\
\text { job / skills match etc. }\end{array}$ \\
\hline
\end{tabular}


Table 3.6

Research Questions and Link to Interview Question 4

\begin{tabular}{|c|c|c|}
\hline $\begin{array}{l}\text { Research } \\
\text { questions }\end{array}$ & $\begin{array}{c}\text { Measure of } \\
\text { capacity } \\
\text { building }\end{array}$ & Interview questions \\
\hline \multirow{2}{*}{$\begin{array}{l}\text { How should } \\
\text { capacity builders } \\
\text { and policy } \\
\text { makers } \\
\text { customize } \\
\text { capacity } \\
\text { building } \\
\text { initiatives for } \\
\text { small urban and } \\
\text { rural nonprofits } \\
\text { separately? }\end{array}$} & Finance / HR & $\begin{array}{l}\text { 1. How can capacity builders and trainers help } \\
\text { you to achieve your fullest financial capacity? } \\
\text { 2. How can capacity builders and trainers help } \\
\text { you to achieve your fullest HR capacity } \\
\text { (consider all board members, staff and } \\
\text { volunteers)? }\end{array}$ \\
\hline & Collaboration & $\begin{array}{l}\text { Questions asked if org mentioned participating in } \\
\text { collaborations } \\
\text { 1. What challenges have come up during } \\
\text { collaborations and how have you tackled } \\
\text { them? } \\
\text { 2. What changes did you see in the following } \\
\text { with this process? }\end{array}$ \\
\hline
\end{tabular}

\section{Coding Process}

Glaser (1992) prescribed two different kinds of coding for inductive approaches and those based in grounded theory - open and theoretical. Strauss and Corbin (1990) advocated three different kinds for the same - open, axial and selective. Under open coding, researchers read the data and similar segments are put under labels based on meanings that emerge from the data (Gallicano, 2013). After open coding is done, Glaser prescribes theoretical coding while Strauss and Corbin advocate for axial coding. Theoretical coding should be done such that the codes are derived from epistemology and are able to be integrated into a theory while axial coding involves categorizing the data 
and making the connections between the categories (Kendall, 1999). While the two approaches differ in how coding should avoid categorizing and / or avoid coding derived from epistemology, they agree that

Codes and categories are selected by the investigators' interpretations of the data, emergence is the process by which codes and categories of the theory fit the data, not the process of fitting the data to predetermined codes and categories (Kendall, 1999, p746).

Because the aim of the research was to avoid fitting codes into pre-existing theories or epistemologies, I chose to use axial coding instead of theoretical coding after the open coding was finished. Once the interviews had been transcribed, open coding was done first to identify emergent themes from the data relevant to the research questions. I chose three domains under which themes and patterns were coded - financial capacity, HR capacity and other (including collaborations). Each of these domains were divided into three categories - UR (signifying the urban rural distinction) or $\mathrm{Sz}$ - signifying size or G-general. Finally, for each theme, I chose three labels: O-Oppose, S - Supports and N - New. For example, if a particular theme was related to financial capacity and it was relevant to the size of the organization, and the finding generally supported the literature, it was coded Fin-Sz-S. If a theme was related to boards or volunteers (or general workers) and it was an observation related to rurality of the organization and it was a new theme that neither supported nor opposed the literature review, it was coded HR-UR-N.

All in total, 27 codes were generated and frequencies for most of these codes were between 0 and 4 . Because it was a qualitative study, codes that had a low frequency between 1 and 2 were also explored in detail in the same way as other codes. Finally, the 
coded texts were grouped into larger segments using focused or axial coding using the research questions as headings under which the data was classified. A summary of these groups and codes are laid down in Tables 5.1 to 5.3 in the chapter 5.

Before delving into the findings, I will revisit the urban-rural distinction and how that variable was operationalized. Participants were given a multiple-choice question on whether they were urban, rural or both. This was followed by an open-ended question asking them the reasons for their choice. I not only analyzed the written answers in the survey but for those who participated in the final qualitative interview, I pursued the question further and probed them for more details. In doing so, I was able to contribute to what I think should be the standard base for defining whether a nonprofit is rural or urban. I will elaborate on the conceptualization of urban/rural in the next chapter. 


\section{Chapter 4: Operationalizing the Urban Rural Variable}

In this chapter I revisit the literature on how urban and rural are defined. I dedicate a separate chapter to this because after I ventured into the research process using traditional classification methods but realized on probing my interviewees that current methods needed to be refined. Studying collaboration is another reason. This study was primarily designed to explore dimensions of financial and human resource capacity based on assumptions of Resource Dependency Theory and Strategic Management Theory. I was not specifically looking at collaborations across regions but exploring the possibilities of learning from similar organizations, exchanging ideas and unique strategies and stories of resilience across Oregon all for the purpose of providing training materials to foundations and capacity builders. My aim was to analyze any capacity deficits and explore possibilities to reduce the same. However, collaborations were mentioned so frequently by respondents that I delved into the literature on urban-rural coalitions mid-way in the interview process to check on whether adding questions on the same would be required. What if some nonprofits I would interview later had built alliances that bridge the urban rural divide?

I studied historical trends of the urban rural regions in Oregon and how that influenced the nonprofit sector in Oregon. This is what I explain first in this chapter. After that, I explain current definitions of urban and rural, showcasing their current limitations of being applicable to the nonprofit sector and suggest exploring for alternate ones, based on emergent themes in this study. Here I try and operationalize the urban 
rural variable based on what 'emerged' in the study and how that definition is similar or different to ones existing in current literature.

\section{Re-visiting the Urban Rural Distinction}

While rural areas have been slower to develop economically than urban ones, theorists have suggested exploring ways to strengthening the linkages between the two so that they can draw on the resources of each other (Holland, Lewin. Sorte \& Weber, 2011). Rural areas often provide services that require 'land resources, ecosystem services and recreational facilities" (p. 81). Since many nonprofits operate in environmental and animal welfare arenas, recreation (like hunting, fishing, etc.), food and agriculture, it would pay for them to have linkages and networks to rural areas that can serve as an effective resource for hosting such services.

At the same time, urban areas offer many services related to financial and technical assistance, legal consulting, and education and capacity building activities across many disciplines (p. 81). People in urban areas often wishing to start small businesses, for example, have greater access to firms providing such services than people in rural areas. However, if rural nonprofits focusing in similar services can draw on linkages and partnerships with urban nonprofits providing similar services, it could help them to bring down costs, draw on the financial and human resource capacities of their urban counterparts and hence provide more services for lesser revenue. While this study specifically asked questions related to capacity on financial and human resource dimensions, the question of collaboration across regions and sectors inevitably came up because it is more often than not small nonprofits that feel the pressure to collaborate. 
Taking a look at both urban development and rural development literatures, it is interesting that the former rarely considers the rural/urban interdependence as a key factor for economic development in urban areas. Rural theorists however will have always addressed the importance of such linkages (p. 82). The same trend is also noticed when researching on nonprofits. While most studies on rural nonprofits have compared and contrasted them to their urban counterparts and concluded the inadequacy of their resources in relation to their urban neighbors, there have been rarely any studies that have focused on the strengths of rural nonprofits and if urban nonprofits can capitalize on rural/urban collaborations. While this dissertation does not specifically analyze the pros and cons of such linkages, it could provide a headstart to studies in future that explore the possibilities of building inter urban rural capacities across the third sector in Oregon. For example, collaborations between nonprofits or memberships with larger budget, urban chapters of a certain nonprofit can help smaller rural organizations to acquire more resources at their disposal. The urban chapter or parent on the other hand can draw on more individual donations and membership fees from the rural regions.

The rural/urban interdependence is often stressed as a key factor for economic development, especially for rural areas. Urban-rural interdependencies are viewed as methods to promote economic development of rural areas and reducing negative effects of sprawl, neighborhood development and population growth in urban areas. The interdependencies also refer to the flow of people, spatial linkages and travel demand economics (Caffyn \& Dahlstrom, 2005). These are used for example, to study employment and flow of labor between urban and rural regions, how food moves from 
rural regions to urban markets or how urban residents make leisure trips to the countryside.

Similar examples can be used in the nonprofit sector. Most studies on rural nonprofits compare and contrast them to their urban counterparts and conclude the inadequacy of their resources in relation to their urban neighbors. For example, soup kitchens and food distribution centers in rural areas have greater capacity challenges delivering their meals to remote neighborhoods than those offering the same services in Portland where the recipients of these services have access to good public transportation.

But urban nonprofits can essentially learn from the strengths of rural nonprofits because of their similarities and not differences. Animal welfare is a good case in point. While both urban and rural regions have fair share of shelters for cats and dogs, those for exotic animals or beasts that require large grounds for maintenance and upkeep are usually located outside urban areas. While both of these kinds of shelters will face capacity challenges that are different (e.g. specialized vets for exotic animals versus common household animals), essentially they face challenges that are similar because they have similar missions and visons related to animal welfare, safety and preservation. Despite their urban rural differences, they can find ways to teach strategies to each other or network / collaborate to achieve joint funding or acquire vets with specialized knowledge to serve their communities.

Even though this study is aimed at analyzing dimensions of financial and HR capacity, respondents' perceptions about being located in a rural (or urban area), how that affects their capacity challenges and if they had considered collaborating across regions 
are questions worth exploring. Even if respondents have not explored collaborations across long distances, it would be worthwhile to know their views about setting up networks outside of their immediate communities.

Finally, collaboration need not be restricted to organizations across different regions operating in the same arena. Nonprofits can find ways to collaborate with those who have separate missions and visions by fundraising together, sharing office space and volunteers. This could be very important for small nonprofits who cannot hire and pay people and are restricted to a limited resource of volunteers.

One of the many goals of this study was analyzing the urban - rural distinction among nonprofits to contribute to the development of theory. Primarily this became a goal for this study after discovering that definitions of urban and rural were based more on geography (definitions by planners, geologists, agricultural studies practitioners etc.) or demographics (definitions by sociologists and anthropologists, health specialists, education researchers, etc.). None of these definitions was all-encompassing for the study of nonprofits and each had its pros and cons.

The US Census Bureau uses a definition based on population density and other measures of dense development when identifying urban territory. In the early part of the twentieth century, incorporated cities and towns with at least 2,500 people were designated urban. Everything else was defined as rural. Over time, the definition of 'urban' evolved to include more people and territory; the definition of 'rural' to this day however, remains as all territory, persons, and housing units not defined as urban. (Ratcliffe, Bird, Holder \& Fields, 2016). 
Drawing on this standard procedure of classifying certain regions as urban, based on size, population density, travel commutes, etc. (and everything else rural), we note that there are two kinds of classifications out there - at the county level and at the subcounty level. The following tables summarize the various definitions under these classifications.

\section{Table 4.1}

RUCC Codes Classification System for Defining 'Urban and Rural'

\begin{tabular}{|c|c|c|c|c|}
\hline Name & $\begin{array}{l}\text { Classifica } \\
\text { tion type }\end{array}$ & Organization & Codes used & Description \\
\hline $\begin{array}{l}\text { Beale } \\
\text { Codes or } \\
\text { Rural } \\
\text { Urban } \\
\text { Continuum } \\
\text { Codes }\end{array}$ & $\begin{array}{c}\text { County } \\
\text { level }\end{array}$ & $\begin{array}{l}\text { United States } \\
\text { Department of } \\
\text { Agriculture }\end{array}$ & 1)Metropolitan & $\begin{array}{l}\text { Three metro codes, all } \\
\text { urban: (a) } 1 \text { million or } \\
\text { more individuals, (b) } \\
\text { between } 250,000 \text { and } 1 \\
\text { million persons, and (c) } \\
\text { less than } 250,000 \text { persons. }\end{array}$ \\
\hline (RUCC) & & & $\begin{array}{l}\text { 2)Non- } \\
\text { metropolitan }\end{array}$ & $\begin{array}{l}\text { Six codes, five are urban } \\
\text { and one is rural) } \\
\text { (a) } 20,000 \text { or more people, } \\
\text { adjacent to metro area (b) } \\
20,000 \text { or more people, } \\
\text { not adjacent to metro area } \\
\text { (c) } 2500-20000 \text { people } \\
\text { adjacent to metro area (d) } \\
2500-20000 \text { not adjacent } \\
\text { to metro area (e) less than } \\
2500 \text { people adjacent to } \\
\text { metro and (f) less than } \\
2500 \text { people, not adjacent } \\
\text { to metro (the only rural } \\
\text { code). }\end{array}$ \\
\hline
\end{tabular}

Source. Hawley et al (2016), Tables 1 and 2; Hailu and Wasserman (2016), Table 3 
Table 4.2

UIC Codes Classification System for Defining 'Urban and Rural'

\begin{tabular}{|c|c|c|c|c|}
\hline Name & $\begin{array}{l}\text { Classifica } \\
\text { tion type }\end{array}$ & Organization & Codes used & Description \\
\hline \multirow[t]{3}{*}{$\begin{array}{l}\text { Urban } \\
\text { Influence } \\
\text { Codes } \\
\text { (UIC) }\end{array}$} & \multirow[t]{3}{*}{$\begin{array}{c}\text { County } \\
\text { level }\end{array}$} & \multirow[t]{3}{*}{$\begin{array}{l}\text { OMB (Office } \\
\text { of } \\
\text { Management } \\
\text { and Budget }\end{array}$} & 1)Metropolitan & $\begin{array}{l}\text { Two codes, both urban: } \\
\text { (a) large metro with } \\
\text { population above } 1 \\
\text { million (b) small metro } \\
\text { with population below } 1 \\
\text { million }\end{array}$ \\
\hline & & & 2)Micropolitan & $\begin{array}{l}\text { Three codes, all urban: (a) } \\
\text { adjacent to large metro (b) } \\
\text { adjacent to small metro (c) } \\
\text { not adjacent to any metro }\end{array}$ \\
\hline & & & $\begin{array}{l}\text { 3) Non-core } \\
\text { areas }\end{array}$ & $\begin{array}{l}\text { Seven codes, five urban, } \\
\text { two rural (a) adjacent to } \\
\text { large area (b) adjacent to } \\
\text { small metro and contains } \\
\text { town with } 2500 \\
\text { population (c) adjacent to } \\
\text { small metro but does not } \\
\text { contain small town of } \\
2500 \text { people (d) adjacent } \\
\text { to micro area and contains } \\
\text { town of } 2500 \text { people (e) } \\
\text { adjacent to micro area and } \\
\text { does not contain town of } \\
2500 \text { people (f) not } \\
\text { adjacent to metro or micro } \\
\text { and encompasses a town } \\
\text { of } 2500 \text { residents (g) not } \\
\text { adjacent to metro or } \\
\text { micro, does not contain } \\
\text { town of } 2500 \text { people. } \\
\text { Categories f and g are the } \\
\text { rural ones }\end{array}$ \\
\hline
\end{tabular}

Source. Hawley et al (2016), Tables 1 and 2; Hailu and Wasserman (2016), Table 3 
Table 4.3

RUCA Codes Classification System for Defining 'Urban and Rural'

\begin{tabular}{|c|c|c|c|c|}
\hline Name & $\begin{array}{l}\text { Classifica } \\
\text { tion type }\end{array}$ & Organization & Codes used & Description \\
\hline \multirow[t]{4}{*}{$\begin{array}{l}\text { Rural } \\
\text { Urban } \\
\text { Commutin } \\
\text { g Area } \\
\text { Codes } \\
\text { (RUCA) }\end{array}$} & \multirow[t]{4}{*}{$\begin{array}{l}\text { Zip codes } \\
\text { or Census } \\
\text { tracts }\end{array}$} & \multirow{4}{*}{$\begin{array}{c}\text { Health } \\
\text { Resources and } \\
\text { Services } \\
\text { Administratio } \\
\text { n's Federal } \\
\text { Office of } \\
\text { Rural Health } \\
\text { Policy } \\
\text { (ORHP) }\end{array}$} & Metropolitan & $\begin{array}{l}\text { This constitutes of a core } \\
\text { area where Population }> \\
50,000 \text { and surrounding } \\
\text { areas are considered if } 10 \text { - } \\
30 \% \text { of the population } \\
\text { regularly commutes to the } \\
\text { core area }\end{array}$ \\
\hline & & & $\begin{array}{l}\text { Micropolitan } \\
\text { (Large Town) }\end{array}$ & $\begin{array}{l}\text { Core area has Population } \\
\text { between } 10-50,000 \text { and } \\
\text { surrounding areas are } \\
\text { considered if } 10-30 \% \text { of } \\
\text { the population regularly } \\
\text { commutes to the core area }\end{array}$ \\
\hline & & & Small town & $\begin{array}{l}\text { Core area has Population } \\
\text { between } 2500-10000 \text { and } \\
\text { surrounding areas are } \\
\text { considered if } 10-30 \% \text { of } \\
\text { the population regularly } \\
\text { commutes to the core area }\end{array}$ \\
\hline & & & Isolated rural & Population under 2500 \\
\hline
\end{tabular}

Source. Hawley et al (2016), Tables 1 and 2; Hailu and Wasserman (2016), Table 3

According to Hawley, et al, (2016), all of the three above kinds of classifications at either the county level (RUCC or UIC) or sub-county level (RUCA) have their own sets of problems when it comes to operationalizing rurality. County level classifications overestimate the degree of rurality found within metropolitan counties and also are less sensitive to the degree of heterogeneity found there i.e. they assume that rural places within metropolitan counties are homogenous while they may be not because people here are regularly commuting to the adjacent metro area. Sub-county classifications based on 
zip codes or census tracts eliminate these problems, but often the data researched is not available at the zip code or tract level. Tracts and zip codes are also more complex and often overlap. A good local example would be the zip code 97222 (could be either in Portland or Milwaukee) or 97224 (overlaps Portland and Tigard), often creating data that may have duplicate values or important ones omitted.

I encountered similar problems when trying to make a database of Oregon nonprofits. The Oregon Department of Justice and Guidestar databases list nonprofits by city, state or zip code, but not county. The National Center for Charitable Statistics allows one to draw lists based on either county, city or zip code (but not zip codes that do not have a physical location and contain only PO Boxes). In Portland, for instance, as many as 30 zip codes belong to the only PO Boxes category $(97207,08,28,38$, any code between 97271 and 97299) and nonprofits who file taxes with these zip codes do not appear in a search by zip code in the NCCS database (they will appear if one searches by county or city). Nonprofits like domestic violence shelters often do not list their physical addresses so they can provide an unknown safe haven to their target clientele.

There is also the problem that some nonprofits, especially small ones, do not have an office space and their meetings / operations may be carried out in public spaces like libraries, house of a board member or their listed address could be the firm that prepares their tax statements. In border counties, it may be the case that the address listed may be out of state (because it is the address of a board member, the tax preparer, etc.). Guidestar and NCCS will list such nonprofits as belonging to the state the address belongs to, even though their work may be primarily based in another state. I assumed that those 
nonprofits within the Oregon DOJ database are listed because at least some, if not all, of their work is based in Oregon. Thus, when creating a database I looked at all the three different sources (i.e. Oregon DOJ, NCCS and Guidestar), eliminated duplicates, took care to see only Oregon nonprofits were chosen, and finally came up with all the tables from which I have provided data before in this study.

None of the databases however gave any insight into urban rural dynamics of nonprofits in Oregon. I took Oregon State University's Rural Explorer's definition to get rough estimates of urban and rural nonprofits. But as I have explained before, OSU's definition like many other definitions of 'urban and rural' is based on similar concepts i.e. population size, adjacency to metro or micro area, commuting time to an urban cluster, etc. All of these definitions primarily define what is urban and that which is excluded gets classified as rural.

It is not surprising that the urban rural literature, including those quoted in this study before, have always identified the problems with rural nonprofits by contrasting them with urban ones and rarely highlighted if they can serve as examples to the urban ones. All urban rural classifications define rural as either of the following 1) the residual place beyond what classifies urban, 2) level of development compared to urban, 3) level of poverty, income inequality, health access, education access compared to urban 4) accessibility or travel / commute times to the closest urban area (Woods, 2015; Wunderlich, 2016).

There is nothing wrong with these definitions; however if I had to study the possibility of urban and rural coalitions in nonprofits, it was important to acknowledge 
that rural areas have become more diverse, that they essentially perform functions for urban areas (like providing food, recreation), and that it is not population size but the quality of interactions among the people that define a place's ruralness or urbanness (Wunderlich, 2016). If, as Woods (2015) says, relative rurality means studying how the countryside is becoming more urbanized, it should also encompass exploring how cities become ruralized (through commuting on the weekends for recreation purposes, being closer to animals and nature, acquiring food supplies fresh off the farm, and so on).

An example I gave earlier was of soup kitchens and food distribution centers in rural areas that have greater capacity challenges delivering their meals to remote neighborhoods than those offering the same services in Portland where the recipients of these services have access to good public transportation. However, lately, even in urban areas, farmers have started to grow produce locally rather than getting it delivered from farms outside of the metro region. Nonprofits like Zenger Farms in Portland collaborate with youth organizations, Future Farmers of America chapters outside of the Portland area, and health authorities to deliver nutritious food to marginalized populations. This suggests that collaborations and coalitions across the urban - rural spectrum is possible where farmers from rural areas can teach urban youth how to grow their own crops and in exchange get to network with urban nonprofits, labor force, potential clients or donors etc. Both urban and rural areas are becoming symmetrical, rather than asymmetrical (Lichter \& Brown, 2011) and this suggests the potential for more networks and coalitions across the urban rural continuum. 
In general, while rural places get defined by the communities, urban areas get defined by the characteristics of their neighborhoods (Logan, 2003). What is more important are the quality of interactions within the community or neighborhood because that contributes to social capital. And as I have pointed before, the demand and supply of nonprofits depends not only on the economy (where diversity and population demographics play a role) but also on the presence of social capital (at least for nonprofits that do not offer tangible goods or services or those that provide services whose value gets accrued over time). Because of these assumptions, in the end instead of choosing any one standard definition that exists either in sociology or geography literature, I let respondents in the study decide if they were predominantly an urban nonprofit or predominantly a rural one. I also asked them the reasons for their choice and identified themes in their responses. This became an emergent study that relied more on an inductive approach and grew alongside the main research questions.

\section{Operationalizing Urban and Rural}

As pointed out earlier, current definitions are limited in their use for nonprofit classifications and hence I did not choose any one standard definition that exists either in sociology or geography literature. I let respondents in the study decide if they were predominantly an urban nonprofit or predominantly a rural one. I also asked them the reasons for their choice and identified themes in their responses.

Of the 113 organizations that responded, I excluded the 8 organizations who had surpassed the $\$ 500,000$ budget and checked the others if they answered the question on whether they thought they were urban, rural or both and the reason for their choice. I 
analyzed the open-ended responses of the 93 organizations hence selected, and found that geography and population size were the factors that were given by organizations who classified themselves as urban.

"We serve city of (name withheld) which is in Greater Portland metro area and has more than 50,000 residents".

"We serve the parks and recreation program within the city of (name withheld) only and this is an urban city with more than 150,000 people".

Those who classified themselves as rural did so because of one or more of three

reasons related to population sizes, distance away from large urban areas, and presence of agriculture and timberlands. Two respondents also talked about being located within Native American reservations.

"We are in Douglas county and our services are limited to Coos and Douglas counties only. Neither of these counties have any city that have a population more than 25,000 ".

"We are in Eastern Oregon, mostly agricultural land, largest city has 11500 residents".

"We are a historical society whose aim is to preserve the history of (town name withheld). It is a small community of 820 within city limits. It is surrounded by hundreds of acres of farming and timber lands".

"We are located on a Native American Indian Reservation, you can't get more rural than that."

And then they were respondents who said their impact extended beyond their

immediate town; however, they still classified themselves as rural.

"Our nonprofit is located in rural Oregon yet serves, through our education program, many from around Marion County, which has many urban settings. But our nonprofit is very much 'facility and 'destination' based. So I would go with rural". 
"We serve the string of small towns that lie along or near Hwy 22 (former timber communities) east of Salem from Aumsville / Scio to Detroit / Idanha. Total population is under 20,000. Though we are not far from Salem at our nearest point, the communities are clearly rural in nature, including the incorporated cities. Largest city has about 8,000 people. The rest are 3000 or less, some as low as 150 ”.

So, while proximity to an adjacent urban area was a theme, what was more important was that the nonprofits defined themselves by their impact. If their work was facility and destination based, their impact very rarely got into the adjacent urban area, even if they were close.

Finally, there were some nonprofits who classified themselves as both urban and rural. I analyzed their responses and noticed that while these were located in urban areas, their impact stretched beyond into the surrounding rural areas.

“Our services are primarily urban, but we've done outreach classes and provided resources to rural areas".

"We have local chapters throughout the state, Overall, we serve city populations as well as out-of-city agricultural areas."

"We are a watershed council and work all over the watershed, which is from the highest geographical location to the lowest and everything in between".

When it was difficult to determine from the written response whether to classify them as urban or rural, I probed the question further in the actual interview. Those with multiple locations or locations across both urban and rural areas usually chose one location as the center point, making it the primary administration and decision-making channel. These organizations had multiple chapters across the state and said that in difficult times, they closed some of the chapters that had difficulty finding enough 
volunteers. There were only three organizations in my sample that adhered to this structure and two were classified urban and one was classified rural based on what they chose as their primary decision center.

However, if there were nonprofits located in a rural area and their impact spread over to the urban area, they classified themselves as urban because 1) many of their community members spent a lot of time commuting to the urban area for work, reducing their availability for nonprofit volunteer work. As such they described themselves as facing the same challenges like an urban nonprofit because rural areas have a better access to retired or local populations to supply volunteers 2) they drew in tourists and donors during summer or tourist-friendly seasons from the urban area nearby and as such their visibility was prominent within the urban area. Thus, their strengths also lay in the fact that they were close to an urban area.

There are very few nonprofits whose impact would be restricted only to the region it is located. Some examples could be a historical society restricted only to a city or a rural school Parent Teacher Association which encompasses very small towns or unincorporated communities within the school district. Such nonprofits are examples of those whose location and impact are in the same place. But for most nonprofits, the impact stretches beyond their immediate location. In such cases, both the location and impact determine whether it is rural or urban as summarized in Table 4.4 below. 
Table 4.4

Mukerjee's Methodology for Classifying Nonprofits as 'Urban and Rural'

\begin{tabular}{|c|c|c|c|}
\hline Location & Impact & Comments & $\begin{array}{c}\text { Final } \\
\text { classification }\end{array}$ \\
\hline Urban & $\begin{array}{l}\text { Within the immediate } \\
\text { urban community and } \\
\text { surrounding rural areas }\end{array}$ & $\begin{array}{l}\text { While impact here is both } \\
\text { urban and rural, such }\end{array}$ & Urban \\
\hline Rural & $\begin{array}{l}\text { Within the immediate } \\
\text { rural community and } \\
\text { surrounding urban areas }\end{array}$ & $\begin{array}{l}\text { nonprofits draw on both the } \\
\text { strengths and limitations of } \\
\text { being close to an urban area }\end{array}$ & Urban \\
\hline Urban & $\begin{array}{l}\text { Only within the urban } \\
\text { place located }\end{array}$ & $\begin{array}{l}\text { Since impact is in immediate } \\
\text { community only, they face } \\
\text { strengths and weaknesses of }\end{array}$ & Urban \\
\hline Rural & $\begin{array}{l}\text { Only within the rural } \\
\text { place located }\end{array}$ & the location only & Rural \\
\hline $\begin{array}{l}\text { Multiple } \\
\text { locations, } \\
\text { both } \\
\text { urban } \\
\text { and rural }\end{array}$ & $\begin{array}{l}\text { Multiple locations, both } \\
\text { urban and rural }\end{array}$ & $\begin{array}{l}\text { Check and probe for the } \\
\text { primary decision and } \\
\text { administrative location / ask if } \\
\text { there are chapters that are } \\
\text { prioritized and remain open } \\
\text { while others close when } \\
\text { resources are scarce }\end{array}$ & $\begin{array}{l}\text { Depends on } \\
\text { the primary } \\
\text { location }\end{array}$ \\
\hline
\end{tabular}

As I pointed before, among the 113 organizations, I excluded the big nonprofits and those who had not responded to whether they were urban or rural. It was found that $43 \%$ (40 organizations) responded to being as rural, 14\% (13) as urban and the rest $43 \%$ (40) as mixed in the qualifying survey. For these 93 organizations, their open-ended response was analyzed for why they chose to be classified as urban, rural or mixed.

Those who classified as mixed were re-coded urban or rural depending on their impact, not just location. 56 organizations (61\%) were coded as rural, the rest 37 (39\%) were coded as urban. For this sample, the urban rural distinction had no effect on budget 
size i.e. small and mid-size nonprofits are equally likely to be located and have an impact on an urban or rural area (Spearson $\mathrm{R}=0.076, \mathrm{p}>0.55$ ). Table 4.5 breaks down the study respondents by urban rural distinction and budget size along with comparing them to the state numbers.

When tabulating numbers for the state, I used the traditional methodologies of distinguishing urban and rural by their location and adjacency to an urban area. I did not have information on all small Oregon nonprofits about their mission, and impact, hence I stuck to the traditional methodology. For the study however, based on the methodology suggested in table 4.4, I operationalized urban and rural. Because of the different methodologies, the proportional representation of urban and rural nonprofits, by budget size is different in the sample as compared to the state.

\section{Table 4.5}

Respondents by Annual Budget and Urban / Rural Distinction, 2009-15

\begin{tabular}{lcccc}
\hline \multicolumn{1}{c}{ Budget size } & \multicolumn{2}{c}{ State } & \multicolumn{2}{c}{ Study } \\
\hline & Urban & Rural & Urban & Rural \\
Below 50,000 & $3874(66 \%)$ & $2596(72 \%)$ & $18(49 \%)$ & $21(38 \%)$ \\
$50,000-100,000$ & $733(13 \%)$ & $413(11 \%)$ & $5(14 \%)$ & $17(30 \%)$ \\
$100000-250,000$ & $782(13 \%)$ & $382(11 \%)$ & $8(20 \%)$ & $11(19 \%)$ \\
$250,000-500,000$ & $466(8 \%)$ & $202(6 \%)$ & $6(16 \%)$ & $7(13 \%)$ \\
\hline
\end{tabular}

Source. Numbers for the state were computed using the traditional methods used before to distinguish urban and rural i.e. OSU Rural Explorer while numbers for the study were determined based on the nonprofit's location and impact, not adjacency to an urban area. Numbers for the study were computed based on suggested methodology in Table 4.4 
As I specified before, I had used stratified random sampling when drawing a database of emails. I have given table 3.1 before where I have shown that after deleting organizations who had exceeded the $\$ 500,000$ annual budget range, the figures in my sample were proportional to those in the state population in terms of budget size. I had also taken care to see they were proportional to subsector and urban rural classification. However, because of the timing of the study I got a high \%age of respondents in the arts and culture category who were more available when they were no celebrations or festivals coming up.

However, after taking into account the urban rural classification system I have proposed I found that my study was not as representative of state figures in terms of budget size. I got higher proportion of rural respondents in certain budget sizes. It is because when drawing email lists, I was using the traditional classification that allows some rural organizations to be classified as urban because they are adjacent to an urban area. But if their impact does not stretch into this adjoining area, these organizations are rural. Hence there was an overestimation of rural respondents in my study sample. A small sample from my study alone is not enough to confirm this hypothesis but this could be the subject for future studies. 


\section{Chapter 5: Results and Findings}

This chapter presents the findings of the study. Since this was primarily a qualitative study, this chapter includes many quotes from the interview participants. I discuss all findings related to financial capacity, boards, volunteers and collaborations under three headings - general findings, findings in conjunction with small size, and findings in conjunction with the urban rural distinction. I examine how the findings agree or disagree with current literature or add to the possibility of generating new theory.

As explained before, I chose three domains under which themes and patterns were coded - financial capacity, HR capacity and collaborations. Each of these domains were divided into three categories - UR (signifying the urban rural distinction) or $\mathrm{Sz}-$ signifying size or G-general. Finally, I chose three labels: O-Oppose, S - Supports and N - New. For example, if a particular theme was related to financial capacity and it was relevant to the size of the organization, and the finding generally supported the literature, it was coded Fin-Sz-S. If a theme was related to boards or volunteers (or general workers) and it was an observation related to rurality of the organization and it was a new theme that neither supported nor opposed the literature review, it was coded HR-UR-N. I illustrate this in an easy format in Tables 5.1, 5.2 and 5.3 
Table 5.1

List of Themes for Financial Capacity by Category and Labels

\begin{tabular}{|c|c|c|c|}
\hline Categories & Ur & $\mathrm{Sz}$ & Gen \\
\hline \multicolumn{4}{|l|}{ Labels } \\
\hline Oppose & & $\begin{array}{l}\text { - Admin / } \\
\text { overhead costs, } \\
\text { emergency } \\
\text { reserve } \\
\text { - Quantifying } \\
\text { intrinsic values }\end{array}$ & \\
\hline Support & $\begin{array}{ll}\text { - } & \text { Demand and } \\
\text { supply } \\
\text { - } \\
\text { - } \\
\text { Diversity } \\
\text { Homogeneity }\end{array}$ & $\begin{array}{l}\text { - } \text { Earned income } \\
\text { - Hire } \\
\text { grantwriter }\end{array}$ & $\begin{array}{ll}\text { - } & \text { Visibility } \\
\text { - } & \text { History } \\
\text { - } & \text { Training }\end{array}$ \\
\hline New & $\begin{array}{l}\text { - Spider vs chain } \\
\text { style }\end{array}$ & $\begin{array}{l}\text { - Ripple down } \\
\text { effect }\end{array}$ & \\
\hline
\end{tabular}

\section{Table 5.2}

List of Themes for Collaborative Capacity by Category and Labels

\begin{tabular}{lcc}
\hline $\begin{array}{l}\text { Categories } \\
\text { Labels }\end{array}$ & Gen \\
\hline Support & $\bullet \quad$ Well documented policies \\
New & $\bullet \quad$ Youth success through service learning \\
\hline
\end{tabular}


Table 5.3

List of Themes for HR Capacity by Category and Labels

\begin{tabular}{|c|c|c|c|}
\hline $\begin{array}{l}\text { Categories } \\
\text { Labels }\end{array}$ & Ur & $\mathrm{Sz}$ & Gen \\
\hline Oppose & & $\begin{array}{l}\text { - } \begin{array}{l}\text { Conflicts } \\
\text { between }\end{array} \\
\text { volunteers and } \\
\text { board, need } \\
\text { for } \\
\text { interchanging } \\
\text { roles }\end{array}$ & $\begin{array}{l}\text { Boards } \\
\text { cover } \\
\text { deficits }\end{array}$ \\
\hline Support & $\begin{array}{ll}\text { - } & \text { Diversity } \\
\text { - } & \text { Barriers to } \\
\text { inclusion } \\
\text { - } & \text { Unaware of } \\
\text { recruiting } \\
\text { strategies }\end{array}$ & $\begin{array}{l}\text { - } \text { W1 - Work } \\
\text { - } \quad \text { } 2 \text { - Wisdom } \\
\text { - } 33-\text { Wealth, } \\
\text { financial skills } \\
\text { rare } \\
\text { - } \text { Motivation } \\
\text { and burnout }\end{array}$ & $\begin{array}{ll}\text { - } & \text { Well } \\
\text { documented } \\
\text { policies } \\
\text { - } & \text { Board } \\
\text { leadership } \\
\text { defines } \\
\text { mission } \\
\text { - Older } \\
\text { people } \\
\text { preferred to } \\
\text { youth }\end{array}$ \\
\hline New & $\begin{array}{l}\text { - Spider vs } \\
\text { chain style }\end{array}$ & $\begin{array}{l}\text { - Checks and } \\
\text { balances } \\
\text { problem }\end{array}$ & \\
\hline
\end{tabular}

As seen in the above tables, there are more findings that are in the 'support' rather than 'oppose' category. In the literature, most hypotheses or theories, especially in the collaboration domain, have had mixed results in the field; sometimes the findings supported and at other times did not support them. Themes I categorized under the 'opposed' label were those that have been mentioned in the literature but on the rarer side. For example, while there is some support for keeping administrative costs low, most literature backs the opposite argument. Therefore, when my study respondents talked 
about the difficulties small nonprofits face in keeping down administrative costs compared to big ones, I coded this theme as Fin - Sz - Oppose. Similarly, almost all themes regarding collaboration were not confined to size or urbanness / rurality alone but both and hence were placed under the 'general' label.

I will describe all the themes in the following order. First, I will start with what I found for financial capacity under three categories - whether the observation was related to the urban rural distinction, small size or a general observation irrespective of size and ruralness / urbanness. For each, I will explain if the discoveries supported and / or opposed current literature or contributed to new literature. Then I will repeat the same process for HR and collaborative capacity.

\section{Findings on Financial Capacity}

\section{Findings on Financial Capacity Related to Small Size}

It Is Difficult to Keep Overhead and Administrative Costs Low or Build up Emergency Liquid Reserves. Most nonprofits are aware that individual donors make a connection to them by listening about the nature of their work and their personal stories of why they are doing this. However, they felt that this connection was missing from grantors and funders especially because they found little opportunities to highlight their work and passion in applications for grants. Funders asked more about how the money was spent.

As an example, grantors and funders did not want to give money that would be used as maintenance costs or sometimes, had conditions like not exceeding a certain \%age on overhead costs. Many small non-profits felt the rules that apply to big nonprofits 
should not be applied to them, especially when it comes to overhead costs. It is harder for smaller nonprofits to keep overhead costs low and they expressed frustration when funders applied parameters like 'low administrative or overhead costs' to select their grantees.

Funders do not generally like to fund general operating or overhead expenses. In big organizations like the Red Cross you will notice how they say 89 cents or something of every dollar goes to the cause and as important as that is, it is necessary to have the right overhead expenses. These expenses are important and if not taken care of the activities that are directly related to the mission get hampered as well and you will cease to exist as an organization. Operating support is hugely important but the granting organizations get frustrated if they are above a certain limit (performance organization in urban Oregon).

When you look at IRS tax forms you see that many nonprofits try to show their overheads costs are low. So over time that has given the perception that it is good to keep them low. But funders need to understand that is not realistic. Even the IRS asks that your overhead is a certain \%age of your budget so funders ask that too. I understand the need for rules in this respect, I mean if you are a $\$ 100,000$ organization then your ED should not be making a $\$ 100,000$ so obviously the rules are different from small nonprofits than for big ones. I mean if we keep our overhead costs low, it hinders our mission and then people leave. And then funders ask why we had such high turnover. Well there is your answer. Our work, our passion is more important than such ratios and proportions, so those are what they should worry about, especially for small organizations where we hardly pay people and expect them to stay only because they are committed and passionate about the project (animal rescue organization in rural southern Oregon).

It is hard to apply their questions and measures of success to something like building and grounds repair. I have to make up fluff stuff to confirm to their parameters, I could do it but I don't want to. (museum in eastern rural Oregon)

Others also explained of how they wanted to keep money in a savings account or build up emergency cash reserves, but these are issues for which they have to solely rely on individual donations because grantors and funders want the money to be spent and accounted for within the time period they are allotted for. 
Not many small nonprofits keep an emergency cash reserve, because honestly they cannot. I think some of the bigger ones do. Some have regular individual donors, people that give good sums to help buy and manage things but I know others have struggled because they don't have that resource to fall back on. Many are on shoestring budgets, always on the edge, no reserves maybe some building or capital but no liquid (nonprofit helping other nonprofits in capacity building efforts, coastal Oregon).

Respondents also pointed out that as small organizations they were more likely to feel the vagaries of seasonal individual donations which go up during Christmas and Thanksgiving but are scarce at other times of the year. It would help them if corporate funders and foundations allowed them to use the money given to be put towards emergency reserves.

A nonprofit in a rural Southern Willamette Valley county said their community comprised mostly of seniors who found it hard to volunteer because of health issues. They found that volunteering rates went up if they were able to provide hearing aids, walking canes or other services that helped the elderly, but often corporate funders and grantors refused to provide grants for such things because they were not directly related to the mission of their organization.

Many understood the need to have rules and regulations but felt that small nonprofits should be allowed to have higher overhead costs and also be allowed to use grants for emergency cash reserves and providing some in-kind compensation to their volunteers, especially those in small rural communities.

\section{Small Nonprofits Mostly Stick to Individual Donations and Grants but are}

Interested in Generating Money from a Small Enterprise. Most study respondents said that they got twice as much or more money from individual donations than grants 
and were happy to keep it that way. Some respondents though, felt that operating a small private enterprise like a gift shop or a restaurant could help bring not only more money but also more visibility to their project.

An environmental protection group said that while T-shirts and other memorabilia sold through their website did not generate much money, it definitely helped getting the word out when volunteers dressed in clothing with their logo attended marches and local cleanup events. Another respondent though had a negative experience saying the previous leader of the organization used the gift store to sell personal belongings and make profit which encouraged a similar culture among the volunteers and staff and she had to take strict steps in discouraging similar antics after taking over.

Some other respondents are thinking of opening up a commercial enterprise but would like to tie it within the mission and vision of their organization, provided they get some training and support on running a small commercial venture. They said that assistance with getting memberships with the Small Business Administration or nonprofits in the field of microfinance or training emerging small businesses would be a huge help.

If we could get opportunities to get assistance or some network opportunities, I would explore at ways to generate a financial revenue stream for our society. We do advertising in our brochures but there must be other ways that create money every day, all year long. We would like to generate some earned income on the side by opening a thrift store, but such kind of business enterprises need some start-up capital and also business assistance (emergency services in Willamette Valley, rural).

The questions you asked are good and thought provoking. It made us think of what we are doing with all our money and how we can get assistance. I would start a hot dog stand. I mean, we want to put up this (art exhibit) of Bobby the Wonder Dog. She was a Scottish dog who went on a vacation with her family to 
Indiana and there she got lost. Her family came back without her. Six months later, Bobby showed up at her doorstep having travelled over 3000 miles. She is a hero here, locally and our (art exhibits) depict the history and culture of the place. So we would open the hot dog stand and bring the legend of Bobby back to life with that (arts and culture organization, rural, Willamette Valley).

Small Nonprofits are Worried about the 'Ripple Down' Effect. Most of the interviews in this study was conducted in 2017, sometime after the 2016 Presidential Election where a major theme had been giving tax breaks to the rich which would translate into a 'trickle down' effect on the poor because the rich would give more. Respondents were prompted if they thought they would see bigger donations in future, but most said 'no'.

Respondents were also asked further, if they were worried because there had been huge cuts in grants from the government towards nonprofits. Almost all of their initial responses were 'no' because as small_nonprofits they get very little funding from the government. Most of the revenue is from individual donations, then foundations and corporate donations, followed by member dues, sales from gift shops or in some cases, a restaurant on the premises, etc. Those who had grants from the government got it mostly at the county or city level.

But when probed in detail, many were quick to realize that the big nonprofits will no longer be getting large grants from the government and they will look for other sources and add to the competition. So, the big organizations who may not have been their competitors in the past will now become so. This finding neither supported nor opposed any existing literature but hints at the possibility of further studies to confirm the 
hypothesis whether a lessening of government grants to big nonprofits creates a 'ripple down' economy for smaller ones.

This will be like a 'ripple down' effect for those of us who are low on the totem pole. The perfect example would be the National Endowment for the Arts. With the current administration trying to get rid of it, we as an organization aren't big enough to get funding from them. Our competitors out there who are bigger than us will not get that funding anymore and will try to supplement that lost income from other resources thus driving up the competition in the funding arena. So we will be one of the smaller grantees in the arts and culture sector, funders will obviously get bigger requests from the bigger theaters as they try to recover their lost income from other sources. This will be a challenging time in the future (theater company in urban metropolitan Portland).

Having a Professional Grant Writer Helps. Of the thirty or more small nonprofits that were interviewed for this project, about ten have grown from a budget of less than $\$ 50,000$ annually to that over $\$ 250,000$ in the past 15 years or so. Hence those who had grown in size attributed their growth to one of two factors that were heard in all their interviews 1) they had a board that had taken the time to write out proper policies and documents and 2) they had hired a professional grant writer at least on a part time basis. As many respondents agreed, grant writing is mostly catering to every foundation individually and what they are looking for. As such it helps to find a person who knows the right grants to apply for. Some respondents said they had often wasted time in writing applications to foundations for whom they were not the tight fit but could have avoided doing so, had they been more knowledgeable about the history of the foundation and their values. Professional grant writers possess unique and relevant knowledge and skills which regular board members or volunteers at small nonprofits may not or also not have the time to get trained on since they are busy managing the nonprofit's programs. 
Each foundation is totally unique so they have their own world view and their own requirements when we apply. We cannot do a one size fits all grant application but tailor it to fit each foundation and emphasize the bits of our program that will appeal to that particular foundation the most. Sometimes it's enhancing the poverty aspect or the rural aspect of our community and that gets their attention.

I mean, we would definitely like it if they asked some questions we wanted them to. But we could make what you want to get heard a part of some question even if that is not directly asked. I think you need to have the talent to sneak it in. That is the skill and finesse of writing grants. It is an art. And a professional grant writer would know that. I used to know a lot of people at those grantmaking foundations but there are new people there and I do not have the same contacts anymore but again a grant writer would have her relevant contacts up-to-date.

Nonprofits also pointed out that often grant applications asked them to quantify what they had achieved while some of their services are of intrinsic value that is hard to quantify. There was the sense that numbers measured through inputs and outputs were more important for foundations than outcomes that could be told through stories or site visits.

You know, I like best the foundations that come and visit and they get a feeling of what is happening and meet us. It is a relief not to sell our case through a written application. It is not a lot of money but still it is great. I mean, we would definitely like it if they asked some questions we wanted them to. One could make what you want to get heard a part of some question even if that is not directly asked in a written application. It would be nice if they asked about inspiring stories about our volunteers, like you did (literacy and education center, urban, Willamette Valley).

\section{Findings on Financial Capacity Related to Urban Rural Distinction}

\section{It Is Deficit on the Demand Side in Urban Areas and Supply Side in Rural}

Areas. As the literature laid down, this study supports the fact that urban areas have a wider variety of sources to gather money but non-profits may not have enough 
knowledge or skills to take advantage of all these resources. Rural areas, on the other hand draw on limited sources of money, so their biggest challenge is convincing the donors and grantors their programs are relevant compared to other non-profits. A glaring example of this contrast was visible through the quotes of environmental organizations in urban and rural Oregon as highlighted below:

We struggle to get the word out, our other problems are compounded because of lack of exposure, experience in using social media, lack of grant writers who have knowledge about what grants are available for our niche (treasurer, urban nonprofit in parks conservation).

Our ability to raise funds is enhanced by the fact we are the only conservation group here. All of our revenue is from memberships and individual donations. It is easiest to fundraise when there is some kind of environmental challenge (founder, rural non-profit in environmental conservation).

Urban areas have higher diversity, more people need nonprofit services and nonprofits are constrained in their capacity to meet those demands. Rural areas have less diversity, but nonprofits are constrained on the supply side - they face capacity challenges in recruiting and retaining sufficient human capital. Similar challenges are present on the financial side as well. An environmental preservation group in urban Oregon feels constrained because they did not have the right human capital to help with their finances and fundraising needs while their counterpart in the rural areas had to work hard in getting more individual donations because that are seen as 'not equally relevant as other local nonprofits' in their community unless there is some kind of environmental challenge.

The Spider Web Vs the Chain Style of Fundraising. Many nonprofits have developed unique events (e.g. events with a theme or a particular dress code) for their 
fundraising activities or aligned their fundraising with important events in the region like annual fairs, festivals, rodeos, etc. Those who are located in areas that have a high influx of tourists also have advertised themselves on tourism brochures to gather funds. It was noticed though that in rural areas, because the supply of donors is limited, fundraisers often started chains where every donor in the chain not only had to donate more than the last one but also find a new one who would donate more than the current. The difference could be as little as $\$ 1$ or $\$ 10$. In urban areas, respondents in this sample did not speak of chains but mentioned that they asked all donors to recruit as many donors from their friends, family and co-worker circle. The intention was thus to increase the donor pool like a spider web spreading in all directions.

Users of both styles said there were merits and demerits to either approaches. In rural areas, sometimes the chain would end before enough donations had been raised and many in the line did not like being asked to recruit a new person to the chain. Reusing the same strategy year after year led to donors avoiding the nonprofit; hence respondents cautioned against overuse. In urban areas, often the spider web would spread to donor pools with other nonprofits engaged in similar activities which would lead to their donors choosing over whom to donate, creating distrust and competition among the nonprofits. Findings on financial capacity, related to both small size and urban rural distinction

Visibility and History are Very Important to Get More Money for Small Nonprofits, in Both Urban and Rural Regions. Most small nonprofits agreed that the major sources of funding came from fundraising events as these drew in individual donors and local businesses that gave money without any restrictions. This was also listed 
as the easiest source to generate revenue because it did not require policies and processes to track expenses and report those to the funders. Those in rural communities adjacent to an urban area did point out though, that while local fundraising events got more money because they were more well-known with the local community, factors like their remote rural location, being a part of a very poor community in Oregon where there is not a lot of jobs can impede the giving capacity of local businesses and individuals. Many have realized that to sustain themselves, they have to advertise and market their work beyond their immediate communities, which is why fundraising events and advertising and promotions have to be planned on a bigger scale. In fact, one of the rural arts and culture nonprofit that started 25 years back said

We are in a little town of 10,000. Starting a new nonprofit in a rural area has its challenges. The person has to be deeply committed and involved with the community to keep it going. It is after all the community that will make it successful. If the community does not care, it is harder. When I started 25 years ago, I could not get anybody to donate even $\$ 5$. Now [the art work] is so successful, so beautiful, so well maintained, the people are proud of them. We tell people that these [art works ] do not belong to our nonprofit, but to the community. It is a win-win for everybody. Our city gets promoted, it gets tourism, in fact now, most of our revenue comes from advertising - we have what we call a walking tour brochure and that is actually a map that shows the locations of the different [art works] in the city and the walking path people can take through the city to go there and look at them. This brochure is actually funded from local merchants and businesses in the city and that pays off for the maintenance as well.

Since the supply of individual donations is tight in rural and suburban communities, it is important for small nonprofits to a) boost their presence in their communities, make the locals take pride in their work, in fact give the community ownership of the work done rather than claiming it themselves and b) work towards improving their visibility beyond the immediate community as well through advertising 
and fundraising events to encourage a tourist economy that can indirectly also benefit the private and public sector and provide more opportunities for corporate, private and public donations (apart from individual donations). In other words, creating history and visibility should be the top priorities to be successful in generating money.

Urban areas do not have a limited availability of donation resources like rural areas. But even here, nonprofits, especially small ones, struggle to get money from individual donors because they have a hard time creating visibility and history. That was also the view echoed by an urban philanthropic group that helps small nonprofits to get more donations from the public.

The big challenges are visibility and history. Small nonprofits don't have the time to be visible and part of that is also because they don't have the long history of success. So they cannot show the history of all the results they have been achieving and without that they cannot make a pitch that it does pay the donor to invest time and money for them. It is important for them to nurture relationships with the local media so they can become more visible and also retain that over time.

\section{Despite Their Hectic Schedules, Small Nonprofits are Eager to Learn. A lot}

of respondents want foundations to give some idea as to what they look for in the recipients, so that they can customize their applications to show they are the right fit. They do not want to waste time applying for grants if the foundation for instance, does want to provide for someone who helps with a particular kind of mission. Some respondents requested that foundations put up examples on their website on what a good grant application looks like or ask permission from a previous recipient to showcase their application on the website. It would also be helpful to have an app or something similar available that can search for foundation grants that are the right fit for the nonprofit. 
Respondents also wanted training to be more effective in grant writing, fiscal management, using social media effectively, how to build a web site, and what information is available on-line. However, while those in urban areas said they had no problems getting to trainings, those in rural areas, especially in Southern Oregon were unable to attend trainings that were in far off places. They requested more webinars and video conferencing options. At the same time, many were not aware of current webinars or online workshops being held by various professional organizations like the NAO, suggesting there is potential for further distribution of newsletters and capacity-building efforts in remote areas.

Training to young and new organizations for how to get grants is good. Then emphasizing on running the business side of nonprofits. It seems just so easy to start one, write up some articles of incorporation and get a few board members. But it is not like that, I mean we have a 990 to fill, make sure that your donations are accounted for, running a nonprofit is like running a business because you have to invest in the skills and talents of your workers, so these things are not easy. People quit when they can't figure this and hence nonprofits come and go. They need to have some assistance training programs to make them professional nonprofit managers. They should be teaching skills so that nonprofits become sustainable in the long run and keep a low cost. Also making the training affordable and accessible.

\section{Findings on Human Resource Capacity (Boards)}

I will first lay down the general findings that emerged on who is the average board member in a small nonprofit. Most people that work on a non-profit board are those who have special skills that are related to services or programs the nonprofit offers. This could be specialized scientific knowledge related to environmental issues, medical knowledge for providing health and counselling services to both people as well as animals, and skills in performing arts. Many people serve at boards because they have 
been personally affected by issues the non-profit is looking to address or are members of a group the nonprofit provides assistance to. However, nonprofits also reach out to people who do not have a history of the issue in question or belong to a certain group so that they can educate people outside of the community served about the needs and issues facing the community the nonprofit serves. On an average, a board member serves a three-year term. None of the nonprofits in this study had any term limits. Once members complete their term, it was automatically renewed. If people had left, it was because of health issues or they moved to a different location.

\section{Findings on Boards Related to Urban Rural Distinction}

All board members are local, especially in urban areas. In rural areas though, some nonprofits whose impact was beyond their immediate local community, recruited a few board members from far off counties. In urban areas, most members worked in the private sector, banks, some with the government, there were some self-employed people as well. Most of those in rural areas were elderly and retired people, in urban areas, the age range is between 30 to 50. Most respondents said their boards were well represented on gender but skewed towards older people in rural and suburban areas.

Tackling Diversity in their Communities is a Challenge. Nonprofits across

Oregon felt they needed to be more diverse in race, ethnicity and communities where English was not the first language of communication. Diversity not only helps to increase their outreach but also is a requirement from most grantors and funders. As many respondents pointed out though, Oregon is racially and ethnically not as diverse as states 
like California and Texas. But the state's diversity is growing over time and it would be great to add more diverse voices to the board.

There aren't that many people of color. We would like to diversify as it increases our outreach to other communities affected by autism and we can teach them in languages other than English. Currently those who do not speak English are not getting the services they need like the Somali community, the Vietnamese community (human service organization in urban Oregon).

Oregon is predominantly Caucasian but those who have had experiences of a different culture can bring in something to the table that is super important. Everyone in our board is super supportive of equity and inclusion, anytime we have a project, we want to tackle barriers to equity and inclusion, there are always barriers that are hidden and we are not aware of them. When we include people that are representative of the minority population, those barriers come to the surface immediately. I think it is important to know if boards are representative of the groups in their communities. Is the board a mirror of your community? (arts and education nonprofit in rural Oregon)

Many claimed that there were in need of learning recruiting strategies to appeal to people from different cultures. Some nonprofits, especially urban ones or those with a parent group said they were lucky to get some diversity training at a conference or from their parent group. But those in remote areas find it difficult to attend training programs or workshops that are located quite far off geographically even though they are very interested in hearing about success stories from other regions about getting a more diverse board.

Almost all nonprofits said that the board members are generally recruited by their current board members. They are people known through other board members or are familiar with the nonprofit like donors, or those who are engaged with them on a regular basis. Sometimes people reach out to nonprofits and volunteer themselves to be board members, especially if they are members of organizations that deal with similar programs 
the nonprofit provides. In either case, often recruiting from within their immediate social circles can often prove to be an impediment when trying to recruit a diverse Board.

The Hispanic population is about $19 \%$ in [city]. We should honor all the diverse groups through their museums and cultural centers, like the Japanese, the Hispanic and European etc. We let people know that we would like to have more voices in the board, but it is difficult for people to give time to our work. We struggle with participation. It is a push and pull situation. Some cultures do not want to get involved. I found it hard to get the Hispanic people to participate. I wish I knew the reason why (community development organization in rural Oregon).

In conversation with the last nonprofit quoted, for example, the interviewee pointed out that it was difficult for their current board members to get people from other races and ethnicities to participate. She even gave examples of how countless times invitations were sent to other groups but nobody ever RSVPed. As a member of a nonCaucasian race and immigrant group, I pointed out that some cultures find it rude to say 'no' and hence a formal RSVP would not be sent with 'no' as the option checked. It would be better to informally approach these groups, get acquainted over time, invite them to volunteer and then over time ask them to participate on the board. The interviewee thanked me and said that was something she had never thought of because she was unaware of customs in other cultures. At the same time, she pointed out how this was a good example of why rural communities struggle to get diversity in their boards. Even if they have diversities in their respective communities, many never had the opportunity to interact with other cultures growing up, had never been able to attend a diversity training in an urban area far away and were often unaware of barriers to inclusion that could be easily broken down, if they knew the right way. 
Some of the nonprofits interviewed have a well thought-out process where they meet informally with potential new recruits over lunch or coffee so that both parties can assess how this work will mutually benefit both the person as well as the nonprofit. An urban nonprofit did point out that it is important that board spend time and money to get policies and procedures revised to do things more thoughtfully, specially recruitment and retention of board members. This would include detailing procedures for adding diverse voices to the board.

\section{Findings on Boards Related to Small Size}

The Three Ws - Work, Wisdom and Wealth are the Most Important. As one nonprofit director put it, the skills / attributes required for board members are very simple and relate to the $3 \mathrm{Ws}$. These three attributes are desirable in any board member, whether the nonprofit is urban or rural.

We look for the $3 \mathrm{Ws}$ - wealth, wisdom and work. Ideally you want a board member with all three i.e. can pitch in, work hard, or donate or help us to pursue our mission. But the reality is, that is not possible hence we look for people who have at least two of the Ws.

Most board members are very involved and are able to volunteer at critical events and programs. As one nonprofit put it "these are the worker bees". Contributing to the first W i.e. work is very important, being able to do hands on work is the most soughtafter skill. In fact, it was the small size of nonprofits that made them request board members who would contribute to the day-today activities of the organization. These functions are generally carried on by paid staff or volunteers at big nonprofits while board members contribute to monitoring them. Small nonprofits are usually unable to 
compensate day to day workers which is why such activities are carried out both by volunteer staff and board members.

For nonprofits specializing in programs and services that require advanced knowledge or technical skills, the second W i.e. wisdom is important. The board should understand how, why, who, when, what programs are run and also be able to educate and connect to the community they serve. They can do this by holding workshops, training new volunteers or recruits or speaking about their work at important fundraising events. Finally, it is important to recruit board members who can contribute to the third $\mathrm{W}$ i.e. wealth. In fact, in this study, all nonprofits who had experienced some growth in their budget size said it was because they started focusing more on the financial aspects or recruiting board members with financial skills. Hence the second and third Ws - Wisdom and Wealth are desired in any nonprofit board member, the first i.e. Work is especially desirable among board members in small nonprofits.

The general consensus was that every member is unique. The board is a collective but it also has individual contributions. Some share their expertise with the community or organize workshops on issues the organization addresses, others pitch into fundraising efforts. Financial skills or donations are on the top of preferred skills / attributes for a board member however, board members who are not donating a lot or providing the organization with valuable budgeting or cost management skills are valued equally as they provide an in-kind donation if they have significant knowledge of the issues their organization addresses. 
Apart from the $3 \mathrm{Ws}$, nonprofits said that they also look for people who get along with other people, board members and workshop attendees or people at fundraisers. They have to have good social skills and work agreeably with not too many opinions. People desired are those who have a good sense of where they want the organization to go, but they should also be able to get their ideas and concerns heard without being disagreeable.

The Checks and Balances Problem. Nonprofits agreed that board members have influence in setting the organizational policy and making sure that everything is being implemented. They rely on opinions given by the President or Founder and the Treasurer, but they are the ones that put forth and guide the overall direction of the policy. They keep a check through reports at Board meetings on what the organization is doing and how they are doing it and ask questions or point out if something is less than acceptable. Both urban and rural nonprofits said that their boards did a good job of monitoring budgets and reviewing profit and loss statements and balance sheets at the meetings. However, this is often in the form of "We trust everything the Treasurer / President says" rather than members scrutinizing the documents on their own or asking hard questions to the Treasurer / President. This undermines the role of the board in providing insight into both the health and management of the organization.

The whole point of the relationship between boards and management is to have a checks and balances system so that the board oversees the management and the management provides the correct information to the board. Unfortunately, in small nonprofits, often the board and the management team are the same, so often it is hard for 
the people to separate their roles and become a monitor for the other group. This

challenge is thus unique to small nonprofits. As one respondent put in very eloquently,

Board members in small nonprofits should remember that if there is an issue with the management, the blame will be put on the board. If the management on the other hand has not communicated properly to the board, that is not a healthy relationship. The bottom line of any nonprofit lies on the board but it is easy to forget that kind of responsibility. They should ask the management more questions, particularly about the financials, to the point of forcing the management to look for answers if they do not have them.

If board members are part of the management, as in small nonprofits, they should still put on their board member caps at board meetings and ask questions, then take off the caps and look for the answers in their roles as managers. And vice-versa.

\section{It is Important to Keep Board Members Motivated so the Organizations}

Stays Active and Vibrant. Despite having board members as volunteers at the same time leads to a checks and balances problem that is unique to small nonprofits, there are some merits to that arrangement. In big nonprofits, usually the board has oversight responsibility and may not be responsible for day to day decisions. Because of this board members sometimes question whether they really contribute to the organization's mission and their job has an intrinsic value to it. Boards in small organizations are aware of the logistics and frontline problems running the programs and can make decisions based on their actual experience on the nonprofit floor and not just financial documents and numbers.

Another thing, boards lose their vibrancy some time. Board members need to figure out what is their role and how they can do it better rather than just existing. This is hard for boards that do not control the day to day operations but only have oversight duties that are statutory. So it is hard to get somebody motivated to work on the board when they are not involved in core operations or day to day work that relates more to the mission of the organizations and that is what the 
people are passionate about. In some ways, the oversight role is legitimate and real but at the same time feels superficial. I mean people want to explore what is the board is all about and what is my role and is it really important. There should be some intrinsic value to this job and small nonprofits and community organizations provide that better (environmental coalition in South Coastal Oregon).

\section{Financial and Fundraising Skills are the Scarcest Skills among Board}

Members. It is well known that board members are expected to be active donors for their organizations. However, as it emerged during most interviews, that while they are comfortable donating their own money, they need to learn strategies in asking their friends to donate. Many board members in small nonprofits are not professional fundraisers and asking acquaintances to donate is something they are not used to doing in their daily lives. One of the biggest challenge is getting board members to feel comfortable asking their friends to come to fundraising events where they will be asked for money. In fact, some pointed out that it would be helpful if they learnt about strategies from trainers and other nonprofits about how they train their board members in not hesitating to ask their friends for money.

We have this culture of our organization - to not ask for money, if people wanted to donate we would thank them graciously but if they don't think of it well... One of the areas that we have to work on and expand is to approach people and ask them to remember us in their will, that is hard, I don't really have someone who is willing to take on that project and run with it (museum in rural Eastern Oregon).

\section{Findings on Boards Related to Both Small Size and Urban Rural Distinction}

Well Documented Policies and Processes are Very Important. This is an important step for recruiting and retaining diverse voices to the board. Usually this is not a high priority among small nonprofits, but those who had taken the time to do so had 
fewer problems or complaints about how the board was currently running or how to handle change effectively when new members came in.

It is really helpful to have well documented processes. Paying attention to the nuts and bolts; things that are not explicitly laid should be made clear like how to get new board members, what is the procedure for a new board member, what if their term has ended and should we renew, etc.

This theme was also captured when related to other challenges that boards face, namely burnout and stress. Most board members have jobs outside of their work at the nonprofit, so they had challenges in juggling paid work, unpaid voluntary work and other family contributions and not getting overwhelmed by all of it. It is not surprising that nonprofits in rural areas and in suburbs exclusively look for people who are retirees who can participate in work on weekdays and not just weekends. However, health issues can often cause barriers among the older generation to contribute to board activities.

The problem with having young people is they don't have time, they have children and they spend all their time in the car driving to work, driving to daycare which is far out, that is the story in all rural communities like ours. People don't want to go out after work, people don't want to go to meetings on the weekend, I am lucky if I can get them to write a check. I tend to look for old people, I shop for people who have just retired (museum in Eastern Oregon)

Most small nonprofits, whether rural or urban, unfortunately cannot afford a fulltime paid staff. Hence, often it is the unpaid board member who takes on the role of the volunteer as well. It is not surprising then, many do not want to undertake additional responsibilities like for instance, legal responsibilities that includes them understanding how relationships work between the board and the management team that delivers the programs and services. Many respondents, who were Presidents or equivalents in their 
organizations pointed out that often board members themselves do not see these duties as important or if they do, cannot commit to the time devoted in these activities.

Respondents, whether urban or rural, all thought that access to templates for policies and processes that can be amended to suit their individual organizations would be helpful.

\section{Board Leadership Matters a Lot and Can Direct the Mission and Vision}

Hugely. Every interview that was about boards generated themes on leadership and how the mission and vision of the organization was greatly dependent on who was at the top. One organization, which was faith based and provided housing, shelter and human services to pregnant teens said they had a hard time getting donations being in an urban area but that changed when a new leader decided to focus less on the religious aspect of it. Community newsletters focused less on outputs like church attendance and more on clients served and getting healthcare. Another spoke of the negative influence a board member had on her organization, until she as the President, spoke vocally against his policies.

Last year we had a board member who wanted to have a recruitment committee to build up the membership. The idea was to have more people to work at the museum, have bigger funding, we would be able to do bigger projects but basically his vision was to transform this historical society into an elite social group that people would be seeking to be members of and some said, "ok we will give it a try". But it is not my vision and we did not have a shared vision and he left. My vision is not to be elite and anyone who is interested is welcome to come, even if they are odd and not elite. I mean, I am inclusive, I don't people to be socially correct or whatever that means in our members. It is my personality and my voice that has a strong impact on our organization and it has changed drastically from what it was, under the last president and I am sure it will change drastically when I am no longer there (museum in Eastern Oregon, rural).

Boards Step in When There is a Capacity Deficit. Despite the challenges and hurdles small nonprofits face, the inspirational stories heard about boards were related to 
the fact that they always stepped in, whenever there was a capacity deficit. Such challenging deficits were related to not having enough money, not having enough staff, a place to work or other resource shortages. In fact, the overwhelming theme was that if nonprofits or their communities served had a capacity deficit, the board went out of their way to overcome it. One nonprofit Director recounted the story of how her board went out of the way to provide services for a client who was unable to get the expensive resources on her own saying,

"This is why we do this job, this is why we raise money, to be able to help people with this kind of help and procuring the right equipment for them. We aim to be the enormous change in their life."

Another nonprofit found that moving to a different location would take over six months before the new building was ready and they had to vacate the old premises right away. Their board found a church as a temporary office space and also recruited additional volunteers to help with the moving so that the regular staff could carry on their day to day work without worrying about the logistics of the new move.

\section{Findings on Volunteers}

\section{Findings on Volunteers Related to Small Size and Urban Rural Distinction \\ Youth Can Be Potential Volunteers but They are Not Highly Desired. As}

pointed before, in small nonprofits, the board and the volunteers are often the same people. Hence many themes that emerged for board members also emerged for volunteers. For instance, most nonprofits look for retirees and elderly people who can contribute to work on both weekends and weekdays. 
As for what we are looking for, apart from being interested in what we do, we do prefer people with flexible schedules on weekdays. The unfortunate thing is we always have plenty of people to cover weekends but weekdays are a problem, so obviously retirees are highly desirable. We do prefer math and biology backgrounds, but they are very rare to find volunteers like those in this area, so we are kind of hamstrung ... there is only a few of us who can cover math and biology. The main thing is people who are willing to do new things (wildlife rescue and habitat research, Southern Oregon \& California).

This leads to its share of merits and demerits. Older volunteers are loyal but also more resistant to change.

When you have had volunteers that have been there for a long time, it is a good thing to have some loyal people, but they can be resistant to change. Just convincing them to do things this new way was not easy but we did it. Then there were volunteers who left us. We let them go but they left with a sense that "it is time for me to let go. I won't be able to do this thing". At the same time, it is a good opportunity for them to move on and thinking of providing their services somewhere else in similar position. About $20 \%$ of our volunteers work at other agencies as well but we have largely a huge community very loyal to us (rural food bank in Mid-Willamette Valley).

In both rural and urban areas, people talked about the potential for recruiting school children and youth in their volunteer circle. The consensus however, was that while the work of the young was appreciated, they were not consistently available. Many volunteered during school vacations or for getting educational credits during the regular school quarter and were rarely available year around.

I have gone to the schools and I have recruited volunteers among the children and I have gotten calls from a couple of children, "Yes I really want to do this, I will come." It is a lot of work for me because I have to be there and second, I have to have projects for them and meaningful work for them so they can help and learn from. I really want to cultivate them and motivate them and think of projects for them and later I will get a text from them saying "I really forgot I am so sorry". Also the culture in the schools is to give children as many things as possible to do. Involve them in all kinds of sports, involve them in crafts, involve them in everything so that they don't do drugs and get in trouble. Every once in a while, you find enthusiastic children. It is good once such relationships have been 
established. Those last a lot of years and it takes a lot to maintain it and so that is good but when they move on, you have to start all over again (historical society in Portland suburbs)

We have people willing to come and clean up the grounds and other tasks and they don't need any training for that. But to do our core tasks, we do require a 2 year commitment from people who will do wildlife care, because it takes about 6 months to get them trained. Then if they walk away after that, I mean if we think we will not get that kind of a long-term commitment from them, we will not waste time to train them. That pretty much removes the student population because they are not going to be here that long. We cannot get them to commit that long say for more than a quarter or a semester and it is really not worth our effort. Most of them do not even last 3 months (exotic animal rescue and shelter, Central Oregon).

\section{There are Conflicts Between Volunteers and Management / Board if}

Volunteers Feel Under-appreciated. The whole point of the relationship between

boards and management is to have a checks and balances system so that the board oversees the management and the management provides the correct information to the board. As pointed before, in small nonprofits, often the board and the management team are the same, which is why the checks and balances problem arises with boards in small organizations. At the same time, though, while every board member in a small nonprofit is usually a member of the volunteer force, not every volunteer is a board member.

In fact, many do not want to undertake additional responsibilities that board members have to like for instance, legal responsibilities and charting and documenting policies and processes for the organization. Because of this, often conflicts can arise between volunteers and board, especially if volunteers feel their time and skills are not appreciated as equally as that of board members. Conflicts like these get complicated in rural areas where everyone in the community knows each other. All small nonprofits in 
this study pointed that they tried their best to match up volunteers with what they loved doing the most rather than with the right skill set so as to keep the volunteer force appreciated, loyal and willing to come back. This is different from large nonprofits, who usually match volunteers with the right skills to the right job.

So that has been a concern for us - how do we build the relations within the volunteers? Our main challenge is - how do we make them feel appreciated? I think the challenges would have been greater in an urban area. We have a very small community here - we have a limited pool from where we can draw volunteers. We try our best to place somebody with what they want to do. Some of our volunteers want to work behind the scenes, some want to directly work with the clients, so we try to determine where they are going to feel more comfortable. Part of our reason for doing that is the retention. We want to make them happy and make them stay for a while. So we try to put a match to their skills and also so that they keep coming back. We have had some volunteers that have been with us for 20 years (human services organization in Yamhill County).

Diversity is an Issue with Volunteers as Well. As with boards, nonprofits have a hard time recruiting diverse voices to their volunteer force because of which it can also be difficult to provide services to a diverse community. Nonprofits that have a parent group or sister organizations found that one of the advantages of having so was getting diversity training and education about civil rights. Of course, this only pertained to organizations that kept regularly in touch with their parent. A parent teacher association in an urban area which is affiliated to the PTA Oregon Congress cited having no noticeable benefits of joining the parent group while organizations that have branches across multiple counties like NAMI, 4 H Clubs, etc. and regularly attend joint conferences and trainings with their sister groups felt they had a lot of learn from others, especially in diversity and civil rights training. 
We do have a contract with the [parent group] in a way and so we have to comply with the federal guidelines. There are advantages of being in a contract, it also helps with our diversity. We have a huge Hispanic population here. By doing the civil rights training, it brings to the forefront of our volunteers of how we should treat everybody. We look very hard to recruit Spanish speaking volunteers and translators. If we were a completely independent agency, without the training, we would have some difficulty with folks. With the training, we make sure that our volunteers know they cannot discriminate anyone (food bank and shelter services, rural, Polk County).

\section{Findings on Collaboration}

\section{Findings on Collaboration Related to Both Size and Urban / Rural}

Collaborating with the Arts and Culture Sector Helps. When asked about unique fundraising strategies, this study got overwhelming number of responses on examples of collaborations with nonprofits involved in arts and culture. Oregon has a high \%age of nonprofits in the arts and culture arena and most of these are small ones.

Funding for arts and culture is unfortunately a low priority amongst all entities, including government and private funders, and individual donors.

One thing by which foundation grantors judge us by is - who is your target audience? What are the concrete results you are looking for? How do we define our target audience, I mean we are devoted to maintaining the culture of this region and there's people who are interested in history, people who like to come to the museums, people who like to come to large music venues, people who want to do genealogy research in the area. It is not like our target audience are the underserved people of color in the community, you know. I think they look for something like that and we do not fall into that category, so it is interesting (historical society in rural Oregon).

Every kind of nonprofit work is as important as the next, and arts and culture nonprofits can enhance educational opportunities, provide therapy and contribute to health and human services and contribute equally to society like nonprofits that provide 
'direct services' whose benefits are usually visible and tangible (like housing, healthcare, youth camps, etc.). But in the end, the nonprofit that will successfully get more donations is the one who uses the right 'pitch' to the right audience and make an emotional connection with them.

And as many respondents pointed out, those skilled in the arts possess such unique talents. For example, one nonprofit organization in the study was a small philanthropic foundation and arts and culture hybrid that helps small nonprofits by giving them an opportunity to speak about their work in the middle of their choir performance, in some instances they have even done a small skit or performance to highlight the work of the other and make an emotional connection to the audience.

We coach our grantees how to emotionally connect to the audience. So tell people not just what you do but how every dollar makes an impact in the lives of people you serve. Make your audience feel involved with the project, not just give money but maybe volunteer with them. In the end, we must remember, it is all about the stories. As a nation, we have and will always like good showmen (urban foundation and community choir).

Another local nonprofit involved in 'environmental protection and cleaning' collaborated with one that taught painting and sculpture-making in local schools and through their art displays were able to get their work more visible to the community. Both organizations benefitted equally from the fundraiser. Others have marketed their work through colorful banners and creative ads made by those working with 'arts and culture' nonprofits in the local media which drew in anonymous donations from outside the community. This is potentially a win-win situation for both groups involved, the nonprofit not involved in arts and culture can devote their time to their work and not concentrate on putting up a performance while the arts and culture counterpart could 
avoid getting overlooked simply because donors often think they are not important

enough.

We have to constantly remind people and our donors and funders what the arts are to our society, how important they are and this is exemplified by the large number that we have in Oregon of performing organizations. We get overlooked when you are having to deal with real issues like healthcare. But when we showcase the work of nonprofits whose work is perceived to be more important, it helps both groups involved. The best example would be when we partnered with the [nonprofit focused on reducing domestic violence] and did a play "The Other Woman' which was about domestic violence, so a portion of our sales went towards that and we also hosted a talk on with a couple of their workers. It is hard yes, to make the time to make a collaboration work really well and both nonprofits have to be invested in the goal else it will fall apart. But, collaboration is a big buzzword. Funders want to see how you can create more by joining forces (urban theater and performance arts organization).

\section{Well Documented Processes and Ground Rules Contribute to the Success of}

Collaborations. There was a consensus among all respondents that boards that understood legal responsibilities and had taken time to draft rules, procedures, policies and processes for everything, no matter how minor, functioned more efficiently and also transitioned to new leaders better. They also performed better when engaged in collaborative projects.

Often members cannot figure out who did what and how much was the contribution of each individual member in a collaboration. Or they did not get credit for it. Usually one or two core people shoulder the responsibility completely even in the individual organization boards. In a collaboration this can become a divisive issue. Like some constituent nonprofits in a collaboration can be unincorporated volunteer councils so legally their name is not thereon any document and they kind of get lost in the background, despite all the hard work they put in. But if policies and processes are well documented within the individual organizations, it will be easier to make a template for a coalition from that so everyone who shoulders what and how much. The intent should be to make day to day decisions and claim responsibility for those decisions (environmental coalition in South Coastal Oregon). 


\section{Collaborations Work Only if Both Parties Understand What They Would}

Mutually Gain From the Process. This was clear in the fact that the only nonprofits

who actively seek youth to volunteer in this study sample were those who had established successful collaborations with educational institutions providing opportunities for service learning to their students. For many, this was a time-consuming process and the returns sometimes were not worth the time, especially when students came in just for a day or two to get the minimum college credit. Others had positive experiences with their wonderful student cohorts having gone on further in life to do the same work they did for the nonprofit.

Then there were others who said that they were always pressurized to collaborate because it was a big buzzword that foundations liked. In rural areas, there was pressure to collaborate because it was assumed that it would lessen work by coming up with joint solutions, shared spaces, shared resources (volunteers and money, etc.). In urban areas, with more nonprofits working in similar spheres, there was more competition than collaboration.

There are some in our rural community who think there are too many small nonprofits locally. One of those people is a Development Director for several of them and she experiences challenges asking for funds from so many of the same people. However, I've always stood for the idea that having more smaller ones is just fine. In fact the housing group I am part of split-off from the conservancy trust 10+ years ago because trying to both workforce housing and land conservation was too big of a mission for a small group to wrap its arms around. It is my contention that multiple small active groups (often pretty nonhierarchical) who really know the warts and wrinkles of the topic \& issues they're involved with is preferable to a fewer number of large, top-down, hard-to-manage large group with many missions. Especially since a small community makes communication easier (housing and shelter nonprofit, rural, Coastal Oregon) 
We have collaborated with some other groups to do fundraising. Different wildlife organizations like Audubon have invited us to do presentations in wildlife events they are putting in. But no intense collaboration or anything related to our programs, it is mostly we all kind of gathered in the same place. Frankly most of the nonprofits here in this area are competing for money, not collaborating (animal welfare with multiple chapters in Oregon).

\section{Despite Not Being Always Successful at Collaborations, Small Nonprofits}

Would Like to Network and Learn from Each Other. A majority of respondents would like to have a platform to share ideas or to get ideas from others through networking. They are more than happy to share what they know with others, and equally interested in wanting to learn from others too. They understand that even though their impact can be beyond their immediate community, at heart they also exist to serve their local communities. Hence they are willing to learn from other communities and apply the strategies in their local communities.

In general, nonprofits have distinct challenges because of small size or urban rural distinction (or both) whether it is in finance, boards and leadership, volunteers, ability to draw resources and not stray from their missions and in being successful at collaborations. They would definitely help and assistance in learning strategies to overcome these challenges and also share their positive experiences with others. As one volunteer manager and Treasurer in Southern Oregon who has had experiences working in both urban and rural regions, very eloquently summed it up.

Our services and impact is across many areas but our location is rural. We don't have that kind of manpower, we can't draw on diverse populations like those in big cities or even those on the coast who draw in diverse crowds. Large urban nonprofits have about 100 volunteers and some paid staff. We don't have enough of a population to draw volunteers, we don't have a large donor pool either. And 
we have a large impact area, we use our own cars or vehicles to do pickups, rescues, etc. so physical logistics plus the fact that we don't have a large donor pool make it very hard. We have collaborated with some other groups to do fundraising. But, frankly most of the nonprofits here in this area are competing for money, not collaborating. We try to reach out to different parts of the country and we have got followers all over the world. It has helped in increasing donations, but our core donor base is still in this area. So while we would like to know what others are doing, we also want to know how to adapt the strategies in our own communities (search and rescue group in Southern Oregon)

Now that I have described all the themes, I will delve into a discussion highlighting how the findings contribute to current literature and implications for future studies.

\section{Discussion on financial capacity}

In general findings on financial capacity resonated more with the foundation perspective than the governmental one. The foundation perspective views grants as a counteractive force to declining individual donations and in recent times, might also act as a buffer to the ripple down effect most respondents talked about because of declining government money to large nonprofits. Respondents wanted foundations to have special grants only for small nonprofits and expressed the desire to be asked more about their outcomes and inspiring stories and not just numbers and outputs. This suggests the potential for more 'capacity grants', 'structured programs' and 'collaboration with a capacity development partner' for small nonprofits, in line with Blumenthal's model of capacity building.

Financial capital drives a nonprofit to achieve better financial stability, and more cash flow and revenue from diverse sources. Financial capital is important both from a resource dependency perspective and an institutional perspective - nonprofits need 
money to run and staff their programs, and achieving financial stability and a large resource of funders is a measure of legitimacy (Froelich, 1999).

Nonprofits acquire revenue from many sources - individual donors, corporate donors, foundation grants, government grants / contracts, sales of tickets or membership and sometimes they might operate a business enterprise to generate revenue (e.g. a nonprofit museum running a restaurant in its premises). Small nonprofits rely more on individual donations than on the government; many respondents said they had no government grants at all. Considering many of them have little or no emergency cash reserves, they rely more on trust and individual donations to keep them running. Respondents in this study agreed with Hall, et al, (2003)'s claim that individual donations are often preferred by nonprofits as they provide core funding rather than project funding which is aimed more at specific programs and activities and cannot be used towards administrative or operating costs. They did request that foundations make an exemption for small nonprofits and allocate some grants that were similarly unrestricted and allowed them to build emergency cash reserves or give in-kind monetary support like hearing aids and walking canes to their senior volunteers.

Government funding is dwindling in the arts and culture arena forcing nonprofits in this sector to compete with hospitals and social service programs. This is not a new problem, in fact the literature states that historically this has always been the case. (Harvey, 1999). Since the current federal administration is majorly pulling off funding for many nonprofit related causes like arts and culture, human services like maternal health and abortion services, planned parenthood, environmental conservation, etc. nonprofits 
are worried about the 'ripple down' effect. This time it is not reliance on corporate grants, foundation grants or government grants that might cause goal displacement as the literature suggests, but competition from bigger nonprofits who lose their regular government funding and start competing with smaller nonprofits for the individual donations. This also hints at the possibility for further studies confirming whether freezing of government grants to large nonprofits translates to a ripple down effect on small ones.

Revenue diversification i.e. having less than $50 \%$ of revenue coming from one source to be classified as 'not dependable on one source' is a big strength for capacity building; so is revenue stability (Carroll \& Stater, 2008). However, as noticed in the study, small nonprofits have a high individual donation to grant money ratio and it makes sense for them to have more than $50 \%$ of their money to come from individual donations. For one thing, they are short on staff who can focus exclusively on finances and budgeting. Like Hall, et al, (2003) suggest, small and mid-size nonprofits in this study said they struggle because they often lack human capacity to pursue alternate sources of revenue or have staff skilled in financial management.

Hiring a grant writer, even on a part time basis who could focus only on getting the right grants seems to be the preferred way to increase in budget size and also bring in financial stability. Grant writing is time consuming and requires skilled staff / volunteers and board members that have special connections to the community (for individual donations) as well as corporations and foundations that provide grants. All respondents in this study whose operating budgets have grown said one of the reasons it did was because 
they got a professional grant writer who applied for the right grants and was able to synchronize information about their programs and services to what the funders were looking for.

Some small nonprofits have ventured into getting income from commercial ventures. On the plus side, it got them visibility and not just another source of income. But those who drifted from their social missions to making profits from their gift shops lost trust and credibility till they had change in leadership who outlawed the old practices. Even those who are thinking of venturing into it in future want the business to be aligning with their social mission. Commercial income therefore was viewed more of a means to gain visibility and trust and not just money.

The portfolio theory argues that nonprofits aim for diverse revenue streams while the normative theory postulated by Young (2007) suggests that nonprofits tailor their revenue structures to the groups they serve. They can choose to rely on philanthropy alone or pursue endowment income and commercial income if they produce goods that provide private benefits and group benefits (have ticket sales or membership dues etc.) or pursue government income if they largely produce collective goods that are not provided by private enterprises. Many of those wishing to pursue commercial income or sales from gift shops in my study sample were organizations that provide indirect services like arts and culture and environmental preservation. Such services can accrue both private benefits (listening to a recital) or group benefits (lessening air pollution benefits a whole community). As such organizations operating in such sectors, in accordance with the 
normative theory, were interested in pursuing income from other sources other than individual, corporate or government donations.

Better financial capacity can translate to provision of training programs for volunteers or board members in book-keeping and financial management skills. (Hall et al, 2003, p. 26). Respondents said their board members needed training on pursuing their friends to donate money, they also wanted to learn about financial rules and guidelines for budgets and taxes. This is also supported by Miller, Kruger and Gauss (1994) that small nonprofits struggle to find board members that are competent in raising money because they do have access to networks of big donors or are uncomfortable asking close friends or acquaintances to donate.

\section{Discussion about HR Capacity}

Respondents concurred with the literature that volunteers are less likely to engage in leadership roles like Doherty, Misener and Kuskelly (2014) postulated. The inability of small nonprofits to provide for compensation and few opportunities for career advancement can hamper retention of skilled board members that pitch in as volunteers when competition from larger firms with less 'flat' organizational structures provide more options for promotion. Having an organizational structure where board member also pitches in as a volunteer makes the staff prioritize the work involved with nonprofit's services and programs over legal responsibilities and due attention to policies and processes or monitoring the nonprofit's overall mission / vision, budgets and the management. 
Active board members who communicate their organization's mission to the right stakeholders, understand the organization's financial statements and regularly monitor whether the organization is achieving its mission or not can contribute more to the nonprofits human capacity than board members who are there for seeking status and not really contributing to the organization (Hall, et al, p. 35). In small nonprofits, as one respondent pointed out people are often not willing to take on these additional responsibilities and quite content to pitch in responsibilities as a volunteer but not as a board member.

Like Booz, Allen and Hamilton (2002) found out, small nonprofits across America find it difficult to get qualified people to serve on their boards. Too much turnover affects organizational culture and continuity while too little turnover makes the organization run out on fresh talent and ideas. This study found that board members usually continue to serve on small nonprofits on an indefinite basis as many small nonprofits do not have term limits. Usually if board members left, it was because they relocated. Nonprofits who had a recent change in leadership said that this made the transition difficult. One nonprofit leader recounted an instance where a new policy was met with stiff resistance by members who wanted things done the old way and left. There were, however, other stories of how change was finally accepted. In general, most respondents said they would have liked to have term limits but found it hard to implement those due to a limited resource pool of people willing to work as board members.

The question of accountability and checks and balances faced some unique difficulties in small nonprofits. Usually as the principal agent theory states, the boards of 
nonprofits monitor those who administer and function with the agency's programs. Because in small nonprofits, often the boards and managers are the same people, it is difficult to have a checks and balances system where the board monitors the activities of the managers and the managers must be accountable to the board.

I also noticed that many small nonprofits in this study were family-based and spoke about not wanting to probe deeply for answers or ask tough questions to avoid personal conflicts. Those who are not family-based organizations expressed the need for board members to ask questions, then take off their board member caps and find the answers as workers / managers / volunteers. They need to distinguish between the roles and responsibilities of both positions in an unbiased, non-partisan way. This could be a good topic for training sessions and studying cases for building theories.

The Lucas and Connolly model postulates that nonprofits erroneously focus their capacity building efforts on strengthening technical and management capacities, even though the need for adaptive and leadership capacity building is greater. I found similar evidence in my study of small Oregon nonprofits. They talked about struggling to changes in the external and internal environment and leadership issues. Many small nonprofits had strong technical capacities to develop, support and deliver programs and services. They had a strong pool of worker bees ready to work, provide wisdom and can be taught to raise money (thus contributing to the $3 \mathrm{Ws}$ ). But many have struggled to bring diverse voices to their workforce (an adaptive change required to be in tune with changes in the external environment and community served) or transitioning to new leadership (abandoning old practices that change the internal environment). Despite that, 
most respondents felt it was important to focus their capacity building efforts on strengthening technical and management capacities, even though the need for adaptive and leadership capacity building is greater.

Unlike board members, volunteers have no term limits. Respondents in the study favored long term volunteers just like they favored long term board members. However, they faced challenges when recruiting a diverse HR force, both in their boards and volunteer force. Most nonprofits have predominantly white staff and would like to know how to include people from other cultures, races and ethnicities. Many said that having less diversity also impeded their ability to get across to serving diverse populations in their community. This also hindered them from getting more grants as foundations often put up criteria for diversity in recipients. Lesser diversity in the HR arena thus also affected financial capacity which agrees with the findings by Daily (1995). But for small organizations in rural Oregon where the base population is less diverse than in urban counties, it is tough to have diversity in boards and volunteers. Those who have an active parent group or sister organizations across multiple counties with whom they regularly attend trainings or conferences or share strategies got better access to diversity training and education on civil rights and were more effective in reaching out to the diverse populations within the communities they serve.

When it comes to age though, nonprofits do not necessarily want a diverse workforce; they prefer the old and retired rather than youth and school kids. Traditional forms of association like working for small community-based organizations are higher in rural settings in America because of higher participation from the elderly as well as 
children who have lesser opportunities for alternate leisure activities as in urban areas and because the youth feel socially excluded and challenging to maintain their individualities in communities dominated by the elderly (Schucksmith, 2004; Torgerson \& Edwards, 2013). In this study, respondents in rural areas felt they had high participation from the elderly but not youth and children. Schools gave children too much work to keep them busy and away from drugs; additionally, not many children and youth volunteered for more than a semester or so and usually left if they found a paid job.

Urban nonprofits reported a younger workforce between 30- 50 years of age, many of whom were not retired. Burnout and stress managing an unpaid job beyond their regular paid jobs were, however, big concerns among their founders.

In general, the study found that there is a deficit between demand and supply of human resources with small nonprofits in both urban and rural areas. The demand for services is always more than what can be supplied. However, in urban areas, this is because there is more diversity and hence more demand for nonprofit services and in rural areas, it is because the supply of human resources is less than what is needed. Urban areas struggled because they had to serve more diverse populations and despite their best efforts to recruit diverse, knowledgeable people, the demand for their services was higher than what they could provide. Those in urban areas did not have as much access to the retired populations who could contribute to work on the regular workday. Hence, despite heavy demand for their services, they have had to turn clients away or scale back their programs (e.g. providing them only on the weekends). 
Rural areas and suburbs had better access to retired populations who could contribute on the regular weekday; however, health issues and lesser number of people available for work means they were constrained on the supply side. There was a limited pool of people to draw on board members and volunteers and often nonprofits had to compete with other nonprofits operating in a different sector to get the same workforce. Hence an animal shelter that required volunteers to have some knowledge of biology and animal triage had to compete with a food bank that was drawing from the same pool of volunteers and needed less specialized workforce. Even if the job required those with specialist knowledge, rural nonprofits could not attract people with those skills as their urban counterparts. They thus spent more time, at least 6 months to train and prepare their volunteer force and thus were also more likely to take more steps to retain the workforce, like matching jobs with interest and passions rather than skillsets to keep their workforce happy. They also tried to avoid conflicts in the workforce, especially between volunteers and board as led to complex situations as everybody in the community knew each other.

\section{Discussion on Collaborations}

Collaborations have been largely successful when arts and culture agencies partnered with those providing direct human services. Here both groups capitalized on the talents of the other - the arts and culture group gave more visibility to the other group and made emotional pitches to getting money while the partnering group provided the same legitimacy to the arts group that nonprofits who provide direct services possess. It is thus possible for collaborations to be within organizations who do not run similar programs but 
have a goal of helping the other partners in the alliance while gaining something themselves The solution to a problem should not focus on the needs and interests of a single institution but also on the interdependencies that exist among the various stakeholders all of whom claim a right to influencing the outcome (Trist, 1983).

However, if the collaborations is within similar spheres, it is necessary for participating groups to feel the need to collaborate i.e. that the problems they are facing is beyond the scope of their organization to tackle alone (Gray, 1985), they trust the other members (Bryson, Crosby \& Stone, 2006) and that changes in culture and practices will shape the institutional environment such that it will not be a zero sum game where some win and some lose (Longoria, 2005). Hence smaller nonprofits serving unincorporated communities should not get lost in the alliance but get a legitimate equal voice in the process while bigger nonprofits with hierarchical structures should set aside those tiers and focus on outcomes and services (Milbourne, 2005) to be successful.

As mentioned in Chapter 4, midway through the study I had revised my definitions of urban and rural. Since collaborations were often being mentioned as a strategy to overcome challenges, at this stage I looked into literature for urban rural alliances. However, this study did not see any instances of positive prospects for the same. Institutional environments hugely affect the external environments in which collaborations work and many small nonprofits, as evident in this study, did not feel ready to traverse the distances across the rural urban spectrum to take a chance at functioning within such new environments. That said, rural areas are having to face more challenges related to diversity 
like urban areas do and urban areas are looking to the country more for their vacations, agriculture and food gleaning practices and being close to environment and nature.

An exchange of ideas along the rural urban spectrum has great potential to make small nonprofits overcome capacity deficits that arise specifically because of the nature of the region they are located and communities they impact. So, while most nonprofits are not that enthusiastic about getting into solid coalitions across various regions of the state with well documented policies and processes, they are definitely up for participating in platforms for networking, educational webinars and training sessions that disseminate ideas across different places. Nonprofits could learn strategies and tactics from organizations in different communities and adapt practices to their local area from such informal networks and alliances.

In this chapter I detailed findings on financial capacity, HR capacity and collaborations and how they differ in nonprofits based on size and urban-rural-ness. In the next chapter, I will use these findings to arrive at answers to the primary questions that drove this study. I will also discuss the implications of these findings for nonprofit leaders, capacity builders and trainers and academicians thus highlighting the contributions of this research to theory and practice. 


\section{Chapter 6: Discussion and Implications}

In this chapter, I answer first and foremost the two primary questions that were the aim behind this study. I also look into the latest Oregon state sector report released after my research was conducted and before this study was published and check if concurrent findings substantiate my research or differ significantly. Thereafter, I lay down limitations of the study, and recommendations for future research. Finally, I talk about the implications of the findings for capacity builders, trainers and other entities whose aim is to help with capacity building initiatives in the third sector. The implications talk not only about what are the strengths and what is lacking among small nonprofits but also provide suggestions on how to utilize their capacity potential to the fullest by minimizing their deficits and exploiting their current assets.

\section{Answering Research Question 1.1: What Core Capacities, Knowledge and Skills Small Urban and Rural Nonprofits in Oregon Currently Possess?}

In general, all nonprofits, whether urban or rural believe to overcome the deficit that exists in the lives of the participants they serve. Those who provide human services wish to make the lives of their clients better; those in arts, research, advocacy or environmental activities that may not have a direct human service component aim to better the quality of life in their communities in general. And to do this, they are willing to work long hours without pay to make a difference.

Most board members are those who possess one or more of the $3 \mathrm{~W}$ 's - work, wisdom and wealth. They can pitch in like worker bees and engage with providing 
programs and services, they can contribute donations and ask others to do so, they can educate the community on the work they are doing, and so on.

Loyalty was something most small nonprofits swore by when asked about inspirational stories. Most of the board members have stayed for life and so have volunteers. Hence many of their workforce have become competent at their activities. The challenge has been mostly in learning new skills. However, most nonprofits even those who found resistance to change eventually managed to overcome those and have embraced the new rules and learnt new skills.

Even with low budgets and reserves, small nonprofits have learnt to make the most of what they have. Nonprofits in Oregon have visibility and history and many have capitalized on unique events in their communities, tourist brochures and collaborating with arts and culture organizations to showcase their work and generate money. They know of unique strategies to get individual donations like a human services organization collaborating with a theater company to showcase their work so that both organizations can show of their talents and generate revenue or have developed fundraising styles like a chain or a spider-web to aid in their fundraising efforts. They are aware that grant makers cannot ask questions they want them to but know that good grant writers can slip in the information in the application and tailor their application to what the grantor wants.

Overall, nonprofits in this study resonated more with the foundation and nonprofit perspective theories rather than the government perspective that believes that nonprofits create public value where the government is restricted. This was not surprising because smaller nonprofits often are not the recipients of government grants. Like their bigger 
counterparts, small nonprofits faced challenges in adaptive and leadership capability with many leaders pointing out how worried they were about the direction their organization would take once they retired or how they were unable to bring diverse voices to the board that would be a representation of their community. Despite this when asked about what tools or help they required, they often asked for assistance with management capacity or imparting useful financial and technical skills amongst their workers. Among the six different functions that capacity building initiatives help with as per the Light model, small nonprofits have learnt strategies to increase resources, achieve better quality and productivity and achieve efficiency. They are still struggling to prevent disaster or build an emergency fund and building an effective way to measure outcomes and performance. This also agreed with Golmar's (2008) findings that small organizations lack the capacity to develop effective performance management systems and save for a rainy day.

Despite this, all small nonprofits are eager to learn. Even those in far flung areas are willing to attend webinars and video conferencing options and are willing to share whatever they know. The fact that some respondents were not aware of all the webinars and capacity building initiatives in Oregon like those by the NAO shows there is great potential in this arena.

\section{Answering Research Question 1.2: Areas of Capacity Deficit and How Capacity Builders and Policy Makers Can Customize Capacity Building Initiatives for Small Urban and Rural Nonprofits}

While board members are comfortable providing work and wisdom, contributing to wealth, especially asking friends and acquaintances for money is something they are 
not comfortable with. Many do not possess enough financial skills to understand the budgets, revenues and costs of the organization. Not all organizations can hire a professional grant writer and need to learn grant writing skills, including finding the right grants to apply to, writing a good application where they can slip in all the good work they are doing that may not be necessarily asked in the questions, and finally proposing changes to current processes so that they are eligible for more grants. Training programs that can impart important financial, grant writing and fundraising skills to the workforce, especially the board members are very much needed in both urban and rural areas.

Organizations need to be trained in having well documented processes and it would help to provide them with templates and case studies related to the same. Diversity training is also required in both urban and rural areas because nonprofits are struggling to make their boards a mirror of the community they serve. Barriers that exist within minority populations cannot emerge because they may not have a representative of the population on the board who can provide input on organization policy and programs that can serve these communities better. And many communities are struggling from lack pf participation from underserved groups. They need to get access to diversity training or have access to a platform where they can share their strategies from other organizations. Currently there is a lot of focus on improving management and technical capacity in nonprofits, programs that increase adaptive capacity so that nonprofits can adapt to the external environment (like dealing with more diverse communities) are needed.

Finally, nonprofit workers must learn to balance both board member and volunteer duties, they need to learn strategies on how to keep a check and balance on 
both roles. This might be possible through rotating volunteer or board member duties or teaching board members how to critique their own work when working as a volunteer.

In general, the study found that there is a deficit between demand and supply of human resources with small nonprofits in both urban and rural areas. The demand for services is always more than what can be supplied. However, in urban areas, this is because there is more diversity and hence more demand for nonprofit services and in rural areas, it is because the supply of human resources is less than what is needed.

Urban areas struggled because they had to serve more diverse populations and despite their best efforts to recruit diverse, knowledgeable people, the demand for their services was higher than what they can provide. Those in urban areas did not have as much access to the retired populations who can contribute to work on the regular workday. Hence, despite heavy demand for their services, they have had to turn clients away or scale back their programs (e.g. providing them only on the weekends). There was also the question of burnout and stress with younger board members and volunteers trying to juggle work, family and nonprofit duties together.

For urban areas, therefore the capacity building initiatives must aim at recruiting more people. The size of the boards and volunteer force must be in accordance with the size of communities served. It will thus help them to teach nonprofits how to do a needs assessment survey of what are the kinds of people they want on their human resources and how to attract the right people with the right skills.

Rural areas and suburbs have better access to retired populations who can contribute on the regular weekday; however health issues and lesser number of people 
available for work means they were constrained on the supply side. There was a limited pool of people to draw on board members and volunteers and often nonprofits had to compete with other nonprofits operating in a different sector to get the same workforce. Even if the job requires those with specialist knowledge, rural nonprofits could not attract people with those skills as their urban counterparts. They thus spent more time, at least 6 months to train and prepare their volunteer force and thus were also more likely to take more steps to retain the workforce, like matching jobs with interest and passions rather than skillsets to keep their workforce happy.

Rather than having a needs assessment survey to determine what kind of people they should recruit, rural nonprofits should assess what kinds of skills they currently possess and do not possess and how to impart the skills not possessed through effective training programs. They also need to know more on retention and motivation strategies and learn if there are special activities, workplace processes that can keep their trained workforce to stay with them and not be tempted to volunteer with a different nonprofit every year. Providing donations for supplying hearing aids, walking canes or other health services for the elderly can also lead to increased participation in rural communities and overcome the HR deficit.

When it comes to bettering financial capacity, nonprofits need to learn strategies to showcase their history and visibility to the donor base. Not all nonprofit workers are good performers, hence collaborating with arts and culture organizations would be a big help. Even joint collaborating with different sectoral nonprofits to fundraise e.g. having a scavenger hunt across the community that exposes the participants to works of the 
different local nonprofits so they can donate a fixed sum to the collaboration (that is distributed equally to all participating nonprofits) rather than donating it to different organizations every year so they compete more and collaborate less with each other.

Grant makers can also contribute to donate money that not only help in core program activities but also contribute to liquid cash reserves. An example could be setting up a competition for the most unique fundraising event and providing the winner with money that goes directly to cash reserves (must be in a savings account for some time or so). They can also help nonprofits provide some basic health services to its volunteers like health screenings, annual checkups or devices that help the elderly. Such in-kind payment can increase the participation rates in both urban and rural communities. Finally, many small nonprofits are not aware of webinars and online education opportunities that are available from outside of their community or find it too expensive to join such platforms. It would be helpful to give special rates or discounts to smaller nonprofits or have a sliding scale fee to avail of such services.

It is also noteworthy that this study was conducted at a time when overall there has been a decrease in funding and resources available to the nonprofit sector in general. As big budget nonprofits will try to find alternatives for government funds they had in the past, they will increasingly turn to individual donors and corporate grants and foundations to compensate. Small nonprofits will have to face this competition. They need to appeal to their donor bases more, write in better grant applications, and hire and train people with the right skills to keep their programs running. It is imperative that capacity builders and theorists focus on small nonprofits and design programs and 
theories that serve this group separately from their big budget counterparts. As one respondent very eloquently put it

"Now more than ever, it is the right time to focus on small nonprofits."

\section{The 2020 Oregon Nonprofit Sector Report - Do the Latest Findings Substantiate This Study?}

The first Oregon Nonprofit Sector Report came out in 2012 where the author served as the Chief Data Analyst. The second ONSR asked a smaller number of questions and the findings came out around the same time while this research was in the field. Third report which came out in March 2020 asked similar questions as ONSR 2.0; NAO also provided tables and data in Tableau on their website. The charts and figures in the written report classify all nonprofits by budget size into seven categories - Under $\$ 150 \mathrm{~K}$, \$150-499K, \$500-999K, \$1-1.9 million, \$2-4.9 million, \$5-9.9 million and above \$10 million. The Tableau tables on the website however, dis-aggregate the data further and numbers for smaller nonprofits are available for 'under 30k, 25-50k, 50-150k, 150-250k, and $250-500 \mathrm{k}$.

Compared to previous reports, larger organizations comprised just over half of the sample (earlier samples had as high numbers above 75\%). While I could not confirm if the researchers made any special efforts to recruit more small organizations, there was some consensus during the webinar presentation that smaller organizations had participated in larger numbers and this was seen positively by practitioners that their outreach efforts to make more small organizations join networks like the NAO were being successful. 


\section{Table 6.1}

Comparing Study Respondents to ONSR 3 Respondents

\begin{tabular}{lccc}
\hline \multicolumn{2}{c}{ Study } & \multicolumn{2}{c}{ ONSR 3.0 } \\
\hline Budget Size $^{\mathrm{a}}$ & Number & Budget Size $^{\mathrm{a}}$ & Number \\
\hline Below 50K & $39(42 \%)$ & Below 50K & Below 30k (32)+30- \\
& & & $50 \mathrm{k}(14)=46(19 \%)$ \\
$50-100 \mathrm{~K}$ & $22(24 \%)$ & $50-150 \mathrm{~K}$ & $22(9 \%)$ \\
$100-250 \mathrm{~K}$ & $19(20 \%)$ & $150-250 \mathrm{~K}$ & $20(8 \%)$ \\
$250-500 \mathrm{~K}$ & $13(14 \%)$ & $250-500 \mathrm{~K}$ & $40(16 \%)$ \\
More than & - & More than & $120(48 \%)$ \\
$500 \mathrm{~K}$ & & $500 \mathrm{~K}$ & \\
\hline
\end{tabular}

a The budget size for the study was an average of 2009-2015 figures while the 2020 ONSR used 2017 figures

However, many findings in this study are synonymous with the results of this study:

a) There was more participation from rural organizations in proportion to the number of organizations in the general population i.e. Oregon state.

b) NAO usually conducts the studies in summer or early Jan when arts and culture organizations are more readily available for interviews. This plus the fact that Oregon has a high number of arts and culture nonprofits contributed to the arts and culture organizations in their top category (17\%) just like this doctoral study.

c) The study found that levels of collaboration had not changed since the first and second ONSR studies. the last five years. However, they also got "overwhelming responses for opportunities to meet (conferences, convenings, 
trainings, etc.) and just building trusting relationships and networks over time" (p 3-4).

d) The study found that " $46 \%$ of nonprofits believe they have the right capacity to achieve their current plans" ( $p$ 4). While comparing mean scores of capacity in the Tableau data, no significant differences were seen either by size, subsector or urban / rural distinction.

e) ONSR 3.0 reports that "rural organizations are slow to respond to the changing demographics as communities of color grow in rural communities across Oregon. 90\% of rural nonprofits have no equity lens" (p 5)

ONSR 3.0 concludes with calling for an "increased attention to succession planning, equity and inclusion work, and deeper collaboration", which agree with what this study found out as well. The State Sector report concluded this by deriving mean scores across statements related to capacity (both financial and boards), collaboration and equity and diversity initiatives. This doctoral research adds to those findings by giving specific examples and suggestions on those topics. By comparing the latest sector reports thus, the author of this dissertation can modestly claim for the validity of this work as well as claim that it attained the academic and practical significance it had set out to do so in the first place (as laid in Chapter 1).

\section{Limitations of this Study}

As with any qualitative study that involves interviews and focus groups, this research has limitations of personal bias, halo effect and influence of a former candidate on subsequent interviews. The interview process was semi- structured so I could probe 
and prompt if needed and also because this was an inductive, emergent design; this also reduces the reliability that is associated with a structured questionnaire. Also, all interviews and focus groups were conducted via telephone which made it impossible to capture non-verbal cues, body language and emotions. I allowed for ice breakers in the beginning of every conversation to make the participants comfortable, made sure interviewees had time to review the questions sent by email beforehand and that there were minimal disruptions, from my side at least during the interview. Still, it was not possible for me to know if some respondents were uncomfortable with the questions and chose not to tell me or that they gave socially desirable responses in such instances.

With an inductive / emergent study approach for certain topics, the research process started before I had some knowledge of the literature or had information that did not fully explain what I found in the field. One case in point was the definition of urban and rural for which I had used traditional classification methods but realized on probing my interviewees that current methods needed to be refined. Collaboration was another topic. This study was primarily designed to explore dimensions of financial and human resource capacity based on assumptions of Resource Dependency Theory and Strategic Management Theory. I was not specifically looking at collaborations across regions but exploring the possibilities of learning from similar organizations, exchanging ideas and unique strategies and stories of resilience across Oregon all for the purpose of providing training materials to foundations and capacity builders. My aim was to analyze any capacity deficits and explore possibilities to reduce the same. However, collaborations were mentioned so frequently by respondents that I delved into the literature later to 
corroborate my findings. Had I planned on tackling this topic earlier, I would have added more specific questions related to collaborations and got better data to analyze for the possibilities of alliances that bridge the urban rural divide or helps small nonprofits work successfully with bigger ones.

Though I chose a stratified random sample to draw my list of emails to include proportional representation across size, urban rural distinction, subsector / NTEE classification, there were over representations of certain groups. Because most interviews were done in February and March, I got many responses from arts and culture organizations whose staff were available for interviews at a time when there were no holidays or important festivals going on that required them to attend intensive practice or performance sessions. In fact, organizations that provide direct human services were not as readily available as those who provide indirect services like animal welfare, environmental groups or arts and culture organizations. There were no health services related organizations apart from a small teen pregnancy clinic in my study sample, primarily because most of them are in the big budget range.

There is a time lag of about two years from when organizations file tax statements that provide information on their revenues, expenses and budget size. Hence some organizations above the $\$ 500,000$ budget also took the survey but they were not considered for the interviews. The traditional methods of classifying urban and rural leads to more rural organizations getting urban status if they are close to an urban area even though their impact may be limited to rural regions only. For all of these reasons, stratification of the sample was not as optimal as desired. 


\section{Scope for Further Research}

This study assumed that the two most important resources to run any nonprofit are money and resources. Even though capacities in this domain influence other dimensions of capacity like mission and vision, outcomes, leadership, etc. those domains could be explored in greater detail. For instance, this study found that nonprofits need capacity building initiatives to improve their adaptive capacity to change with internal and external environments. This would mean adapting to increasing diversity in the communities served or transitioning into new leaderships or processes. There is the possibility of exploring how smaller organizations, both urban and rural can harvest capacity building initiatives that increase adaptive capacity.

Another subject worthwhile exploring would be inter-sectoral collaboration with the arts. Respondents in this study had been very successful in such alliances where the arts and culture group got legitimacy through the coalition while showcasing visibility and emotional appeal of the other nonprofit's work to prospective donors. Collaborations thus need not be restricted to organizations with similar policy spheres. It would also be worth exploring if nonprofits that provide other indirect services could form alliances with those that provide direct human services and what factors would hinder or help such collaborations.

Currently nonprofits are defined as urban and rural based on their location and proximity to an urban area. However, some nonprofits are facility and destination based, have their impact limited to only rural areas despite adjacency to an urban area or have multiple chapters across the urban rural continuum. While I have suggested a 
methodology in this study to help with urban rural classifications for nonprofits, it might be worthwhile to explore whether the degree of ruralness or urbanness could be measured on numerical ordinal scale, based on different factors and criteria. Also by using the methodology suggested, it may be possible to get some estimates of how much overestimation of urbanness occurs while using the current traditional systems - this can give values for variances that can help researchers determine how their samples differ from the main population.

Small nonprofits may be family-based organizations. Another potential research worth exploring would be how the findings on different aspects of capacity building differ across small family based and non-family based settings.

Finally, this research presented challenges that small nonprofits face like the checks and balances problem, the ripple down effect and so on but did not delve into possible solutions to solve those problems. Tackling case studies or brainstorming ideas to new and unique problems for small nonprofits would be another worthwhile contribution to third sector research.

\section{Implications of the Study - How it Contributes to Theory and Practice and}

\section{Suggestions for Academics and Practitioners}

\section{How to Define Urban and Rural for Nonprofits}

This study found out the limitations of current urban and rural definitions in their applicability to nonprofit organizations. Rural places have been defined by communities, while urban areas by the characteristics of their neighborhoods (Logan, 2003). What is more important are the quality of interactions within the community or neighborhood 
because that contributes to social capital. And as I have pointed before, the demand and supply of nonprofits depends not only on the economy (where diversity and population demographics play a role) but also on the presence of social capital.

This study found that different interactions lead to different factors being considered by nonprofits in determining whether they want to be classified as urban or rural. Geography and population size were the factors that were given by organizations who classified themselves as urban. Those who classified themselves as rural did so because of one or more of three reasons related to population sizes, distance away from large urban areas, and presence of agriculture and timberlands. Then there were nonprofits located in a rural area and their impact spread over to the urban area, they classified themselves as urban because 1) many of their community members spent a lot of time commuting to the urban area for work, reducing their availability for nonprofit volunteer work. As such they described themselves as facing the same challenges like an urban nonprofit because rural areas have a better access to retired or local populations to supply volunteers 2) they drew in tourists and donors during summer or tourist-friendly seasons from the urban area nearby and as such their visibility was prominent within the urban area. Thus, their strengths also lay in the fact that they were close to an urban area. The above three kinds of nonprofit organizations confirmed to the traditional definitions of urban and rural as given in the literature.

But there were others who deviated from the norm. There were nonprofits whose impact extended beyond their immediate town into the adjoining urban area; however, they still classified themselves as rural. If their work was facility and destination based, 
such kind of interactions meant their impact very rarely got into the adjacent urban area, even if they were close. Finally, those with multiple locations or locations across both urban and rural areas usually chose one location as the center point, making it the primary administration and decision-making channel. These organizations had multiple chapters across the state and said that in difficult times, they closed some of the chapters that had difficulty finding enough volunteers. The chapter most likely to stay open in tough times determined whether the organization was urban or rural.

There is no database at either the national or state or local level which provides details on these unique kinds of interactions for every nonprofit. Hence when working with secondary data or research that only involves working with such datasets, the best alternative still would be to adhere to the traditional definitions. However, if the project involves interaction with nonprofit organization, it is recommended that the methodology proposed in this study under Table 4.5 be used for classification purposes.

\section{Size and Urban-Rural-ness Should Not Be Considered Synonymous}

Past studies and reports have addressed small and rural in the same vein. Analysis of the data in Oregon does confirm that large organizations are more likely to be found in urban settings. This however does not mean that rural organizations should be equated to small ones or that urban and large are synonymous with each other. Both size and degree of urban-rural-ness present unique as well as overlapping challenges and strengths to organizations. Hence, I do not call for dividing the field in a four-part square with bigurban, big-rural, small-urban and small-rural as quadrants. As my research shows, there are challenges to being small (e.g. having the same folks as board members and 
volunteers) that apply to all small nonprofits irrespective of being urban or rural.

Similarly, there are strengths to being in an urban area (having access to larger pool of money) that can be reaped by all organizations irrespective of size. As such challenges and strategies can overlap. The key is not to equate small with rural or big with urban. Large rural organizations may need similar strategies to survive as their smaller counterparts.

\section{Organizations Providing Human Services Can Collaborate with Those Who Do Not}

One of the common impediments to effective collaborations, as stated by nonprofits in the Oregon state reports before was that there were no other organizations doing the same work they did, thus making it impossible to strategically combine resources. Even in urban areas where this is less of a challenge than in rural areas, differences in size, power and the fear that competition would outdo collaboration leads small nonprofits to shy away from such alliances. This study saw evidence that such challenges can be overcome if the organizations are not competing in the same arena, in fact this allowed them to draw on the strengths of the other. Arts and culture organizations especially, can prove to be very useful. They can not only showcase the work of the other organization and give them prominence and visibility but also increase their legitimacy by aligning with programs that are considered less elitist. It has not been rare for nonprofits to set up their own foundations to fundraise for their organization specifically. I would also recommend that nonprofits who do not have the capacity to do so can alternatively align with an arts / performing organization to fundraise for them on some occasions. On the same note, arts organizations should consider showcasing and 
fundraising for other nonprofits as a unique opportunity (or an effective PR technique) to raise money for themselves as well and position themselves as stronger, visible players in the third sector.

\section{The Case for Detailed Qualitative or Ethnographic Studies for Small Nonprofits}

Small, rural nonprofits have been under- represented in data routinely collected about nonprofits which means the literature overrepresents large nonprofits in strategies to address capacity issues. Ironically, this can also pose a capacity challenge to those who are helping or studying nonprofits. Capacity builders, foundations and trainers, academic scholars themselves may not have adequate capacity to evaluate smaller organizations on a one-on-one basis or provide customized solutions to the challenges arising there.

Qualitative studies are more expensive and time consuming. Conducting, transcribing and decoding 30 interviews requires more resources than analyzing a larger database of quantitative responses. However, quantitative surveys often pave the way for an one-size-fits-all solution or a mass training session. There are benefits to group seminars and training and so these should not be dismissed altogether. A pragmatic solution should be to have a base questionnaire evaluating the organization that can be adapted on a case-by-case basis and solutions customized based on the same. Another way forward would be to have quantitative surveys to get a general overview of the sector and following up with qualitative studies focusing on different issues from time to time. That coupled with group networking and brainstorming should pave the way for small nonprofits to carve their unique paths forward apart from reaping the benefits of being a part of the nonprofit community. 


\section{Final Thoughts}

Nonprofit and voluntary organizations are part of the third sector that adds on to the services of the public and private sectors by addressing civic interests, participation in democracy and providing social programs that improve quality of life. The aim of this research was to explore the financial and human resource capacity of small nonprofit and voluntary organizations in Oregon to fulfill their objectives and thus provide policymakers, nonprofit capacity building organizations and key leaders in the third sector in Oregon an assessment of what these organizations needed to improve in their capacity to achieve their missions. The findings and implications of this study however not only are relevant to the state alone but generally to small nonprofits organizations anywhere and how urban-rural-ness affects them.

The past couple of years has seen increased polarization not only in America but also in other countries as well. Both urban and rural folks have stronger distrust of the other and this is translating into political, cultural and economic changes as well. Nonprofits can serve as an effective medium to bridge these gaps, especially small nonprofits. Grassroot groups, small nonprofits and community organizations are the building pillars of the society. If these organizations are strong and healthy, they build trust, solidarity and networks. Social capital can build bonds within a group and it can also build bridges across groups. People across different geographies may have different political affiliations, religious (or otherwise) norms to adhere to but the kinds of issues people worry about are usually similar. While interviewing respondents for this study, I was initially worried that rural respondents would be hesitant in contributng to my study 
by perceiving me as the urban Portlander who is very different from them. If anything, I found that we were more alike in what we wanted in our communities. There was also an air of warmth and openness towards diverse groups thus bearing evidence to the adage that nonprofits can build solidarity.

The demand for public services is always more than what can be supplied. In times when the public and private sectors and the media have not been successful in ending the polarization (rather contributing to it in some instances), it is the third sector that should provide hope in these troubling times. It can only if we provide it with the best resources to causes that will lead to a better quality of life. Political, economic or cultural affiliations should not equate with our sense of empathy, public service and civility. Hence as long as our nonprofits are healthy and fostering strong public service, they will ensure that despite all their capacity challenges they will keep our society functioning compassionately and ethically. 


\section{References}

Agranoff, R. \& McGuire, M. (2003). Collaborative public management: New strategies for local governments. Washington DC: Georgetown University Press.

Allison, G. (1969). Conceptual models and the Cuban missile crisis. American Political Science Review, 63(3):689-718.

Anheier, H. K. (2005). Nonprofit organizations: Theory, management, policy. New York: Routledge.

Anheier, H. K. (2014). Nonprofit organizations: Theory, management, policy. New York: Routledge.

Anheier, H.K., \& Salamon, L.M. (1998). The nonprofit sector in comparative perspective. In W.W. Powell and Steinberg, R. (Eds) The Nonprofit Sector: A Research Handbook (p 89-114). New Haven, CT: Yale University Press.

Arrow, K. J. (1963). Uncertainty and the welfare Economics of medical care. American Economic Review 53(5), 941-973.

Backer, T.E. (2000). Strengthening nonprofits capacity building and philanthropy. Los Angeles: Human Interaction Research Institute.

Backer, T., Bleeg, J. E., \& Groves, K. (2004). The expanding universe: New directions in nonprofit capacity building. Washington, DC: Alliance for Nonprofit Management.

Ben-Ner, A. and van Hoomissen, T. (1991). Nonprofit organizations in the mixed economy. A demand and supply analysis. Annals of Public and Cooperative Economics, 62(4S), 519-550. 
Bevir, M. (2010). Democratic governance. Princeton, NJ: Princeton University Press.

Bielefield, W., Murdoch, J.C. \& Waddell, P. (1997). The influence of demographics and distance on nonprofit location. Nonprofit and Voluntary Sector Quarterly, 26(2), 207-225.

Blumenthal, B. (2003). Investing in capacity building: A guide to high-impact approaches. Foundation Center.

Booz, Allen and Hamilton. (2002). Board recruitment in the nonprofit sector. New York: Booz, Allen and Hamilton. Accessed Oct 14, 2015 from http://www.boozallen.com/content/dam/boozallen/media/file/116778.pdf

Bowman, W. (2014). Finance fundamentals for nonprofits: Building capacity and sustainability. Hoboken, NJ: John Wiley \& Sons.

Brown, C. (2014). The purpose, design, and effects of foundation-funded nonprofit capacity building programs. University of Nebraska. (Doctoral dissertation). Available from ProQuest Dissertations and Theses database. (UMI 3666481).

Brudney, J.L. (1992). Administration of volunteer services: Their needs for training and research. Nonprofit Management and Leadership, 2(3), 271-282.

Brudney, J. L. and York, P. (2015). Effective volunteer engagement for sustainability and growth: Strategies for the capacity builder. The 2015 Alliance National Conference on Nonprofits: Research to Practice Documentation. Oct 7, 2015: Portland, OR. 
Brysonm J.M., Crosby, B.C., \& Stone, M.M. (2006). The design and implementation of cross sector collaborations: Propositions from the literature. Public Administration Review Special Issue, 66, 44-55.

Caffyn, A., \& Dahlstrom, M. (2005). Urban-rural interdependencies: Joining up policy in practice. Regional Studies, 39(3), 283-296.

Carroll, D.S. \& Stater, K.J. (2008). Revenue diversification in nonprofit organizations: Does it lead to financial stability? Journal of Public Administration Research and Theory, 19(4), 947-966.

Chang, C \& Tuckman, H. (1996). Revenue diversification among nonprofits. Voluntas: International Journal of Voluntary and Nonprofit Organizations, 5(3), 273-90.

Chang, C. and Tuckman, H. (1996). The goods produced by nonprofit organizations. Public Financial Quarterly, 24(1), 25-43.

Chikoto, G.L. \& Nealy, D.G. (2014). Building nonprofit financial capacity: The impact of revenue concentration and overhead costs. Nonprofit and Voluntary Sector Quarterly, 43(3), 570-588.

Claussen, C. (2011). Capacity building for organizational effectiveness literature review. Journey of High Performance. United Way of Calgary and Area.

Clucas, R.A., Henkels, M. \& Steel, B.S. (2011). The politics of one Oregon: Causes and consequences of the rural-urban divide and prospects for overcoming it. In Toward One Oregon. M. Hibbard, E. Seltzer, B. Weber \& B. Ernshoff (eds). Corvallis, OR: Project Muse, Oregon State University. 
Conolly, P \& Lucas, C. (2002). Strengthening nonprofit performance: A funder's guide to capacity building. Saint Paul, MN: Amherst H. Wilder Foundation.

Conolly, P \& Lucas, C. (2003). Building the capacity of capacity builders: A study of management support and field-building organizations in the nonprofit sector. The Conservation Group. https://www.tccgrp.com/pdfs/buildingthecapacityofcapacitybuilders_full.pdf

Cooper, P.J. (2003). Governing by contract: Challenges and opportunities for public managers. Washington DC: CQ Press.

Daily, C. M. (1995). The relationship between board composition and leadership structure and bankruptcy reorganization outcomes. Journal of Management, 21(6), 1041-1056.

De Vita, C., \& Fleming, C. (2001). Building capacity in nonprofit organizations. Washington, DC: The Urban Institute.

DiMaggio, P.J. \& Powell, W.W. (1983). The iron cage revisited: Institutional isomorphism and collective rationality in organizational fields. American Sociological Review, $48(2), 147-160$.

Doherty, A., Misener, K., Cuskelly, G. (2014). Towards a multi-dimensional framework of capacity in community sport clubs. Nonprofit and Voluntary Sector Quarterly, 43(2), 124S - 142S.

Eagan, C. (2009). Nonprofits' contribution to the Oregon economy. Oregon Labor Trends August 2009. Worksource: Oregon Employment Department. Retrieved 
Feb 1, 2011 from

http://library.state.or.us/repository/2010/201010061145443/Aug2009.pdf

Eagan, C. (2011). Driven by purpose: Oregon's nonprofits. Oregon Labor Trends October 2011. Worksource: Oregon Employment Department. Retrieved Feb 1, 2011 from http://library.state.or.us/repository/2010/201010061145443/Oct2011.pdf

Eco Northwest. (2012). Arts, culture, and Oregon's economy: An analysis of the economic contributions and fiscal impacts of the Oregon Cultural Trust and its eligible cultural nonprofits. Retrieved Jan 25, 2018 from https://olis.leg.state.or.us/liz/2013R1/Downloads/CommitteeMeetingDocument/8 $\underline{676}$

Eisinger, P. (2002). Organizational capacity and organizational effectiveness among street level food assistance programs. Nonprofit and Voluntary Sector Quarterly, 31(1), 115-130.

Fernsler, T. (2005). The value of capacity building. Nonprofit World, 23(1), 30.

Frederickson H.G. (2005). Whatever happened to public administration?: Governance, governance everywhere. In Ferlie E., Lynn L.E., and Pollitt C., (Eds) The Oxford handbook of public management. Oxford University Press.

Fridley, D. (2015). Oregon's nonprofits 2013. Oregon Labor Trends August 2015. Worksource: Oregon Employment Department. Retrieved Jan 21, 2016 from https://www.qualityinfo.org/documents/10182/89830/Oregon+Labor+Trends?ver $\underline{\text { sion }=1.13}$ 
Fridley, D. (2017). Oregon's nonprofits in 2015. Worksource: State of Oregon Employment Department. Retrieved Jan 21, 2018 from https://www.qualityinfo.org/-/oregon-s-nonprofits-in-2015

Froelich, K.A. (1999). Diversification of revenue strategies: evolving resource dependence in nonprofit organizations. Nonprofit and Voluntary Sector Quarterly, 28 (3), 246-268.

Gallicano, T.D. (2013). Relationship management with the Millennial generation of public relations agency employees. Public Relations Review, 39(3), 222-225.

Galbraith, J.K. (1998). The affluent society. (40 ${ }^{\text {th }}$ anniversary edition). Boston, MA: Houghton Mifflin Company.

Geertz, C. (1973). The interpretation of cultures. New York: Basic Books.

Germann, K., \& Wilson, D. (2004). Organizational capacity for community development in regional health authorities: A conceptual model. Health Promotion International, 19(3), 289-298.

Getha-Taylor, H. (2006). Book review: Investing in capacity building: A guide to highimpact approaches. Nonprofit and Voluntary Sector Quarterly, 35 (2), 322-325.

Gilmer, S.D. (2012). A description of nonprofit executive leaders' perceptions of human resource capacity building within their organizations. (Doctoral dissertation). Available from ProQuest Dissertations and Theses database. (UMI No. 3505839).

Glaser, B. (1992). Emergence vs. forcing: Basics of grounded theory analysis. Mill Valley, CA: Sociology Press. 
Golmar, W. (2008). Capacity building and nonprofit organizational effectiveness. (Doctoral dissertation). Available from ProQuest Dissertations and Theses database. (UMI No. 3313851).

Gray, B. (1985). Conditions facilitating inter-organizational collaboration. Human Relations, 38(10), 911-936.

Gray, B. (1989). Collaborating: Finding common ground for multiparty problems. San Francisco: Jossey-Bass.

Greenlee, J. S., \& Brown, K.L. (1999). The impact of accounting information on contributions to charitable organizations. Research in Accounting Regulation, 13, $111-126$

Greenlee, J. S., \& Trussel, J. M. (2000). Predicting the financial vulnerability of charitable organizations. Nonprofit Management and Leadership, 11(2), 199-210.

Guidestar. (2018). The financial health of the United States nonprofit sector: Facts and observations. Accessed Jan 9, 2019 from https://learn.guidestar.org/hubfs/Docs/The\%20Financial\%20Health\%20of\%20the \%20US\%20Nonprofit\%20Sector.pdf

Gumulka, G., Barr, C., Lasby, D., \& Brownlee, B. (2005). Understanding the capacity of sports \& recreation organizations. Toronto, ON: Imagine Canada

Hager, M. (2001). Financial vulnerability among arts organizations: A test of the Tuckman-Chang measures. Nonprofit Management and Leadership, 30(2), 376392. 
Hailu, A., and Wasserman, C. (2016). Guidelines for using rural-urban classification systems for community health assessment. Washington State Department of Health. Accessed Jul 24, 2017 at https://www.doh.wa.gov/Portals/1/Documents/1500/RUCAGuide.pdf

Hall, M.H., Andrukow, A., Barr, C., Brock, K., deWit, M., Embuldeniya, D., Jolin, L., Lasby, D., Levesque, B., Malinsky, E., Stowe, S., Vaillancourt, Y. (2003). The capacity to serve: A qualitative study of the challenges facing Canada's nonprofit and voluntary organizations. Toronto, ON: Canadian Center for Philanthropy.

Hall, P.D. (2016). Historical perspectives on nonprofit organizations in the United States. In The Jossey-Bass Handbook of Nonprofit Leadership and Management D.O. Renz (ed). Hobokens, NJ: John Wiley \& Sons, Inc.

Hardy, C., \& Philipps, N. (1998). Strategies of engagement: Lessons from the critical examination of collaboration and conflict in an inter-organizational domain. Organization Science, 9(2), 217-230.

Harvey, J. (1999). A portrait of Canadian arts service organizations in 1999. Ottawa: Canadian conference of the Arts.

Hawley, L., Koziol, N., Bovaird, J., McCormick, C., Welch, G., Arthur, A., \& Bash, K. (2016). Defining and describing rural: Implications for rural special education research and policy. Rural Special Education Quarterly, 35(3), 3-11.

Hodge, M. M., \& Piccolo, R. F. (2005). Funding source, board involvement techniques, and financial vulnerability in nonprofit organizations: A test of resource dependence. Nonprofit Management and Leadership, 26(2), 171-190. 
Hooghe, M. \& and Botterman, S. (2012). Urbanization, community size and population density: Is there a rural / urban divide in participation in voluntary organizations or social network formation? Nonprofit and Voluntary Sector Quarterly, 41(1), $120-144$

Holland, D., Lewin, P., Sorte, B. \& Weber, B. (2011). The declining economic interdependence of the Portland metropolitan core and its periphery. In Toward One Oregon. M. Hibbard, E. Seltzer, B. Weber \& B. Ernshoff (eds). Corvallis, OR: Project Muse, Oregon State University.

Hyman, V. (2006). Capacity building defined and demystified. Nonprofit tools you can use. The Fieldstone Alliance.

Inglehart, R. \& Weizel, C. (2010). Changing mass priorities: The link between modernization and democracy. Reflections, 8(2): 551-567.

James, E. (1987). The nonprofit sector in comparative perspective. In W.W. Powell and Steinberg, R. (Eds) The nonprofit sector: A research handbook (p 397-415). New Haven, CT: Yale University Press.

James, E. (1993). Why do different countries choose a different public-private mix of educational services? Journal of Human Resources, 28(3), 571-592.

Kanter, R.M. (1994). Collaborative advantage: Successful partnerships manage the relationships, not just the deal. Harvard Business Review, 74(4), 96-108.

Keegan, P. (1990). Fundraising for nonprofits. New York: Harper Perennial.

Kendall, J. (1999). Axial coding and the grounded theory controversy. Western Journal of Nursing Research, 21(6), 743-757. 
Leap of Reason Ambassador's Community (2017). Small, but mighty: The performance imperative for small nonprofits. Creative Commons: Morino Institute

Lichter, D.T., \& Brown, D.B. (2011). Rural America in an urban society: Changing spatial and social boundaries. Annual Review of Sociology, 37, 565-592.

Light, P.C. (2004). Sustaining nonprofit performance: The case for capacity building and the evidence to support it. Washington, DC: Brookings Institution Press.

Light, P.C., Hubbard, E.T., \& Kibbe, B. (2004). The capacity building challenge. New York: The Foundation Center.

Logan, J. (2003). Life and death in the city: Neighborhoods in context. Contexts, 2(2), 3340.

Longoria, R.A. (2005). Is inter-organizational collaboration always a good thing? Journal of Sociology \& Social Welfare, 32(3), 123-139

Markusen, A., \& Kitchener, A. (2012). Working with small arts organization: Why and how it matters. Grantmakers in the Arts Reader, 23 (2). https://www.giarts.org/article/working-small-arts-organizations

Marrow, H.B. (2011). New destination dreaming: Immigration, race and legal status in the rural American south. Stanford University Press.

McKeever, B. (2015). The nonprofit sector in brief 2015: Public charities, giving, and volunteering. National Center for Charitable Statistics. https://www.urban.org/research/publication/nonprofit-sector-brief-2015-publiccharities-giving-and-volunteering 
Milbourne, L. (2005). Children, families and inter-agency work: Experiences of partnership work in primary education settings. British Education Research Journal, 31(6), 681-701.

Milbourne, L. (2009). Remodelling the third sector: Advancing collaboration or competition in community-based initiatives. Journal of Social Policy, 28(2), 277-297.

Miller, L.E., Kruger, E.J., \& Gauss, M.S. (1994). Nonprofit boards and perceptions of funding. Nonprofit Management and Leadership, 5(1), 3-18.

Milward, H.B. (1982). Inter-organizational policy systems and research on policy organizations. Administration and Society, 13(4), 457-478.

Morgan, D.L. (2014). Integrating qualitative and quantitative methods: A pragmatic approach. Thousand Oaks, CA: Sage Publications.

Natenshon, D \& Walker, K. (2018). Small, but mighty: A resource for small nonprofit leaders. Beth's blog. Accessed July 6, 2018 from http://www.bethkanter.org/small-but-mighty/

Nelson, R. \& Krashinsky, N. (1973). Public control and Organisation of day care for young children. Public Policy, 22(1), 53-75.

National Center for Charitable Statistics. (2015). Quick facts about nonprofits. The Urban Institute.

Nonprofit Association of Oregon. (2014). Oregon's nonprofit sector in brief. Portland, OR.

Nonprofit Association of Oregon. (2017). 2016 Northwest nonprofit capacity report. Portland, OR. 
Nonprofit Finance Fund. (2012). Small nonprofits solving big problems. Accessed Jan 10, 2019 from

https://www.nonprofitfinancefund.org/sites/default/files/paragraphs/file/download lccer_final12-12.pdf

Nonprofit Finance Fund. (2015). 2015 State of the nonprofit sector. Accessed Feb 10, 2016 from http://survey.nff.org/?filter=state:OR

Nuehoff, A. \& Dunckelman, A. (2011). Small but tough: Nonprofits in rural America. The Bridgespan Group.

Patton, M.Q. (2002). Qualitative research and evaluation methods. Thousand Oaks, CA: SAGE Publications.

Pfeffer, J., \& Salancik, G. R. (1978). The external control of organizations: A resource dependence perspective. New York: HarperCollins.

Phillips, N., Lawrence, T. B., \& Hardy, C. (2000). Inter-organizational collaboration and the dynamics of institutional fields. Journal of Management Studies, 37(1), 23-43.

Pohjoispuro, J.J. (2006). The nature of nonprofit professional development and training in Montana. Available from Graduate Student Theses, Dissertations, \& Professional Papers 1054.

Powell, W.J. \& Steinberg, R. (2006). The nonprofit sector: A research handbook. New Haven, CT: Yale University Press

Provine, D.M. (2010). Local immigration policy and global ambitions in Vancouver and Phoenix. In Varsanyi, M.W. (Ed) Taking local control. Stanford University Press. 
Putnam, Robert D. (2000). Bowling alone: The collapse and revival of American community. New York: Simon \& Schuster.

Rainey, H.R. (2003). Understanding \& managing public organizations, $3^{\text {rd }}$ edition. San Francisco, CA: John Wiley \& Sons (Jossey-Bass).

Ratcliffe, M., Burd, C., Holder, K., and Fields, A. (2016). Defining rural at the US Census Bureau: American community survey and geography brief. US Department of Commerce Economics and Statistics Administration: US Census Bureau. Accessed Jul 26, 2017 at https://www2.census.gov/geo/pdfs/reference/ua/Defining_Rural.pdf

Rose-Ackerman, S. (1996). Altruism, nonprofits and economic theory. Journal of Economic Literature, 34, 701-728.

Rosenthal, D. (1996). Who “owns” AIDS service organizations: Governance accountability in nonprofit organizations? Polity, 29(1), 97-118.

Saidel. J. (1991). Resource interdependence: The relationship between state agencies and nonprofit organizations. Public Administration Review, 51(6), 543-553.

Salamon, L.M. (2003). The resilient sector: The state of nonprofit America. Washington DC: Brookins Institution Press.

Salamon, L.M. \& Anheier, H.K. (1998). Social origins of civil society: Explaining the nonprofit sector cross-nationally. Voluntas: International Journal of Voluntary and Nonprofit Organizations, 9(3), 213-247

Selznick, P. (1957). Leadership in administration: A sociological interpretation. Berkeley, CA: University of California Press. 
Schroeer, A., Medora, D., Mukerjee, A. \& Wallinger, G. (2011). Oregon nonprofit sector report: The state of the nonprofit sector in Oregon. Portland, OR: Nonprofit Association of Oregon

Sherman, A.L. (2004). Pros and cons of receiving government funding. Hudson Instititute. Accessed Jan 15, 2016 from http://www.urbanministry.org/wiki/prosand-cons-receiving-government-funding

Shucksmith, M. (2004). Young people and social exclusion in rural areas. Rural Sociology, 44(1), 43-59

Stone, M. M., Hager, M. A., \& Griffin, J. J. (2001). Organizational characteristics and funding environments: A study of a population of United Way affiliated nonprofits. Public Administration Review, 61(3), 276-289.

Stowe, S \& Barr, C. (2005). The rural charitable sector research initiative phase II: The capacity challenges of nonprofit \& voluntary organizations in rural Ontario. Toronto, ON: Imagine Canada

Strauss, A., \& Corbin, J. (1990). Basics of qualitative research. Newbury Park, CA: SAGE Publications.

Strawser, C.C. (2017). Community foundations as capacity builders: An examination of how community foundations are enhancing the nonprofit sector. Unpublished capstone report. Bay Path University.

The Independent Sector. (2016). America's nonprofit sector-impact. https://www.independentsector.org/wp-content/uploads/2016/12/IS-NonprofitImpact2016.pdf 
Torgerson, M. \& Edwards, M.E. (2013). Demographic determinants of perceived barriers to community involvement: Examining rural / urban differences. Nonprofit and Voluntary Sector Quarterly, 42(2), 371-390.

Trist, E. (1983). Referent organizations and the development of inter-organizational domains. Human Relations, 36(3), 269-284.

Trochim, W.M.K. (2006). Philosophy of research. Accessed Jan 22, 2016 from http://www.socialresearchmethods.net/kb/philosophy.php

Tuckman, H. \& Chang, C. (1991). A methodology for measuring the financial vulnerability of charitable nonprofit organizations. Nonprofit and Voluntary Sector Quarterly, 20(4), 445-460.

Van de Ven, A. H. \& Walker, G. (1984). The dynamics of inter-organizational coordination. Administrative Science Quarterly, 29(4), 598-621.

Warren, M. E. (2001). Democracy and association. Princeton, NJ: Princeton University Press.

Waterman Jr, R.H. (1982). In search of excellence: Lessons from America's best-run companies. New York: Harper.

Weisbrod, B.A. (1975). Towards a theory of the voluntary nonprofit sector in a threesector economy. In Altruism, Morality and Economic Theory. (p. 171-195) E. Phelps (ed). New York: Russell Sage.

Wicker, P., \& Breuer, C. (2011). Understanding the importance of organizational resources to explain organizational problems: Evidence from nonprofit sport clubs 
in Germany. Voluntas: International Journal of Voluntary and Nonprofit Organizations, 24(2), 461-484.

Wolch, J.R. \& Geiger, R.K. (1983). The distribution of urban voluntary resources: An exploratory analysis. Environment and Planning, A(15), 1067-1082.

Woods, M. (2015). Conceptualizing rural areas in metropolitan society: A rural view. Paper presented at the Workshop on Rationalizing Rural Area Classifications, April, National Academies of Sciences, Engineering, and Medicine, Washington, DC. Accessed Jan 21, 2018 at http://sites.nationalacademies.org/DBASSE/CNSTAT/DBASSE_160632

Wright, V.K. (2011). Nonprofit capacity: A comparative case study of capacity building in community-based organizations (Master's thesis). Retrieved from ProQuest Dissertations and Theses database. (UMI No. 1502572).

Wunderlich, G.S. (2016). Rationalizing rural area classifications for the economic research service: A workshop summary. Washington, DC: The National Academies Press

Young, D.A. (2007). Toward a normative theory of nonprofit finance. In Financing Nonprofits: Putting Theory into Practice (p. 339-372). Lanham, MD: Altamira Press. 


\section{Appendix A: Questionnaires}

\section{PRELIMINARY QUANTITATIVE SURVEY}

Q1 Which of the following tax classifications applies to your organization? (select all that apply).

$501(\mathrm{c}) 3$

口 $501(\mathrm{c}) 4$

$\square$ Other 501 (c) organization, please specify here:

We have applied for, but not yet received, 501 (c) status from the IRS.

$\square$ Public organization

$\square$ We are not a nonprofit organization. (non-qualifier)

Q2 Please briefly write about the programs your nonprofit runs. (e.g. finding affordable housing in Lane county for low income populations)

Q3 Many nonprofits at one Oregon location are one of several organizations with the same name but operating in different regions of Oregon (or beyond) and with different Employee Identification Numbers (EIN) e.g. NAMI, Big Brother Big Sister etc. Are you one of several sister organizations like specified?

O No

Yes we are one of several sister organizations with similar names but different EINs

Other please explain 
Q4 Does your organization have a formal office / headquarters in Oregon?

- No, we do not have a formal office but have meetings at members' houses or libraries or other public spaces in Oregon. Primarily we meet in the city of -

- Yes, we have one office in Oregon located in the city of

- Yes, we have multiple offices in Oregon with the primary one located in the city of

- We are not primarily based in Oregon (non-qualifier)

Q5 Please tell us the cities from where the majority of your clients come from. You may provide the names of the top 3 CITIES ranked by number of customers. (If less than 3 , leave blank as applicable). If you do not provide direct services to people, you may think of other customers (e.g. pet owners for Animal Welfare organizations, subscribers to your publications and journals, cities from where your audience comes to watch performances or displays etc).

Largest CLIENTELE City 1

Second largest CLIENTELE City 2

Third largest CLIENTELE City 3

Does not Apply / we do not collect this information

Q6 We would like to know more about the demographics of your organization. Please provide us the following numbers. Your best estimate is okay. (Enter 0 for none)

\begin{tabular}{|c|c|c|c|c|c|}
\hline & $\begin{array}{c}\text { Board } \\
\text { members }\end{array}$ & $\begin{array}{c}\text { Paid staff, } \\
\text { full time }\end{array}$ & $\begin{array}{c}\text { Paid staff, } \\
\text { part time }\end{array}$ & $\begin{array}{c}\text { Unpaid } \\
\text { volunteers, } \\
\text { full time }\end{array}$ & $\begin{array}{c}\text { Unpaid } \\
\text { volunteers, } \\
\text { part time }\end{array}$ \\
\hline $\begin{array}{c}\text { Total } \\
\text { Number }\end{array}$ & & & & & \\
\hline
\end{tabular}


Q7 Please tell us the year your organization (and not the PARENT, if any) was

- Founded?

- Got $501 \mathrm{C}$ status (expected year, if have applied but still not obtained)

Q8 a Would you classify yourself or an urban or rural nonprofit or Mixed?

- Urban

- Rural

- Both

b. Why do you identify this way?

Q9 What was your organization's average annual operating budget in 2015 ?

\begin{tabular}{|c|c|c|c|c|c|}
\hline & & & & $\begin{array}{c}\$ \text { More than } \\
\$ 500,000\end{array}$ \\
& $\begin{array}{c}\text { Under } \\
\$ 50000\end{array}$ & $\begin{array}{c}\$ 50,001 \\
\$ 100,000\end{array}$ & $\begin{array}{c}\$ 100,001- \\
\$ 250,000\end{array}$ & $\begin{array}{c}\$ 250,001- \\
\text { (non- }\end{array}$ \\
\hline FY & 0 & 0 & 0 & 0 & 0 \\
\hline 2015 & 0 & & & & \\
\hline
\end{tabular}

Q10 Please enter the following (we are asking names only to avoid duplicate responses names will not be released in the results)

Organization name (full name, no acronyms, please) 
Q11 Would your organization be interested in participating in a more comprehensive qualitative study i.e. telephone interviews that should last about 30 - 45 minutes). If yes, select the group / (s) you are interested in participating.

Financial capacity (discussions on strategies to earn revenue, financial management and fundraising)

Human Resource capacity (discussions on board members, staff and volunteers)

Other, please specify ------

I do not wish to participate.

Q12. If you have indicated a wish to participate above, please provide the details of the contact person.

Name of person

Phone number

Email

In what capacity does this person serve on your nonprofit?

For how long?

a. Any other comments or questions? 


\section{QUESTIONNAIRE for FINANCIAL CAPACITY}

First, I would be interested in hearing about you and your nonprofit (icebreaker - 5 to 10 minutes)

1. What does your nonprofit do? Which communities and regions do you operate / serve?

2. What responsibilities and duties are carried out by you at this organization? How long have you been in your current position?

Next, I would like to ask you some general questions about nonprofits (20-30 minutes) 3. What are the most pressing concerns facing the community you serve? What are the challenges that small nonprofits face in your community in addressing these concerns? 4. What challenges do you think rural nonprofits face in addressing these concerns versus urban ones?

Next, we will specifically address questions on financial capacity (70-80 minutes)

5. What are your primary sources of revenue? Probes - Individual donations, corporation grants, foundation grants, government funding, earned income, any other source.

6. Of these sources, which is the most difficult to obtain? Why? Which is the easiest? Why?

7. What kinds of information do your donors and grantors ask from you? What kinds of information do you think they should be asking for?

8. What are the biggest impediments to achieving sufficient financial capacity for small nonprofit organizations? Do you feel these impediments and barriers are the same in urban and rural settings? How?

9. In what way do you feel is your organization's ability to fundraise unique? Can you give examples where you have tried something new?

10. What can small rural (or urban) nonprofits do to make themselves more competitive to get more grants and donations and other revenues?

11. What can they do to have stable revenues and accumulate liquid cash reserves for emergency purposes? 
12. How can capacity builders and trainers help you to achieve your fullest financial capacity?

13. Any other topics we have not covered?

\section{QUESTIONNAIRE FOR HUMAN CAPACITY}

First, I would be interested in hearing about you and your nonprofit (icebreaker - 10 minutes)

1. What does your nonprofit do? Which communities and regions do you operate / serve?

2. What responsibilities and duties are carried out by you at this organization? How long have you been in your current position?

Next, I would like to ask you some general questions about nonprofits (20-30 minutes) 3. What are the most pressing concerns facing the community you serve? What are the challenges that small nonprofits face in your community in addressing these concerns? 4. What challenges do you think rural nonprofits face in addressing these concerns versus urban ones?

(Q6 to 10 refer to either boards or volunteers. Use accordingly.)

Next, we will specifically address questions on board members (20-30 minutes).

6. What are the most common methods you use to recruit board members?

7. What specific skills / attributes do you look for while recruiting board members?

Probes - willingness to give time, knowledge of mission, relationship to other board members, financial or technical expertise, employment background, representative of the populations served, etc.

8. What are the activities that your board members are good at performing?

9. What are some areas that your board members face challenges and need to improve?

10 . Do you have an inspiring story about your board? 
Next, we will specifically address questions on staff and volunteers (20-30 minutes).

6. Tell us something about their demographic profile. Probes - age, gender, schooling, employment status, etc.

7. What are the most common methods you use to recruit staff and volunteers? Do you look for certain skills / attributes?

8. How long on an average do they serve your organization? Do you have challenges retaining them for over a year?

9. What are the activities that your staff and volunteers are good at performing?

10. What are some of the challenges faced by your people? How do you find ways to overcome such challenges?

(Q11 to 13 are for boards and volunteers).

11. What strategies have you undertaken to achieve the best potential out of your workers?

Possible probes - training, orientation, feedback on performance, job / skills match etc. 12. How can capacity builders and trainers help you to achieve your fullest HR capacity (consider all board members, staff and volunteers)?

15. Any other topics we have not covered? 


\section{Appendix B: Kinds of 501 c Organizations}

According to the IRS Publication 557, in the Organization Reference Chart section (p.

67-68), the following is an exact list of 501(c) organization types and their corresponding descriptions.

- $\quad 501(\mathrm{c})(1)$ - Corporations Organized Under Act of Congress

- $\quad 501(\mathrm{c})(2)$ - Title-holding Corporations for Exempt Organizations

- $\quad$ 501(c)(3) - Religious, Educational, Charitable, Scientific, Literary, Testing for Public Safety, to Foster National or International Amateur Sports Competition, or Prevention of Cruelty to Children or Animals Organizations

- $\quad$ 501(c)(4) - Civic Leagues, Social Welfare Organizations, and Local Associations of Employees

- $\quad$ 501(c)(5) - Labor, Agricultural and Horticultural Organizations, Education Foundations

- $\quad$ 501(c)(6) - Business Leagues, Chambers of Commerce, Real Estate Boards, etc.

- $\quad 501(\mathrm{c})(7)$ - Social and Recreational Clubs

- $\quad$ 501(c)(8) - Fraternal Beneficiary Societies and Associations

- $\quad$ 501(c)(9) - Voluntary Employee Beneficiary Associations

- $\quad$ 501(c)(10) - Domestic Fraternal Societies and Associations

- $\quad$ 501(c)(11) - Teachers' Retirement Fund Associations

- $\quad$ 501(c)(12) - Benevolent Life Insurance Associations, Mutual Ditch or Irrigation Companies, Mutual or Cooperative Telephone Companies, etc.

- $\quad 501(\mathrm{c})(13)-$ Cemetery Companies

- $\quad$ 501(c)(14) - State-Chartered Credit Unions, Mutual Reserve Funds

- $\quad 501(\mathrm{c})(15)$ - Mutual Insurance Companies or Associations

- $\quad$ 501(c)(16) - Cooperative Organizations to Finance Crop Operations

- $\quad 501(\mathrm{c})(17)$ - Supplemental Unemployment Benefit Trusts

- $\quad$ 501(c)(18) - Employee Funded Pension Trust (created before June 25, 1959)

- $\quad 501(\mathrm{c})(19)$ - Post or Organization of Past or Present Members of the Armed Forces

- $\quad$ 501(c)(20) - Group Legal Services Plan Organizations

- $\quad$ 501(c)(21) - Black Lung Benefit Trusts

- $\quad$ 501(c)(22) - Withdrawal Liability Payment Fund

- $\quad 501(\mathrm{c})(23)$ - Veterans Organizations

- $\quad 501(\mathrm{c})(24)$ - Section 4049 ERISA Trusts

- $\quad$ 501(c)(25) - Title Holding Corporations or Trusts with Multiple Parents

- $\quad 501(\mathrm{c})(26)$ - State-Sponsored Organization Providing Health Coverage for HighRisk Individuals

- $\quad$ 501(c)(27) - State-Sponsored Workers' Compensation Reinsurance Organization

- $\quad$ 501(c)(28) - National Railroad Retirement Investment Trust

- $\quad$ 501(c)(29) - Qualified Nonprofit Health Insurance Issuers 
- $\quad 501(\mathrm{~d})-$ Religious or apostolic organizations with the purpose of operating a religious community where the members live a communal life following the tenets and teachings of the organization.

- $501(\mathrm{e})$ - Cooperative hospital service organizations that are organized to provide services for multiple tax-exempt hospitals.

- $\quad 501(\mathrm{f})$ - Cooperative service organizations of educational organizations that invest assets contributed by each of the organization's members.

- $\quad 501(\mathrm{j})$ - Amateur sports organizations that either conduct national or international sporting competitions or develop amateur athletes for national or international sporting competitions

- $\quad 501(\mathrm{k})$ - Day care centers

- $\quad 501(n)-$ Charitable risk pools that pool insurable risks of its members, which are tax-exempt charities.

- $\quad$ 521(a) - Farmers' cooperative associations that market its member farmers' products at market rates, make purchases at wholesale rates, and remit earnings to member farmers.

- $\quad 527$ - Political organizations that operate primarily to raise or spend money to influence the selection, nomination, election, or appointment of any individual to any Federal, State, or local public office

- 528 - Homeowner associations, condominium management associations, residential real estate management associations

- $\quad 529-$ Qualified tuition plans operated by a state or educational institution.

- $\quad 4947(a)(1)$ - Non-exempt charitable trusts that have exclusively charitable interests.

- $\quad 4947(a)(2)-$ Split-interest trusts. 